Check for updates

Cite this: Mater. Adv., 2021, 2, 2153

Received 15th December 2020 Accepted 9th February 2021

DOI: 10.1039/d0ma00982b

rsc.li/materials-advances

\section{Magnetic metal-organic framework composites: structurally advanced catalytic materials for organic transformations}

\author{
Sneha Yadav, Ranjana Dixit, Shivani Sharma, Sriparna Dutta, Kanika Solanki and \\ Rakesh K. Sharma (iD *
}

\begin{abstract}
Over the past two decades, metal-organic framework (MOF) research has been a rising star in modern materials chemistry and engineering that has contributed immensely to advancing the frontiers of science. Amalgamation of MOFs with magnetic nanostructures represents a newer promising trend that allows researchers to design complex hybrid catalytic materials with enhanced separability, reusability and activity for desired organic reactions in comparison to the individual counterparts. There are a series of meritorious examples in the literature wherein magnetic MOF composites have been successfully employed as versatile catalytic systems. Thus, the present review article aims to present a compendious account of all those magnetic MOF composite-based catalytic materials reported to boost several organic transformations, including oxidation, hydrogenation, coupling, condensation, esterification and multicomponent reactions. A progressive trend of increasing applications of these magnetic MOF composites in the area of photocatalysis and biocatalysis has also been incorporated. Further, the synthetic routes employed to date for the fabrication of magnetic MOF composites depending upon mutual interactions that exist between the magnetic nanoparticles and the MOF during unification have been illustrated in detail. It is further anticipated that this review will not only enlighten the readers about magnetic MOF composites but also assist researchers in designing novel functionalized catalysts for sustainable development.
\end{abstract}

Green Chemistry Network Centre, Department of Chemistry, University of Delhi, NewDelhi-110007, India. E-mail: rksharmagreenchem@hotmail.com; Fax: +91-011-27666250; Tel: +91-011-276666250

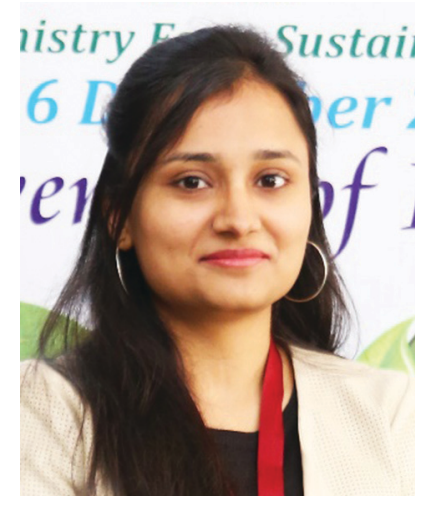

Sneha Yadav
Sneha Yadav is an active member of the Green Chemistry Network Centre and is currently pursuing a PhD under the supervision of Prof. $R$. K. Sharma from the Department of Chemistry, University of Delhi (DU). She graduated from Hindu College in 2014 and completed her postgraduate study at the Department of Chemistry, DU, India in 2016. She was conferred the meritorious award by Hindu College for securing the highest marks in MSc Chemistry. Her research work includes the design and development of magnetic metal-organic framework composites and their application in the field of catalysis. She has numerous publications in renowned international journals, including Inorganic Chemistry, ACS Omega and Material Chemistry Frontiers, and has also authored a chapter entitled "Gold Nanoparticles by Green Chemistry" in 21st Century Nanoscience - A Handbook edited by Klaus D. Sattler.

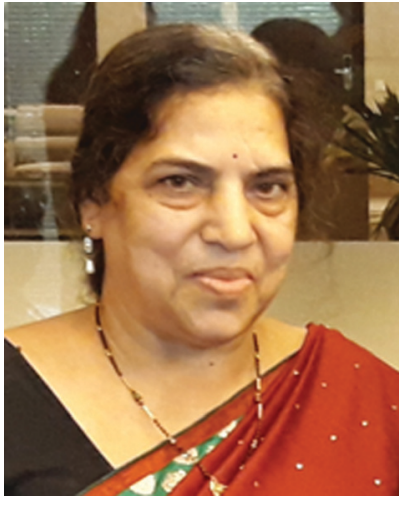

Ranjana Dixit
Dr Ranjana Dixit is an Associate professor at Ramjas College, University of Delhi, Delhi and an active member of the Green Chemistry Network Centre, DU She completed her PhD under the supervision of Prof. B. S. Garg at the Department of Chemistry, DU in 1987. She has more than 30 years of teaching experience. Her research interests include green synthetic processes, management of e-waste, catalysis, bioinorganic chemistry as well as chemistry and application of nanomaterials. 


\section{Introduction}

Nature is without doubt the mastermind behind all evolutionary processes. Inspired by nature's mastery to construct complex systems for performing advanced functions, researchers have been able to make impressive developments in the fabrication of porous crystalline polymers, the synthesis of which is governed by the well-defined principles of coordination chemistry. In this regard, metal-organic frameworks (MOFs), consisting of spatially assembled multifunctional organic linkers and inorganic secondary building units (metal clusters) to yield a highly organized 3-D crystalline lattice, offer massive design space for resourceful purposes. ${ }^{1-4}$ The availability of a virtually infinite choice of spacers to build MOFs offers commercial opportunities to imaginative chemists that harness their versatile chemistries in a plethora of potential applications, including water remediation, catalysis, gas storage and separation, photoluminescence, photocatalysis, sensors, drug storage and delivery, imaging, molecular sensing, gas capture and degradation of harmful chemical warfare agents. $^{5-12}$

Amongst them, catalysis represents one of the most distinct and dynamic arenas for MOFs. The catalytic behavior of MOFs

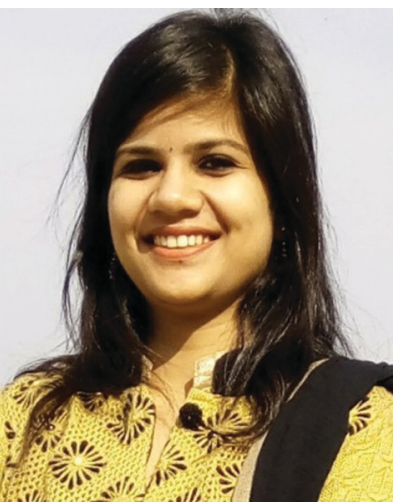

Shivani Sharma
Dr Shivani Sharma is an Assistant Professor at Ramjas College, University of Delhi, Delhi and an active member of the Green Chemistry Network Centre, DU She completed her PhD under the supervision of Prof. R. K. Sharma at the Department of Chemistry, DU in 2017. Her working area includes the design and synthesis of silicabased organic-inorganic hybrid nanomaterials and their applications in the field of sensors and catalysis. She has published several research and review articles in various RSC and ACS journals. Moreover, she has contributed as an author and co-author in various books, such as Hazardous Reagent Substitution in the RSC Green Chemistry Series and SilicaBased Organic-Inorganic Hybrid Materials from World Scientific Publications.

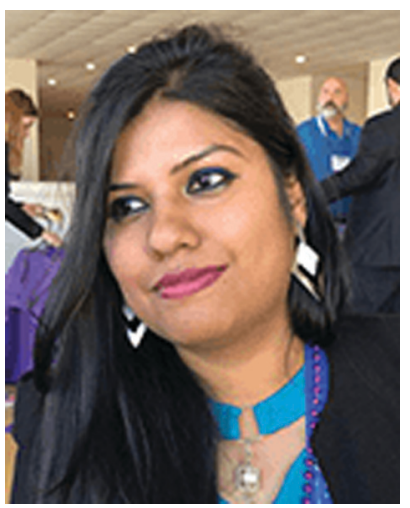

Sriparna Dutta

Dr Sriparna Dutta is an Assistant Professor at the Department of Chemistry, University of Delhi (DU) and an active member of the Green Chemistry Network Centre, DU. She completed her PhD under the supervision of Prof. R. K. Sharma at the Department of Chemistry, DU in 2019. She is a recipient of the Prof. K. N. Johri Memorial Gold Medal (awarded by DU) for securing the highest marks in MSc. Chemistry with inorganic specialization. Her research work includes the design and synthesis of magnetically retrievable core-shell structured nanocatalysts and their use in various organic transformations. She has numerous publications in renowned international journals, such as Green Chemistry, Dalton Transactions, and Inorganic Chemistry. She was awarded Young Scientist Award in 2019 for her excellent research work.

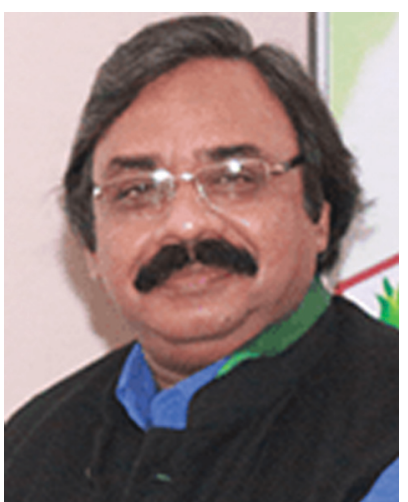

Rakesh K. Sharma

Dr R. K. Sharma is a professor and coordinator of the Green Chemistry Network Centre at the University of Delhi, India. He is also an Honorary Professor at Deakin University, Australia. He went to the University of Tokyo and Kumamoto University on a JSPS Post-Doctoral Fellowship. He has published numerous book chapters, reviews and research articles in renowned international journals. He has also written/ edited various books on Green Engineering and Technology, Bikaner and as a senior research fellow at the Rajasthan University of Veterinary and Animal Sciences, Bikaner.

Chemistry published by the Royal Society of Chemistry, World Scientific and Wiley. Dr Sharma is also the Honorary Secretary of the Royal Society of Chemistry (North India Section) and faculty advisor of the ACS International Student Chapter at the University of Delhi. http://greenchem.du.ac.in/. 
arises from both their metal centers and organic linkers. Broadly, three different types of active site in MOFs act as reaction chambers: (i) coordinatively unsaturated metal centers that coordinate with the substrate and catalyze the reaction, (ii) the second type of site involves encapsulation or incorporation of active catalytic species inside the pores of MOF for synergistically enhanced catalysis, and (iii) functionalized ligands present in the framework to initiate the reaction. ${ }^{13-15}$ MOFs have several other remarkable features that contribute to cooperative catalysis, such as high density and spatially separated catalytic active sites. The interior of MOFs along with the pore size and void volume can also be modified for size-selective catalysis. Further, high porosity and surface area in MOFs along with permeable channels promote facile adsorption and mass transport of reactants, which permits sufficient interaction of substrates with catalytic sites located within the cavities. ${ }^{16-20}$ Besides this, the structural tunability of MOFs allows insertion of additional functional moieties via post-synthetic modifications, which are desirable for improved catalytic efficiency in a variety of organic transformations. ${ }^{21-23}$

Though MOFs constitute a burgeoning genre of porous substructures that continues to expand at a progressive rate, there are some issues related to the instability of MOFs that have always been under scrutiny by chemists, impeding their utilization in realistic applications. MOFs possess low chemical, thermal as well as hydrothermal stability, as a result of which the structural framework is more likely to decompose under acidic, basic or moist conditions. ${ }^{24-26}$ Further, MOFs synthesized via traditional routes possess feeble mechanical strength, thereby making them less competitive in comparison to commercial catalysts when utilized under harsh reactive conditions. ${ }^{27,28}$ Therefore, it is highly imperative to design stable MOF catalysts with superior features for bulk chemistry.

In this regard, researchers have come up with a promising and well-designed scientific approach that integrates MOFs with extrinsic functional systems, thereby fostering the development of an entirely newfangled category of hybrid MOF composites. Some notable review articles highlighting this aspect have been reported by several research groups. ${ }^{29-34}$ Further, the synergistic coupling of peculiar features of MOF (structural tunability, high porosity and ordered crystalline pores) with functional materials (possessing unique magnetic, catalytic, optical, thermal stability, extremely high surface area) render the newly designed composite materials with unprecedented hallmarks that simultaneously overcome the drawbacks associated with the discrete components. To date, several hybrid MOFs with sophisticated architectures have been reported, wherein magnetic nanoparticles (MNPs), graphene oxide, silica, alumina, titanium oxide, carbon nanotubes, quantum dots, polymers have been incorporated resulting in highperformance composites with enhanced chemical and physical properties. $^{35-44}$

In particular, MNPs possessing large surface area to volume ratio, low toxicity, biocompatibility and high saturation magnetization value have been gaining increasing attention from the scientific community. To date, a variety of magnetic metal oxide nanoparticles (NPs), such as $\mathrm{Fe}_{3} \mathrm{O}_{4}, \alpha-\mathrm{Fe}_{2} \mathrm{O}_{3}, \gamma-\mathrm{Fe}_{2} \mathrm{O}_{3}$, $\mathrm{CoFe}_{2} \mathrm{O}_{4}, \mathrm{NiFe}_{2} \mathrm{O}_{4}, \mathrm{MnFe}_{2} \mathrm{O}_{4}, \mathrm{CuFe}_{2} \mathrm{O}_{4}$ and $\mathrm{ZnFe}_{2} \mathrm{O}_{4}$, have been successfully synthesized and reported in the literature. ${ }^{45-47}$ The synergistic integration of MOFs with superparamagnetic metal oxide NPs not only offers a high surface area but also leads to increased thermal stability and significant enhancement in catalytic activity. ${ }^{48-51}$ Besides this, sufficiently high saturation magnetization value of magnetic MOF composite materials offers precise positioning with rapid and facile separation under the influence of an external magnet from complicated matrices with improved efficiency. Indeed, magnetic separation appears to be a robust, reliable, highly effective and effortless catalyst recovery tool as compared to the traditional time- and energy-intensive separation methods, including filtration and centrifugation. ${ }^{52-54}$ In fact, in chemical and manufacturing industries, quick separation and reusability of catalytic material are some of the most sought-after objectives from an environmental and economic point of view. ${ }^{55}$ In view of the aforementioned benefits, a myriad of magnetic MOF composites have been utilized by several research groups in many industrially significant organic transformations, including oxidation, hydrogenation, coupling, condensation, and esterification. These studies reveal that such magnetic MOF composites have been recognized as a highly versatile catalytic material for many organic reactions with remarkable efficacy in terms of excellent product yield, simple work-up procedure, and facile recoverability and reusability. ${ }^{56-58}$ Although a few remarkable reviews have been penned in the literature on magnetic MOF composites, ${ }^{30,31}$ so far none of the reviews have shed extensive light on their catalytic applications.

\subsection{Scope of the review}

Considering the necessity of an inclusive, encyclopedic and futuristic review on magnetic MOF composite-based catalysts, this review attempts to assimilate all the scattered research on this quintessential subject that focuses on the competent synthetic strategies for fabricating magnetic MOF composites, paying particular attention to the applications in the field of catalysis. Furthermore, a detailed discussion of literature reports based on magnetic MOF composite-catalyzed industrially significant organic transformations, such as oxidation, hydrogenation, coupling, condensation, esterification, photocatalysis and biocatalysis, has been provided. Further, significant challenges encountered in this flourishing research area and opportunities in diverse innovative applications have also been elucidated in the concluding note. It is anticipated that this review will not only act as a scientific introduction and holy grail to the newcomers but also as a reference guide for experienced investigators and scientists. Moreover, we envisage that this review will provide sparkling ideas for the design and fabrication of functional magnetic MOF composite materials that will assist researchers and chemists to come up with several new catalytic protocols that can be commercialized in the near future for sustainable development. 


\section{Fabrication of magnetic MOF composites}

\subsection{Synthesis of magnetic nanoparticles (MNPs)}

The synthesis of magnetic NPs represents the primary step towards the fabrication of the desired composite materials. A comprehensive literature survey reveals that magnetic nanoparticles such as $\mathrm{Fe}_{3} \mathrm{O}_{4}, \alpha-\mathrm{Fe}_{2} \mathrm{O}_{3}, \gamma-\mathrm{Fe}_{2} \mathrm{O}_{3}, \mathrm{CoFe}_{2} \mathrm{O}_{4}, \mathrm{MnFe}_{2} \mathrm{O}_{4}$, $\mathrm{NiFe}_{2} \mathrm{O}_{4}, \mathrm{MgFe}_{2} \mathrm{O}_{4}, \mathrm{CuFe}_{2} \mathrm{O}_{4}$ and $\mathrm{ZnFe}_{2} \mathrm{O}_{4}$ have been successfully integrated with MOFs to afford magnetic MOF composites. ${ }^{59-68}$ The synthetic methodology employed while preparing magnetic nanoparticles is ascertained to have a profound effect on the shape, size, morphology and surface chemistry of the resulting nanostructures, which further escalates their utilization in diversified fields. Numerous preparative techniques, such as co-precipitation, ${ }^{69}$ solvothermal and hydrothermal, ${ }^{70}$ thermal decomposition, ${ }^{71}$ sonochemical, ${ }^{72}$ sol-gel, ${ }^{73}$ electrochemical, ${ }^{74}$ microwave-assisted, ${ }^{75}$ bio-inspired (microbial- and plantmediated $)^{76}$ and microemulsion, ${ }^{77}$ are very well described in several reviews documented in the literature. ${ }^{46,78-80}$

In recent years, several sophisticated neoteric routes, including template-assisted, ${ }^{81}$ laser pyrolysis, ${ }^{82}$ nano-imprint lithography, ${ }^{83}$ continuous and microwave flow, ${ }^{84,85}$ atomic layer deposition (ALD), ${ }^{86}$ gas aggregation ${ }^{87}$ and solution combustion, ${ }^{88}$ have been intensively explored for rendering a wide array of magnetic metal oxide nanostructures, offering excellent reproducibility along with systematic control over the size and shape in comparison to traditional routes.

Template-assisted synthesis involves utilization of a preexisting sacrificial template, such as surfactants, polymers, biomolecules, structure-directing agents, silica, carbon or inorganic frameworks, to direct the growth of nanostructures. This template is eventually removed either at high temperature or by employing acidic or basic conditions to generate the final nanostructures. Weller and co-workers designed a versatile protocol for the synthesis of iron oxide (maghemite) nanorods using iron oleate as the precursor salt while water and ethanol act as the soft template. ${ }^{89}$

Use of flow reactors has been recognized as an outstanding technique for producing high-purity nanoparticles with a short reaction duration. It offers additional benefits of uniform heating, mixing control, ease of scalability and good reproducibility for batch synthesis. In this perspective, Gao and co-workers reported a continuous-flow synthetic technique for acquiring biocompatible PEGylated $\mathrm{Fe}_{3} \mathrm{O}_{4}$ nanoparticles after pyrolyzing $\mathrm{Fe}(\mathrm{acac})_{3}$ in anisole at elevated temperatures in the presence of $\alpha, \omega$-dicarboxyl-terminated polyethylene glycol and oleylamine. ${ }^{90}$

Lately, an extended LaMer's mechanistic approach (involving steady-state growth conditions) has been employed by Huber and co-workers for producing highly crystalline magnetic nanoparticles by simply monitoring the reaction time period along with the volume and rate at which the iron oleate precursor was added to the reaction medium. ${ }^{91}$ The Verdaguer research group utilized a continuous laser-induced pyrolysis method devoid of surfactants and additives for preparing ultrasmall iron oxide nanoparticles possessing spheroid morphology from an iron pentacarbonyl precursor. ${ }^{92}$

Nowadays, integrated approaches like microwave-assisted solvothermal, co-precipitation-assisted hydrothermal, co-precipitation with microwave-assisted hydrothermal and templateassisted combustion have also gained significant momentum for synthesizing high-quality magnetic nanoparticles with phenomenal properties. ${ }^{93-96}$ For instance, Manukyan et al. took advantage of the template-assisted redox-combustion route for fabricating hematite nanoparticles, wherein ferric nitrate was employed as the iron precursor, ammonium nitrate as the oxidizer, glycine as fuel along with mesoporous silica as the template. ${ }^{97}$ Within a short span of time, the precursors were readily converted into ultrasmall crystalline hematite nanoparticles at elevated temperatures.

\subsection{Synthetic approaches for magnetic MOF composites}

Knowledge or understanding of the growth mechanisms that form the foundation of magnetic MOF composites is crucial for devising novel MOF-based heterostructures oriented towards specific applications. Therefore, various approaches that stimulate the formation of magnetic MOF composites have been reviewed in detail in this section. Depending on the type of dynamic interactions existing between the MNPs and MOFs, four approaches (layer-by-layer, embedding, encapsulation and mixing) have been deduced so far that facilitate their integration (Scheme 1). Furthermore, depending upon the synthetic strategy applied, the features of magnetic MOF composites can be tailored accordingly for particular organic transformations. Table 1 compiles some of the representative magnetic MOF composites reported in the literature and synthesized via different approaches.

2.2.1 Layer-by-layer. This approach smartly exploits the dynamic interactions existing between the magnetic functionalities and MOF precursor salts to generate magnetic MOF composites. In order to achieve the desired composite, magnetic particles are initially decorated with certain appropriate functional groups, such as carboxylic acids and amines, which further promote the layer-by-layer growth of the MOF via liquid-phase epitaxy method. This kind of surface modification is crucial for facilitating controlled crystal growth of MOFs, ultimately resulting in core-shell heterostructures. For instance, Zhang and co-workers employed a layer-by-layer method for covering $\mathrm{Fe}_{3} \mathrm{O}_{4}$ NPs with an MOF shell to form $\mathrm{Fe}_{3} \mathrm{O}_{4} @ M I L-100(\mathrm{Fe})$, which acted as an effective material for the detection and enrichment of phosphopeptides (Scheme 2). ${ }^{98}$ In the aforementioned heterostructure, solvothermally synthesized ferrite NPs were initially modified with mercaptoacetic acid (MAA) followed by the introduction of the MOF shell. Additionally, the authors highlighted that the presence of the MAA moiety prior to the MOF decoration is crucial as they tried to introduce the MIL-100(Fe) layer on the ferrite NPs directly but the anticipated results were not obtained. However, once modification with MAA was carried out, it was easier to wrap the MOF layer because the carboxylic functionalities acted as initiators for the subsequent growth of the MOF on the surface of the pre-formed ferrite NPs. Primarily, these 
(a) LAYER-BY-LAYER
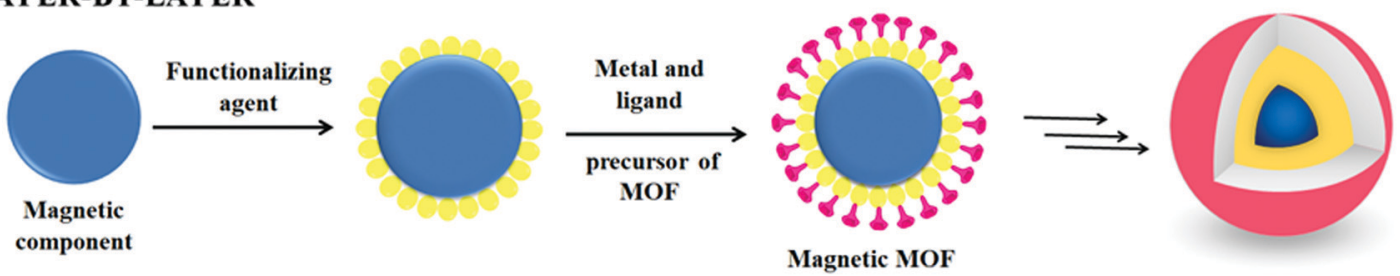

Functionalizing agents : Mercaptoacetic acid, Citric acid, 1,6-hexanediamine

\section{(b) EMBEDDING}

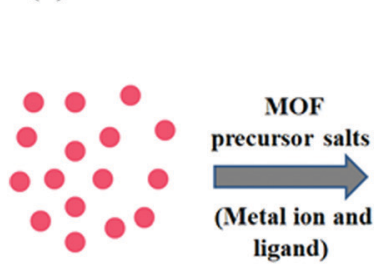

(c) ENCAPSULATION

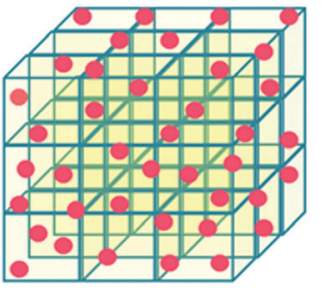

\section{(d) MIXING}

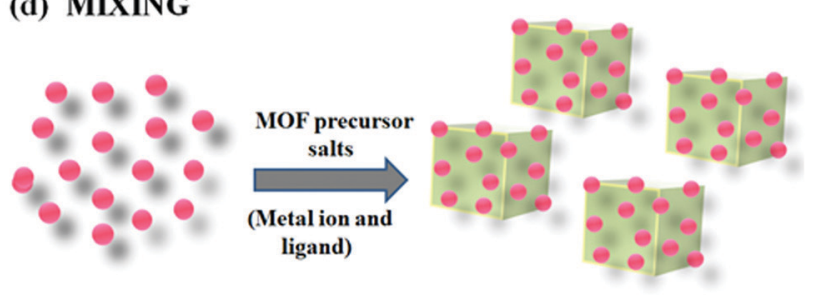

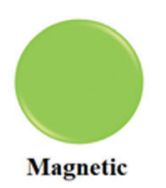

component
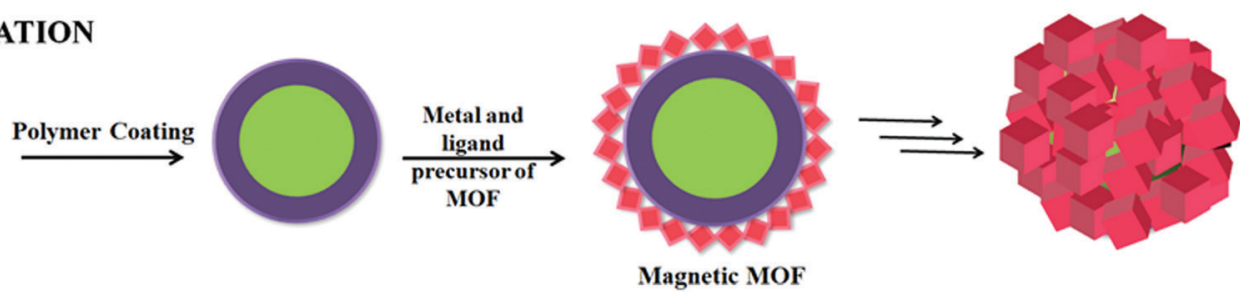

Coating agents: Polydopamine (PDA), Silica, Polyacrylic acid (PAA), Polyvinylpyrrolidone (PVP), (Poly(sodium 4styrene-sulfonate)) (PSS), Chitosan, Carbon

Scheme 1 Illustration showing different approaches for the synthesis of magnetic MOF composites. (a) Layer-by-layer; (b) embedding; (c) encapsulation; and (d) mixing.

carboxylate groups adsorbed a large amount of $\mathrm{Fe}^{3+}$ ions, after which BTC (benzene-1,3,5-tricarboxylate) units bound to it and ultimately yielded the desired $\mathrm{Fe}_{3} \mathrm{O}_{4} @ \mathrm{MIL}-100(\mathrm{Fe})$ composite.

Another well-known and illustrious $\mathrm{Cu}_{3}(\mathrm{BTC})_{2}$ MOF with magnetic functionality was fabricated by Qiu and co-workers by utilizing MAA as a functionalizing agent. ${ }^{99}$ Firstly, the synthesized MAA-functionalized $\mathrm{Fe}_{3} \mathrm{O}_{4}$ nanospheres were alternatively dispersed in an ethanolic solution of copper acetate and $\mathrm{H}_{3} \mathrm{BTC}$ at $25{ }^{\circ} \mathrm{C}$. In this report, the authors demonstrated that the thickness of the MOF shell has a profound and direct relationship with the assembly cycle number; therefore, it is essential to control the thickness of the shell precisely while synthesizing core-shell heterostructures. Fig. 1 depicts the TEM images of core-shell structured $\mathrm{Fe}_{3} \mathrm{O}_{4} @\left[\mathrm{Cu}_{3}(\mathrm{BTC})_{2}\right]$ obtained after different assembly cycles. The authors further stated that functionalization of ferrite NPs before the assembly process was crucial as grafting of carboxylic moieties using MAA on ferrite NPs instigated the binding of copper ions to the COO- groups, which later bind with the BTC units.

Literature reports suggest that citric acid is another impressive functionalizing agent that has been employed recurrently by various research groups for modifying the surface of MNPs. Recently, Lv and his research group explored the fabrication of a HKUST-1@ $\mathrm{Fe}_{3} \mathrm{O}_{4}$-based bi-enzyme system consisting of glucose oxidase (GOx) and horseradish peroxidase (HRP) for cascade catalysis. ${ }^{100}$ Citric acid-functionalized ferrite NPs were prepared and dispersed in an aqueous solution of copper acetate and $\mathrm{H}_{3}$ BTC alternatively to form HKUST-1@Fe $\mathrm{O}_{3} \mathrm{O}_{4}$ NPs by stirring at room temperature for $8 \mathrm{~h}$. By following the aforementioned procedure, some more layers of HKUST-1 were introduced on citric acid-modified ferrite NPs.

In addition, fabrication of another magnetic MOF composite was beautifully illustrated by Zhou's research group, wherein carboxyl moiety-enriched $\mathrm{Fe}_{3} \mathrm{O}_{4}$ nanospheres were coated with a Mg-MOF-74 shell consisting of magnesium ions and a 2,5-dihydroxyterephthalate (DOT) ligand to form $\mathrm{Fe}_{3} \mathrm{O}_{4}$ @ Mg-MOF-74 (Scheme 3). ${ }^{101}$ Plentiful carboxyl functionalities existing on the surface of ferrite NPs served as an initiator for the subsequent growth of Mg-MOF-74, which was dispersed alternatively in a dimethylformamide (DMF) solution of magnesium ions and 2,5-dihydroxyterephthalic acid (DOT) for $30 \mathrm{~min}$.

In a different publication, Liang et al. constructed a fusiform-like $\mathrm{Fe}_{3} \mathrm{O}_{4}-\mathrm{NH}_{2} @ M O F-235$ composite for the adsorption of insecticides. ${ }^{102} \mathrm{~A}$ one-pot in situ solvothermal approach entailing concomitant addition of $\mathrm{FeCl}_{3}$, ethylene glycol and 1,6-hexanediamine was utilized to obtain $\mathrm{NH}_{2}$-functionalized $\mathrm{Fe}_{3} \mathrm{O}_{4}$ NPs. The subsequent addition of MOF precursors, 
Table 1 Literature reports of magnetic MOF composites synthesized using various approaches: layer-by-layer, embedding, encapsulation and mixing

\begin{tabular}{ll}
\hline S. & $\begin{array}{l}\text { Magnetic MOF } \\
\text { no. Approach }\end{array}$ \\
\hline
\end{tabular}

no. Approach composite

1 Layer-by-layer $\mathrm{Fe}_{3} \mathrm{O}_{4} @ M I L-100(\mathrm{Fe})$

\section{2}

Layer-by-layer $\quad \mathrm{Fe}_{3} \mathrm{O}_{4} @ M g-M O F-74$

3 Layer-by-layer $\quad \mathrm{Fe}_{3} \mathrm{O}_{4}-\mathrm{NH}_{2} @ \mathrm{MOF}-235$

4 Layer-by-layer $\mathrm{CoFe}_{2} \mathrm{O}_{4} @ \mathrm{MIL}-100(\mathrm{Fe})$

5 Layer-by-layer $\mathrm{Fe}_{3} \mathrm{O}_{4} / \mathrm{Cu}_{3}(\mathrm{BTC})_{2}$

6 Layer-by-layer Magnetic PCN-250

$7 \quad$ Layer-by-layer $\quad \mathrm{Fe}_{3} \mathrm{O}_{4} @ \mathrm{MIL}-100(\mathrm{Fe})$

8 Embedding $\quad \mathrm{Fe}_{3} \mathrm{O}_{4} / \mathrm{Cu}_{3}(\mathrm{BTC})_{2}$

$9 \quad$ Embedding $\quad \mathrm{Fe}_{3} \mathrm{O}_{4} @ M I L-101$

10 Embedding $\mathrm{Fe}_{3} \mathrm{O}_{4} / \mathrm{MIL}-96(\mathrm{Al})$

11 Embedding

Magnetic Fe-BTC

12 Embedding

Magnetic MIL-101- $\mathrm{SO}_{3} \mathrm{H}$

13 Embedding

Magnetic Mg-MOF-74

14 Embedding

$\mathrm{Fe}_{3} \mathrm{O}_{4} @$ IRMOF-3

15 Embedding

$\mathrm{Fe}_{3} \mathrm{O}_{4} @ \mathrm{ZIF}-8$

16 Embedding

$\mathrm{PFe}_{3} \mathrm{O}_{4} @ \mathrm{NH}_{2}-\mathrm{MIL}-125$ (Ti) where $\mathrm{P}=$ polymer capped $\mathrm{Fe}_{3} \mathrm{O}_{4}$

17 Embedding

$\mathrm{Fe}_{3} \mathrm{O}_{4} @ U i O-66 @ P P I$ (PPI = poly(propyleneimine))

18 Embedding

$\mathrm{CoFe}_{2} \mathrm{O}_{4} / \mathrm{TMU}-17-\mathrm{NH}_{2}$

19 Embedding

Hollow magnetic $\mathrm{Fe}_{3} \mathrm{O}_{4} @ \mathrm{NH}_{2}-\mathrm{MIL}$ 101(Fe)
Synthetic conditions

$\mathrm{Fe}_{3} \mathrm{O}_{4}+\mathrm{MAA}+\mathrm{FeCl}_{3} \cdot 6 \mathrm{H}_{2} \mathrm{O}+\mathrm{H}_{3} \mathrm{btc}+$ Core-shell structure in which

$\mathrm{EtOH}+70{ }^{\circ} \mathrm{C}, 30 \mathrm{~min}$ for repeated $\mathrm{Fe}_{3} \mathrm{O}_{4}$ core coated with cycles

Citrate-coated $\mathrm{Fe}_{3} \mathrm{O}_{4}+\mathrm{Mg}\left(\mathrm{NO}_{3}\right)_{2}+$ 2,5 dihydroxyterephthalic acid + $\mathrm{DMF}+$ sonicated $(30 \mathrm{~min})$, heated in autoclave at $125{ }^{\circ} \mathrm{C}$ for $5 \mathrm{~h}$

1,6-Hexanediamine-functionalized MOF-235 shell on $\mathrm{Fe}_{3} \mathrm{O}_{4}$

$\mathrm{Fe}_{3} \mathrm{O}_{4}+\mathrm{FeCl}_{3} \cdot 6 \mathrm{H}_{2} \mathrm{O}+\mathrm{H}_{2} \mathrm{BDC}+$

$\mathrm{DMF}+$ heated in autoclave at $80{ }^{\circ} \mathrm{C}$ for $24 \mathrm{~h}$

$\mathrm{CoFe}_{2} \mathrm{O}_{4}+\mathrm{MAA}+\mathrm{FeCl}_{3} \cdot 6 \mathrm{H}_{2} \mathrm{O}+$

$\mathrm{H}_{3} \mathrm{BTC}+\mathrm{EtOH}+70{ }^{\circ} \mathrm{C}, 30 \mathrm{~min}$

$\mathrm{Fe}_{3} \mathrm{O}_{4}+\mathrm{MAA}+\mathrm{Cu}(\mathrm{OAc})_{2}+\mathrm{H}_{3} \mathrm{BTC}+$ $\mathrm{EtOH}$, stirred for $2 \mathrm{~h}$

Citrate-modified $\mathrm{Fe}_{3} \mathrm{O}_{4}+\mathrm{Fe}_{2} \mathrm{Co}(\mu$ $3-\mathrm{O})\left(\mathrm{CH}_{3} \mathrm{COO}\right)_{6}$ metal clusters +

$3,3^{\prime}, 5,5^{\prime}$-azobenzenetetracarboxylic acid + mixed with vortex mixer +

exposed to magnetic field for $1.5 \mathrm{~h}$

$\mathrm{Fe}_{3} \mathrm{O}_{4}+\mathrm{MAA}+\mathrm{FeCl}_{3} \cdot 6 \mathrm{H}_{2} \mathrm{O}+$

$\mathrm{H}_{3} \mathrm{BTC}+\mathrm{EtOH}+70{ }^{\circ} \mathrm{C}, 30 \mathrm{~min}$ for multiple cycles

$\mathrm{Fe}_{3} \mathrm{O}_{4}$ nanorods $+\mathrm{H}_{3}$ BTC solution of $(1: 1) \mathrm{DMF} / \mathrm{EtOH}+\mathrm{Cu}(\mathrm{OAc})_{2}+$ $70{ }^{\circ} \mathrm{C}$ for $4 \mathrm{~h}$

Bare MIL-101(Cr) $\mathrm{MOF}+\mathrm{FeCl}_{2}$ and $\mathrm{FeCl}_{3}+$ stirred in $\mathrm{N}_{2}$ atmosphere for $1 \mathrm{~h}+\mathrm{NH}_{3}$

$\mathrm{Fe}_{3} \mathrm{O}_{4}+$ DMF- $\mathrm{H}_{2} \mathrm{O}+$ aluminium nitrate $+\mathrm{H}_{3} \mathrm{BTC}+$ refluxing conditions at $140{ }^{\circ} \mathrm{C}$ for $36 \mathrm{~h}$

MIL-100(Fe) shell

Core-shell structure having Glycopeptide

Application

Ref.

$\mathrm{Fe}_{3} \mathrm{O}_{4}$ core and $\mathrm{Mg}-\mathrm{MOF}-74$ shell enrichment

101

作

Adsorptive removal

102

Core-shell microstructure in

which MIL-100(Fe) layer coated of arsenic

on $\mathrm{CoFe}_{2} \mathrm{O}_{4}$

$\mathrm{Fe}_{3} \mathrm{O}_{4}$ covered by $\mathrm{Cu}_{3}(\mathrm{BTC})_{2}$ shell Adsorptive removal of methylene blue

Growth of MOF crystals around $\mathrm{CO}_{2}$ capture and

MNPs release

Core-shell $\mathrm{Fe}_{3} \mathrm{O}_{4} @ M I L-100(\mathrm{Fe}) \quad$ Catalysis (Claisen-

108

Schmidt condensation reaction)

$\mathrm{Fe}_{3} \mathrm{O}_{4}$ nanorods interspersed Drug delivery 109

within MOF matrix

$\mathrm{Fe}_{3} \mathrm{O}_{4}$ NPs incorporated into the Catalysis (benzyl matrix of MIL-101 alcohol oxidation)

Spindle and granular morphol- $\mathrm{Pb}(\mathrm{II})$ adsorption ogy of MIL-96(Al) and $\mathrm{Fe}_{3} \mathrm{O}_{4}$ respectively along with the uniform embedding of $\mathrm{Fe}_{3} \mathrm{O}_{4}$ within MIL-96(Al)

$\mathrm{Fe}_{3} \mathrm{O}_{4}+$ neat ground with $\mathrm{H}_{3} \mathrm{BTC}+\mathrm{Fe}_{3} \mathrm{O}_{4}$ NPs interspersed in the ground with $\mathrm{FeCl}_{3}$ in EtOH- $\mathrm{H}_{2} \mathrm{O}$ Fe-BTC matrix

Bare MIL-101(Cr) $\mathrm{MOF}+\mathrm{FeCl}_{2}$ and $\mathrm{Fe}_{3} \mathrm{O}_{4}$ NPs incorporated in the $\mathrm{FeCl}_{3}+$ stirred in $\mathrm{N}_{2}$ atmosphere pores of MIL-101 for $1 \mathrm{~h}+\mathrm{NH}_{3}+\mathrm{ClSO}_{3} \mathrm{H}$ in $\mathrm{CHCl}_{3}+$ stirred for $2 \mathrm{~h}$

$\mathrm{Fe}_{3} \mathrm{O}_{4}+\mathrm{Mg}\left(\mathrm{NO}_{3}\right)_{3}+2,5$ dihydrox- $\mathrm{Fe}_{3} \mathrm{O}_{4}$ NPs incorporated within yterephthalic acid mixed in 14:1:1 matrix of Mg-MOF-74 $\mathrm{DMF} / \mathrm{EtOH} / \mathrm{H}_{2} \mathrm{O}$, heated in an autoclave at $125{ }^{\circ} \mathrm{C}$ for $20 \mathrm{~h}$ $\mathrm{Zn}\left(\mathrm{NO}_{3}\right)_{2}+2$-aminoterephthalic acid $\left(\mathrm{NH}_{2}-\mathrm{H}_{2} \mathrm{BDC}\right)+\mathrm{Fe}_{3} \mathrm{O}_{4}$ suspension in DMF-EtOH + PVP + heated in autoclave for $4 \mathrm{~h}$ at $100{ }^{\circ} \mathrm{C}$

$\mathrm{Zn}\left(\mathrm{NO}_{3}\right)_{2}+2$-methylimidazole +

$\mathrm{Fe}_{3} \mathrm{O}_{4}$, stirred for $30 \mathrm{~min}$

$\mathrm{PFe}_{3} \mathrm{O}_{4} \mathrm{NPs}+\mathrm{DMF}-\mathrm{MeOH}+$

titanium isopropoxide +2 -

aminoterephthalic acid + heated

at $160{ }^{\circ} \mathrm{C}$ for $12 \mathrm{~h}$

(a) $\mathrm{Fe}_{3} \mathrm{O}_{4}+\mathrm{ZrCl}_{4}+$ terephthalic acid UiO-66 coated on $\mathrm{Fe}_{3} \mathrm{O}_{4}$ NPS

$+\mathrm{DMF}+$ heated at $130{ }^{\circ} \mathrm{C}$ for $12 \mathrm{~h}$

(b) $\mathrm{Fe}_{3} \mathrm{O}_{4}$ @UiO-66 + PPI $+\mathrm{MeOH}$,

r.t., $2 \mathrm{~h}$

$\mathrm{CoFe}_{2} \mathrm{O}_{4}+$ zinc nitrate +2 -

aminoterephthalic acid and

1,4 bis(4-pyridyl)-2,3-diaza-2,3-

butadiene $+\mathrm{DMF}+$ heated at $90{ }^{\circ} \mathrm{C}$

in autoclave for 3 days

Hollow $\mathrm{Fe}_{3} \mathrm{O}_{4}+$ ferric chloride $+\quad \mathrm{Fe}_{3} \mathrm{O}_{4}$ incorporated in

2-aminoterephthalic acid + stirred $\mathrm{NH}_{2}-\mathrm{MIL}-101(\mathrm{Fe})$

at $70{ }^{\circ} \mathrm{C}$ for $4 \mathrm{~h}$
$\mathrm{CoFe}_{2} \mathrm{O}_{4}$ NPs embedded inside the matrix of TMU-17- $\mathrm{NH}_{2}$

$\mathrm{Fe}_{3} \mathrm{O}_{4}$ NPs incorporated within Zn-based MOF

$\mathrm{Fe}_{3} \mathrm{O}_{4}$ NPs embedded within ZIF-8

$\mathrm{PFe}_{3} \mathrm{O}_{4}$ NPs present on surface and inner shell cavity of

$\mathrm{NH}_{2}$-MIL-125

Adsorption of direct and acid dyes

Catalysis

(dihydropyrimidine synthesis)

Phosphate removal

Drug delivery and MRI contrast agent

Adsorption and separation of $\mathrm{UO}_{2}{ }^{2+}$ $\mathrm{Pb}$ (II) adsorption
103

104

107

Drug delivery

of 1,3,5-

triarylbenzenes and

2,4,6-triaryl

pyridines)

$\mathrm{CO}_{2}$ capture and

release 
Table 1 (continued)

\begin{tabular}{llll}
$\begin{array}{l}\text { S. } \\
\text { no. }\end{array}$ & Approach & $\begin{array}{l}\text { Magnetic MOF } \\
\text { composite }\end{array}$ & Synthetic conditions \\
\hline 20 & Encapsulation & $\mathrm{Fe}_{3} \mathrm{O}_{4} @ P D A @ Z r-M O F$ & $\mathrm{Fe}_{3} \mathrm{O}_{4}+\mathrm{PDA}+\mathrm{DMF}+\mathrm{ZrCl}_{4}+$ \\
& & $\mathrm{H}_{2} \mathrm{BDC}$, stirred at $140{ }^{\circ} \mathrm{C}, 20 \mathrm{~min}$
\end{tabular}

21 Encapsulation $\mathrm{Fe}_{3} \mathrm{O}_{4} @ \mathrm{SiO}_{2} @ \mathrm{Zr}-\mathrm{MOF}$

22 Encapsulation ZIF-8@CoFe $\mathrm{O}_{4}$

23 Encapsulation $\mathrm{Fe}_{3} \mathrm{O}_{4} / \mathrm{Fe}-\mathrm{MIL}-101$

25 Encapsulation $\mathrm{Fe}_{3} \mathrm{O}_{4} @ P D A @$ UiO-66- $\mathrm{NH}_{2}$

26 Encapsulation MagNP@PDA@ZIF-8

27 Encapsulation $\mathrm{Fe}_{3} \mathrm{O}_{4} @ \mathrm{SiO}_{2}$ @UiO-67

28 Encapsulation $\mathrm{Fe}_{3} \mathrm{O}_{4} @ \mathrm{SiO}_{2} @ \mathrm{MOF}$

29 Encapsulation $\mathrm{Fe}_{3} \mathrm{O}_{4} @ \mathrm{MIL}-101(\mathrm{Fe})$

30 Encapsulation $\mathrm{Fe}_{3} \mathrm{O}_{4}$ @PVP-PEI@ MOF-PBA

31 Encapsulation $\mathrm{Fe}_{3} \mathrm{O}_{4} @ P 4 V P @$ MIL-100(Fe)

32 Encapsulation $\mathrm{Fe}_{3} \mathrm{O}_{4}$ @ZIF-8

33 Encapsulation $\mathrm{Fe}_{3} \mathrm{O}_{4} / \mathrm{Cu}_{3}(\mathrm{btc})_{2}$

34 Mixing

$\mathrm{Fe}_{3} \mathrm{O}_{4} / \mathrm{MIL}-53(\mathrm{Fe})$

$35 \quad$ Mixing

$\mathrm{HPU}-13 @ \mathrm{Fe}_{3} \mathrm{O}_{4}$

36 Mixing

$\mathrm{Fe}_{3} \mathrm{O}_{4} / \mathrm{MIL}-100(\mathrm{Fe})$

37 Mixing

$\mathrm{NH}_{2}$-MIL-88B(Fe)/Fe $3 \mathrm{O}_{4}$

$38 \quad$ Mixing

MOF-199/ $/ \mathrm{Fe}_{3} \mathrm{O}_{4}$

39 Mixing

$\mathrm{CoFe}_{2} \mathrm{O}_{4} / \mathrm{Mn}-\mathrm{BDC}$
$\mathrm{Fe}_{3} \mathrm{O}_{4}+\mathrm{TEOS}+\mathrm{DMF}+\mathrm{ZrCl}_{4}+$ 2-aminoterephthalic acid + stirred at $120{ }^{\circ} \mathrm{C}$ for $6 \mathrm{~h}$ $\mathrm{CoFe}_{2} \mathrm{O}_{4}+\mathrm{PVP}+\mathrm{MeOH}+$ 2-methylimidazole $+\mathrm{Zn}\left(\mathrm{NO}_{3}\right)_{2}+$ reflux, $70{ }^{\circ} \mathrm{C}$ for $20 \mathrm{~h}$

PAA-modified $\mathrm{Fe}_{3} \mathrm{O}_{4}+\mathrm{PVP}+$ stirred at $110{ }^{\circ} \mathrm{C}$ for $24 \mathrm{~h}$

$\mathrm{Fe}_{3} \mathrm{O}_{4}+\mathrm{PDA}+\mathrm{EtOH}+\mathrm{Cu}(\mathrm{OAc})_{2}+$ $\mathrm{H}_{3}$ btc, stirred at $70{ }^{\circ} \mathrm{C}$

$\mathrm{Fe}_{3} \mathrm{O}_{4}+\mathrm{PDA}+\mathrm{DMF}+\mathrm{ZrCl}_{4}+$ $\mathrm{NH}_{2}-\mathrm{H}_{2} \mathrm{BDC}, 120{ }^{\circ} \mathrm{C}, 45 \mathrm{~min}$

$\mathrm{Fe}_{3} \mathrm{O}_{4}+\mathrm{PDA}+\mathrm{MeOH}+\mathrm{Zn}\left(\mathrm{NO}_{3}\right)_{2}+$ 2-methylimidazole, r.t., $12 \mathrm{~h}$ $\mathrm{FeCl}_{3} \cdot 6 \mathrm{H}_{2} \mathrm{O}+\mathrm{H}_{2} \mathrm{BDC}+\mathrm{DMF}+$

Composite description

Core-shell-shell morphology in Phosphopeptide

which $\mathrm{Fe}_{3} \mathrm{O}_{4}$ core covered with enrichment intermediate PDA shell and outer Zr-MOF shell

Core-shell architecture with Removal of pharma$\mathrm{Fe}_{3} \mathrm{O}_{4}$ core and UiO-66- $\mathrm{NH}_{2}$ shell ceutical compounds

Core-shell ZIF-8@ $\mathrm{CoFe}_{2} \mathrm{O}_{4}$ having $\mathrm{CoFe}_{2} \mathrm{O}_{4}$ core and ZIF-8 shell

$\mathrm{Fe}_{3} \mathrm{O}_{4}$ encapsulated within Fe-MIL-101 MOF

Adsorptive removal of Congo Red and Basic Red-2 dye Oxidation of alcohols 137 and epoxidation of olefins

$\mathrm{Fe}_{3} \mathrm{O}_{4}+\mathrm{TEOS}+\mathrm{DMF}+\mathrm{ZrCl}_{4}+$ biphenyl-4, $4^{\prime}$-dicarboxylic acid, heated at $120{ }^{\circ} \mathrm{C}$ for $24 \mathrm{~h}$ in autoclave

$\mathrm{Fe}_{3} \mathrm{O}_{4}+\mathrm{TEOS}+\mathrm{DMF}+\mathrm{ZrCl}_{4}+$ $\mathrm{H}_{2} \mathrm{BDC}+1$,4-phenylenebisboronic acid, stirred at $120^{\circ} \mathrm{C}, 4 \mathrm{~h}$

PVP-modified $\mathrm{Fe}_{3} \mathrm{O}_{4}+\mathrm{FeCl}_{3} \cdot 6 \mathrm{H}_{2} \mathrm{O}+$ $\mathrm{H}_{2} \mathrm{BDC}+\mathrm{DMF}+$ heated in autoclave at $110{ }^{\circ} \mathrm{C}$ for $20 \mathrm{~h}$

$\mathrm{Fe}_{3} \mathrm{O}_{4}+\mathrm{PVP}+\mathrm{PEI}$ (polyetherimide) + MOF shell on PVP-PEI coated $\mathrm{Fe}\left(\mathrm{NO}_{3}\right)_{3}+1$,4-phenylenebisboronic $\mathrm{Fe}_{3} \mathrm{O}_{4} \mathrm{NPs}$ acid (PBA) $+\mathrm{CH}_{3} \mathrm{CN}+\mathrm{DMF}+120^{\circ} \mathrm{C}$, $2 \mathrm{~h}$

$\mathrm{Fe}_{3} \mathrm{O}_{4}+\mathrm{P} 4 \mathrm{VP}+\mathrm{FeCl}_{3} \cdot 6 \mathrm{H}_{2} \mathrm{O}+\quad$ MIL-100(Fe) shell on

$\mathrm{H}_{3} \mathrm{BTC}, 70{ }^{\circ} \mathrm{C}$, 30 min for 20 cycles $\mathrm{Fe}_{3} \mathrm{O}_{4} @ \mathrm{P} 4 \mathrm{VP}$ (core-shell) microspheres

$\mathrm{Fe}_{3} \mathrm{O}_{4}+\mathrm{PSS}+\mathrm{MeOH}+\mathrm{Zn}\left(\mathrm{NO}_{3}\right)_{2}+$ Uniform ZIF-8 shell on $\mathrm{Fe}_{3} \mathrm{O}_{4}$ 2-methylimidazole + stirred microspheres

at $50{ }^{\circ} \mathrm{C}$ for $3 \mathrm{~h}$

PAA-modified $\mathrm{Fe}_{3} \mathrm{O}_{4}+\mathrm{Cu}(\mathrm{OAc})_{2}+\mathrm{Cu}_{3}(\mathrm{btc})_{2}$ shell on $\mathrm{Fe}_{3} \mathrm{O}_{4}$ core $\mathrm{H}_{3}$ btc $+70{ }^{\circ} \mathrm{C}, 60 \mathrm{~min}$ for 10 cycles

$\mathrm{Fe}_{3} \mathrm{O}_{4}+\mathrm{DMF}+\mathrm{FeCl}_{3}+\mathrm{H}_{2} \mathrm{BDC}+$ $150{ }^{\circ} \mathrm{C}, 12 \mathrm{~h}$ in autoclave

$\mathrm{Fe}_{3} \mathrm{O}_{4}$ anchored on MIL-53(Fe) microrods

$\mathrm{Fe}_{3} \mathrm{O}_{4}+\mathrm{CuSO}_{4}+2$-(5-pyridin-4-yl$2 \mathrm{H}$-[1,2,4]triazol-3-yl)-pyrimidine EtOH: $\mathrm{H}_{2} \mathrm{O}, 160{ }^{\circ} \mathrm{C}$ for $72 \mathrm{~h}$ in autoclave

MIL-100(Fe) $+\mathrm{FeCl}_{3}+$ ethylene glycol $+200{ }^{\circ} \mathrm{C}, 10 \mathrm{~h}$ in autoclave $\mathrm{FeCl}_{3}+\mathrm{DMF}+\mathrm{NH}_{2}-\mathrm{H}_{2} \mathrm{BD}$
$170{ }^{\circ} \mathrm{C}, 24 \mathrm{~h}$ in autoclave

$\mathrm{Fe}_{3} \mathrm{O}_{4},(1: 1) \mathrm{DMF}: \mathrm{EtOH}+$ $\mathrm{Cu}(\mathrm{OA}$ $\mathrm{CoFe}_{2} \mathrm{O}_{4}+\mathrm{DMF}-\mathrm{MeOH}+\mathrm{MnCl}_{2}+\mathrm{Mn}-\mathrm{BDC}$ microflakes decorated $\mathrm{H}_{2} \mathrm{BDC}+120{ }^{\circ} \mathrm{C}, 24 \mathrm{~h}$ in autoclave with $\mathrm{CoFe}_{2} \mathrm{O}_{4} \mathrm{NPs}$ of HPU-13

MIL-100(Fe) decorated with

$\mathrm{Fe}_{3} \mathrm{O}_{4}$ NPs hexagonal prism like morphology
$\mathrm{Fe}_{3} \mathrm{O}_{4} @ P D A$ wrapped with small crystals of $\mathrm{Cu}_{3}(\mathrm{btc})_{2}$ layer UiO-66- $\mathrm{NH}_{2}$ shell grafted on $\mathrm{Fe}_{3} \mathrm{O}_{4} @ P D A$ (core-shell) microspheres

Carrier for enzyme immobilization Glycopeptide and phosphopeptide enrichment 4-Nitrophenol reduction and methylene blue degradation MagNP@PDA (core-shell) NPs

Organophosphorous pesticide removal

Glycopeptide and phosphopeptide enrichment

Catalytic oxidation of 144 Acid Orange 7

Glycoprotein capture 145 and release

Catalysis (selective 146 oxidation of

alcohols)

Catalysis (Knoevenagel 147 condensation

reaction)

Catalysis (oxidation 148 of alcohols and olefins)

Photocatalytic degra- 149 dation of rhodamine B and $p$-nitrophenol

$\mathrm{Fe}_{3} \mathrm{O}_{4}$ coated on rod-like crystals $\mathrm{Cr}(\mathrm{vI})$ removal

Adsorptive removal

151 of rhodamine B

Enzyme

$88 \mathrm{~B}(\mathrm{Fe})$ possessing bipyramidal immobilization

$\mathrm{Fe}_{3} \mathrm{O}_{4}$ NPs attached on surface of Neonicotinoid insecticide removal

Catalysis (multicomponent click reaction) i.e., ferric chloride and benzene-1,4-dicarboxylic acid or $\mathrm{H}_{2} \mathrm{BDC}$, to $\mathrm{Fe}_{3} \mathrm{O}_{4}-\mathrm{NH}_{2}$ NPs under solvothermal conditions accelerated the chelation of $\mathrm{NH}_{2}$ functionalities with $\mathrm{Fe}^{3+}$ ions that further merged with $\mathrm{H}_{2}$ BDC to yield a shell of MOF-235. 


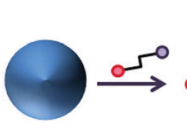

$\mathrm{Fe}_{3} \mathrm{O}_{4}$ MIL-100(Fe).
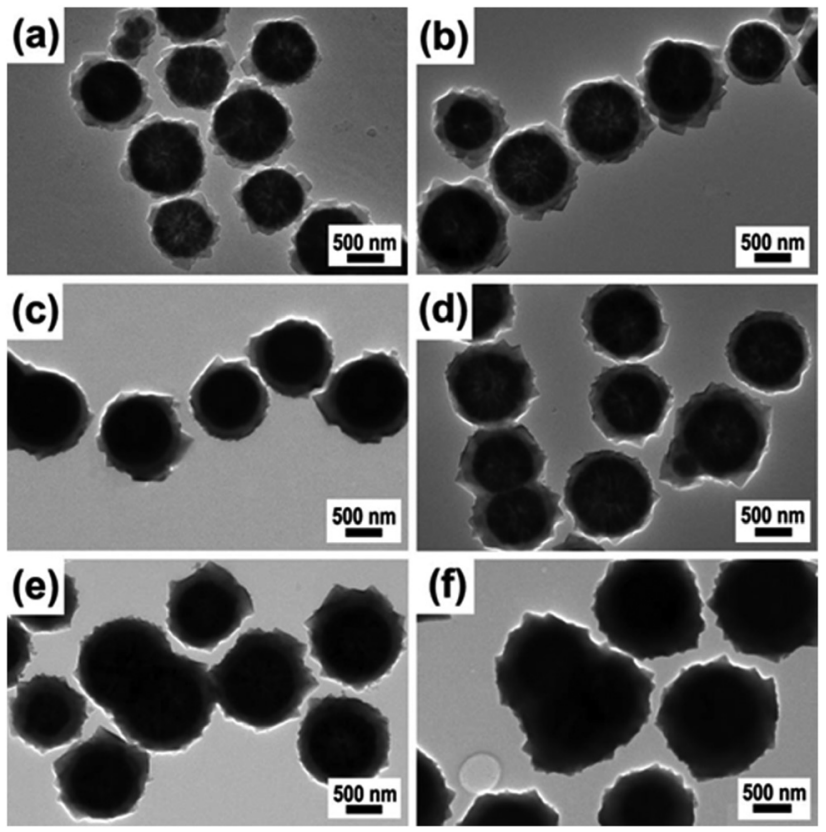

Fig. 1 TEM images of core-shell $\mathrm{Fe}_{3} \mathrm{O}_{4}\left(\mathrm{a}\left[\mathrm{Cu}_{3}(\mathrm{BTC})_{2}\right]\right.$ architecture obtained after (a) 10, (b) 20, (c) 25, (d) 30, (e) 40, and (f) 50 assembly cycles. Reproduced with permission from ref. 99. Copyright 2012 Royal Society of Chemistry.

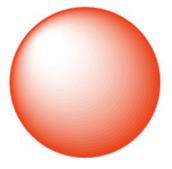

$\mathrm{Fe}_{3} \mathrm{O}_{4}$

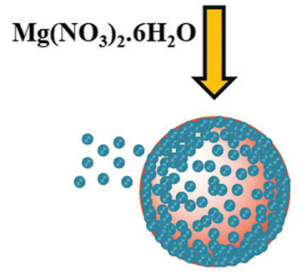

$\mathrm{Fe}_{3} \mathrm{O}_{4} @ \mathrm{Mg}^{2+}$

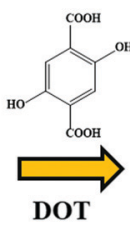

OT

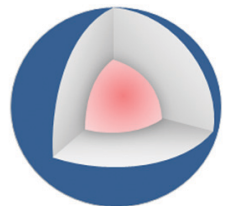

$\mathrm{Fe}_{3} \mathrm{O}_{4} @ M g-M O F-74$

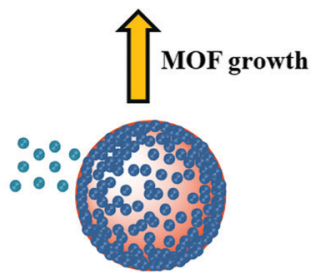

$\mathrm{Fe}_{3} \mathrm{O}_{4} @ \mathrm{Mg}^{2+} / \mathrm{DOT}$

Scheme 3 Schematic fabrication of $\mathrm{Fe}_{3} \mathrm{O}_{4} @ \mathrm{Mg}-\mathrm{MOF}-74$

This layer-by-layer approach has also been successfully exploited for fabricating several other magnetic MOF composites, including $\mathrm{CoFe}_{2} \mathrm{O}_{4} @ \mathrm{MIL}-100(\mathrm{Fe}), \mathrm{Fe}_{3} \mathrm{O}_{4} / \mathrm{ZIF}-8 @ \mathrm{GOx}, \mathrm{Fe}_{3} \mathrm{O}_{4} @ \mathrm{MIL}-$ $100(\mathrm{Fe}) / \beta \mathrm{CD}$, and $\mathrm{Fe}_{3} \mathrm{O}_{4} @ U$ UiO-66, that further find significant applications in several emerging fields. ${ }^{103-108}$
2.2.2 Embedding. In this methodology, firstly the magnetic support material is synthesized. Then the support is added to the MOF mother batch solution, i.e., a solution containing the progenitor inorganic metal salts, organic ligand and solvent or mixture of solvents. This approach does not entail decorating the surface of support material with certain functionalizing agents but rather involves direct addition of MNPs into the MOF solution, as a result of which the MNPs automatically get embedded within the pores of the MOF. Generally, a solvothermal strategy is employed to synthesize magnetic-embedded hybrid MOF materials.

The fabrication of a novel magnetic MOF composite, $\mathrm{Fe}_{3} \mathrm{O}_{4} /$ $\mathrm{Cu}_{3}$ (BTC) $)_{2}$, by incorporating $\mathrm{Fe}_{3} \mathrm{O}_{4}$ nanorods within the nanocrystals of a $3 \mathrm{D} \mathrm{Cu}_{3}(\mathrm{BTC})_{2}$ MOF was explored by Qiu and co-workers. ${ }^{109}$ In order to achieve the aforesaid objective, the authors explored the possibility of designing two different $\mathrm{Fe}_{3} \mathrm{O}_{4} / \mathrm{Cu}_{3}(\mathrm{BTC})_{2}$ composites with dissimilar concentrations of ferrite nanorods. For this, an ethanolic suspension of $\mathrm{Fe}_{3} \mathrm{O}_{4}$ nanorods (10 $\mathrm{mL}$ and $5 \mathrm{~mL}$, designated as 1 and 2 , respectively) was initially added into a $1: 1 \mathrm{DMF} /$ ethanol solution of $\mathrm{H}_{3} \mathrm{BTC}$ under heating at $70{ }^{\circ} \mathrm{C}$ after which aqueous copper acetate was introduced into the above system and finally heated at $70{ }^{\circ} \mathrm{C}$ for $4 \mathrm{~h}$. Microscopic techniques such as TEM (Fig. 2) unveiled the embedding of $\mathrm{Fe}_{3} \mathrm{O}_{4}$ nanorods within the MOF matrix.

Quite astonishingly, the protocols reported till now for magnetic MOF composites involve the addition of MNPs to an aqueous solution of MOF salts, wherein in situ formation of the MOF takes place. Nevertheless, Saikia et al. for the very first time prepared bare MIL-101(Cr) MOF and then added this MOF into an aqueous solution containing $\mathrm{FeCl}_{2}$ and $\mathrm{FeCl}_{3}$ salts to obtain the magnetic nanocomposite $\mathrm{Fe}_{3} \mathrm{O}_{4} @ \mathrm{MIL}-101 .{ }^{110}$ Furthermore, MIL-101(Cr) possessing a structurally massive surface area enables superior dispersion and incorporation of magnetite NPs on its surface.

Mehdinia et al. fabricated a magnetic $\mathrm{Fe}_{3} \mathrm{O}_{4} / \mathrm{MIL}-96(\mathrm{Al})-$ based framework trap for the adsorption of $\mathrm{Pb}^{2+}$ from aqueous media. ${ }^{111}$ A hydrothermal approach was employed wherein
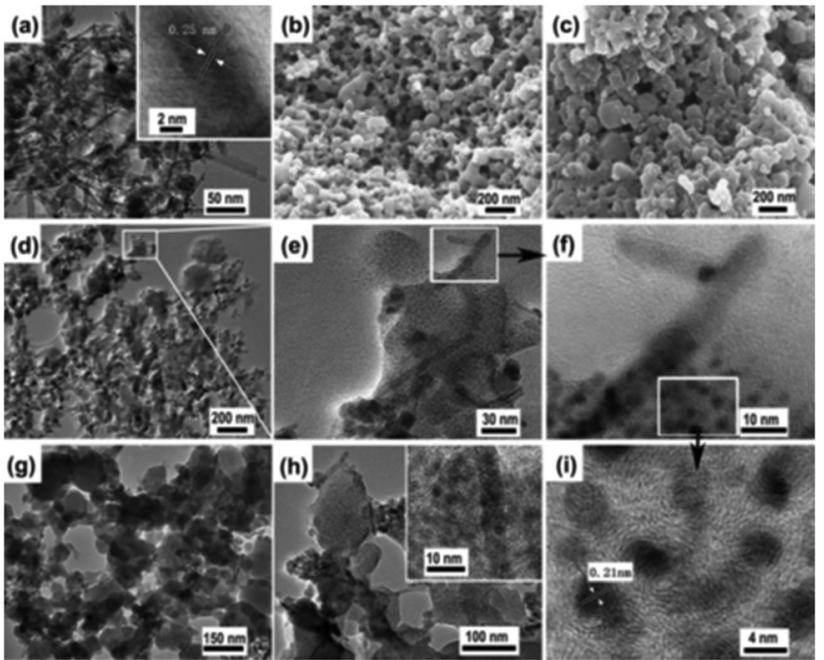

Fig. 2 TEM images of $\mathrm{Fe}_{3} \mathrm{O}_{4} \mathrm{NPs}(\mathrm{a}), \mathrm{Fe}_{3} \mathrm{O}_{4} / \mathrm{Cu}_{3}(\mathrm{BTC})_{2} 1$ (d-f and i) and 2 ( $\mathrm{g}$ and $\mathrm{h}$ ), and SEM images of 1 (b) and 2 (c). Reproduced with permission from ref. 109. Copyright 2011 Royal Society of Chemistry. 
(A)

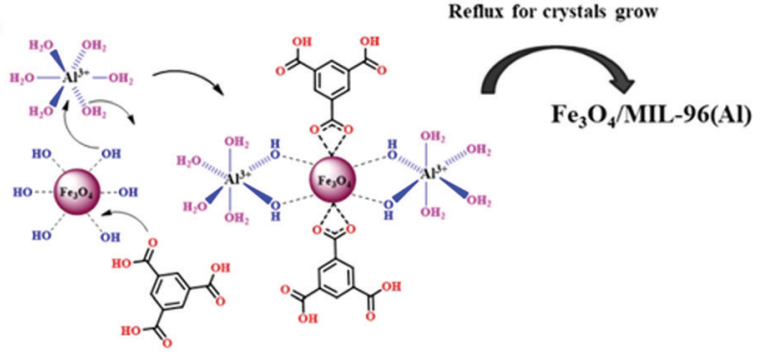

(B)

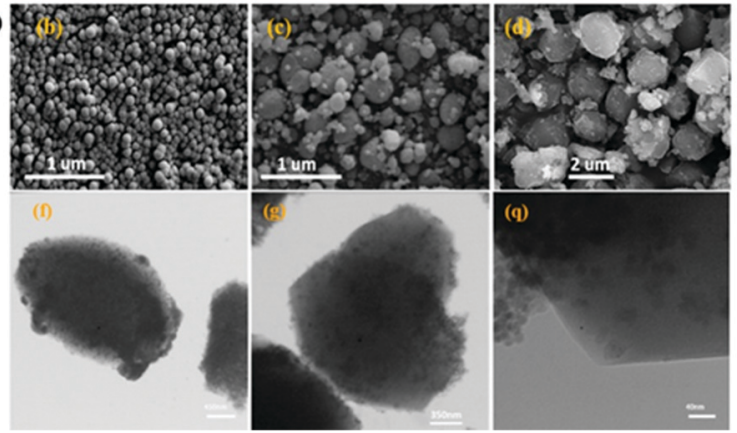

Fig. 3 (A) Figure depicting probable mechanisms involved in the embedding of $\mathrm{Fe}_{3} \mathrm{O}_{4}$ in MIL-96(Al). (B) SEM micrographs of (b) $\mathrm{Fe}_{3} \mathrm{O}_{4} \mathrm{NPs}$ and (c) MIL-96(Al). FE-SEM image of (d) $\mathrm{Fe}_{3} \mathrm{O}_{4} / \mathrm{MIL}-96$ (Al) and (f, $g$ and q) TEM micrographs of $\mathrm{Fe}_{3} \mathrm{O}_{4} / \mathrm{MIL}$-96(Al). Reproduced with permission from ref. 111. Copyright (2018) American Chemical Society.

pre-formed $\mathrm{Fe}_{3} \mathrm{O}_{4}$ NPs were mixed in DMF- $\mathrm{H}_{2} \mathrm{O}$ solution containing MOF salts, i.e. aluminium nitrate and $\mathrm{H}_{3} \mathrm{BTC}$, under refluxing conditions. The authors explicated two probable mechanisms through which $\mathrm{Fe}_{3} \mathrm{O}_{4}$ was embedded within the MIL-96(Al) (Fig. 3A). The first mechanism was based on the fact that $\mathrm{Al}^{3+}$, having Lewis acidic character with vacant $\mathrm{d}$ orbitals, effectively formed coordination bonds with the $\mathrm{OH}$ groups of the $\mathrm{Fe}_{3} \mathrm{O}_{4}$ NPs and further nucleation resulted in growth of MIL-96(Al) crystals around the $\mathrm{Fe}_{3} \mathrm{O}_{4}$. The alternative mechanistic approach encompassed coordination of $\mathrm{H}_{3} \mathrm{BTC}$ ligand with $\mathrm{Fe}^{3+}$ sites on $\mathrm{Fe}_{3} \mathrm{O}_{4}$ and heat-impelled refluxing conditions drove the growth of MIL-96(Al) crystals all around the $\mathrm{Fe}_{3} \mathrm{O}_{4}$. The latter mechanism was further supported by the emergence of an $\mathrm{Fe}-\mathrm{O}-\mathrm{C}$ peak in the high-resolution XPS spectrum ascribed to bond formation between oxygen atoms of the carboxylic moieties of the ligand and $\mathrm{Fe}^{3+}$ ions of the $\mathrm{Fe}_{3} \mathrm{O}_{4}$. Additionally, TEM and SEM analysis (Fig. 3B) also divulged the spindle and granular morphology of MIL-96(Al) and $\mathrm{Fe}_{3} \mathrm{O}_{4}$, respectively, along with the uniform embedding of $\mathrm{Fe}_{3} \mathrm{O}_{4}$ in MIL-96(Al).

Bellusci and his research group illustrated the earliest example of a magnetic MOF composite fabricated using a mechanochemical approach. ${ }^{112}$ The first step towards accomplishing the desired objective involved the synthesis of $\mathrm{Fe}_{3} \mathrm{O}_{4}$ NPs from ferric chloride and sodium hydroxide using sodium chloride as a dispersing agent via a ball milling method. Afterwards, the authors smartly employed a neat grinding method for modifying the surface of the MNPs using $\mathrm{H}_{3}$ BTC ligand. Later on, a liquid-assisted milling method was applied in which ferric chloride was ground with water and ethanol to get the final magnetic $\mathrm{MOF}\left(\mathrm{Fe}_{3} \mathrm{O}_{4} @ \mathrm{Fe}-\mathrm{BTC}\right)$ composite. In this way, magnetic iron oxide NPs were easily embedded in the framework matrix of iron(III) carboxylate.

Similarly, numerous other magnetic MOF composites have been synthesized utilizing this approach. ${ }^{113-120}$

2.2.3 Encapsulation. In this approach the surface of MNPs is pre-treated with an interface material that has high compatibility towards the MOF fabrication. In light of this, researchers have proposed an efficient and promising strategy for synthesizing core-shell architectures with a magnetic component as the core and a polymer shell comprising copious functional groups and hydrophilic sites, which significantly increases the affinity of the MOF shell for the magnetic part. Remarkable examples have been reported in the literature, wherein the surface of the magnetic core has been effectively modified with polydopamine (PDA), silica, polyacrylic acid (PAA), poly(sodium 4-styrene-sulfonate) (PSS), polyvinylpyrrolidone (PVP), chitosan, etc. which enhances MOF-substrate binding and further ensures controlled growth of MOF layers. ${ }^{121-129}$ Dopamine is one such organic molecule that undergoes oxidative selfpolymerization leading to the formation of polydopamine (PDA) with abundant multiple bonded groups, such as oxygen and nitrogen, that further interact with the metal ions of the MOF through chelation. ${ }^{130-132}$ It is worth mentioning here that Deng and co-workers developed a facile preparative route for attaining a splendid and magnetic responsive core-shell-shell $\mathrm{Fe}_{3} \mathrm{O}_{4} @ P D A @ Z r-M O F$ composite for the effective and selective capture of phosphopeptides (Scheme 4). ${ }^{133}$ In the abovementioned protocol, the authors initially prepared $\mathrm{Fe}_{3} \mathrm{O}_{4}$ magnetic microspheres and encapsulated them within a polymeric layer, i.e. polydopamine obtained after the polymerization of dopamine hydrochloride in the presence of Tris buffer under alkaline conditions. After that, $\mathrm{Fe}_{3} \mathrm{O}_{4} @ P D A$ microspheres were added into a solution of MOF precursor salts, i.e., $\mathrm{ZrCl}_{4}$ as well as benzene-1,4-dicarboxylic acid $\left(\mathrm{H}_{2} \mathrm{BDC}\right)$, then heated at $140{ }^{\circ} \mathrm{C}$ for $20 \mathrm{~min}$. According to the authors, chelation between $\mathrm{Zr}^{4+}$ ions and aromatic ring of polydopamine facilitated the continual and uninterrupted progression of Zr-MOF on the magnetic support.

Very recently, a fascinating magnetic MOF composite exhibiting unprecedented adsorption efficacy towards salicylic acid and acetylsalicylic acid was presented by Yang and co-workers. ${ }^{134}$ A magnetic UiO-66- $\mathrm{NH}_{2}$ MOF composite with $\mathrm{Zr}$ as the metal node and 2-aminoterephthalic acid as the organic

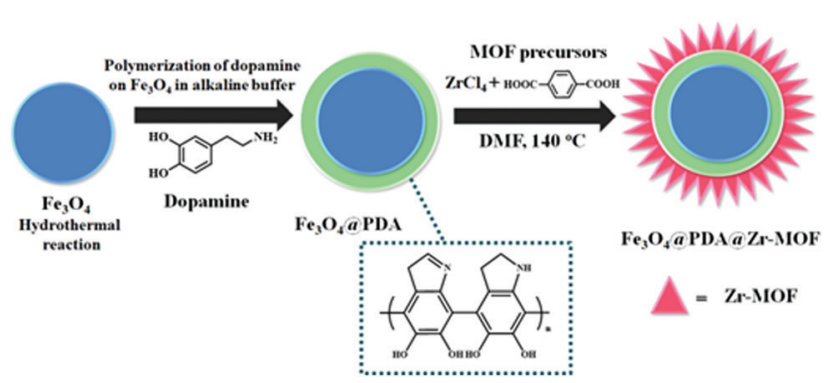

Scheme 4 Fabrication pathway for the $\mathrm{Fe}_{3} \mathrm{O}_{4}$ aPDA@Zr-MOF. 
linker was designed wherein the elementary step involved the coating of $\mathrm{Fe}_{3} \mathrm{O}_{4}$ NPs with a layer of silica using TEOS. Thereafter, $\mathrm{Fe}_{3} \mathrm{O}_{4} @ \mathrm{SiO}_{2}$ and $\mathrm{ZrCl}_{4}$ were ultrasonically dispersed in DMF and mixed with a separately prepared DMF solution of 2-aminoterephthalic acid. The subsequent heating of the resulting solution with constant stirring at $120{ }^{\circ} \mathrm{C}$ for $6 \mathrm{~h}$ yielded $\mathrm{Fe}_{3} \mathrm{O}_{4} @$ $\mathrm{SiO}_{2} @ \mathrm{Zr}-\mathrm{MOF}$. The protective coating of silica not only protected the magnetic core from undergoing corrosion but also promoted the controlled growth of Zr-MOF onto $\mathrm{Fe}_{3} \mathrm{O}_{4}$ via chelating interactions between the $-\mathrm{OH}$ groups of the silica and the $\mathrm{Zr}^{4+}$ ions of the MOF.

In an attempt to provide an encouraging platform for targeted delivery of anticancer drugs, Sahu and co-workers nicely delineated the preparation of a nanoscale MOF that incorporated fabrication of MOF and folic acid in a one-pot process. ${ }^{135}$ A strikingly different methodology of combining IRMOF-3 and chitosan-coated ferrite NPs was presented here. The coating of $\mathrm{Fe}_{3} \mathrm{O}_{4}$ NPs with OCMC (O-carboxymethyl chitosan) not only prevented their agglomeration but also rendered uniform growth of the MOF shell. In the final step, folic acid and IRMOF-3 were integrated by mixing zinc nitrate, $\mathrm{NH}_{2}-\mathrm{H}_{2} \mathrm{BDC}$ (or $\mathrm{NH}_{2}$-BDC) in DMF-ethanol solution containing PVP, folic acid and OCMCcoated $\mathrm{Fe}_{3} \mathrm{O}_{4}$ NPs, and finally heated in an autoclave at $100{ }^{\circ} \mathrm{C}$ for $6 \mathrm{~h}$.

Zhang et al. prepared a core-shell MOF composite for the solid-phase extraction of Congo Red and Basic Red 2 dyes, wherein cobalt ferrite NPs were enclosed within zeolitic imidazolate framework (ZIF)-8 shells. ${ }^{136}$ However, prior to covering with the MOF shell, the cobalt ferrite NPs were initially coated with a layer of PVP polymer and then dispersed in the methanolic solution of zinc nitrate and 2-methylimidazole with further refluxing at $70{ }^{\circ} \mathrm{C}$ for $20 \mathrm{~h}$ to form the ZIF-8@ $\mathrm{CoFe}_{2} \mathrm{O}_{4}$ core-shell magnetic composite (wherein $\mathrm{CoFe}_{2} \mathrm{O}_{4}$ acted as the core component and ZIF-8 behaved like a shell).

Wang and co-workers demonstrated the fabrication of a magnetic $\mathrm{Fe}_{3} \mathrm{O}_{4} / \mathrm{Fe}-\mathrm{MIL}-101$ composite via a two-step encapsulation process. ${ }^{137}$ In order to accomplish the desired objective, the authors prepared PAA-modified magnetic iron oxide NPs using a facile co-precipitation technique that prevented their agglomeration. In the next step, PAA-modified $\mathrm{Fe}_{3} \mathrm{O}_{4}$ NPs acted as seeds and were coated with PVP to ensure continuous and smooth growth of MOF crystals. The encapsulation strategy generated highly stable as well as greatly dispersed $\mathrm{Fe}_{3} \mathrm{O}_{4} \mathrm{NPs}$ efficiently embodied in the MOF heterostructure.

Working on similar lines, several research groups have synthesized $\mathrm{Fe}_{3} \mathrm{O}_{4} @ P D A @ \mathrm{Cu}_{3}(\mathrm{BTC})_{2}, \mathrm{Fe}_{3} \mathrm{O}_{4} @ \mathrm{P} 4 \mathrm{VP} @ \mathrm{MIL}-100(\mathrm{Fe})$, $\mathrm{Fe}_{3} \mathrm{O}_{4} @ \mathrm{PDA} @ U i \mathrm{O}-66-\mathrm{NH}_{2}, \quad \mathrm{Fe}_{3} \mathrm{O}_{4} @ \mathrm{SiO}_{2} @ U i \mathrm{O}-67, \quad \mathrm{Fe}_{3} \mathrm{O}_{4} @ \mathrm{MIL}-$ 101(Fe), $\mathrm{Fe}_{3} \mathrm{O}_{4} @$ @PV-PEI@MOF-PBA, etc. using an encapsulation strategy and their efficacy has been successfully explored in the field of catalysis, detection, sensing and water remediation. ${ }^{138-148}$

2.2.4 Mixing. In this approach, neither functionalizing agents are utilized for modifying the surface of ferrite NPs nor is there a polymer coating to stimulate the growth of MOFs. This strategy simply involves the mixing of synthesized ferrite NPs into the precursor solution salt of MOF or vice versa. This kind of approach was very well demonstrated by Jiang and Ai

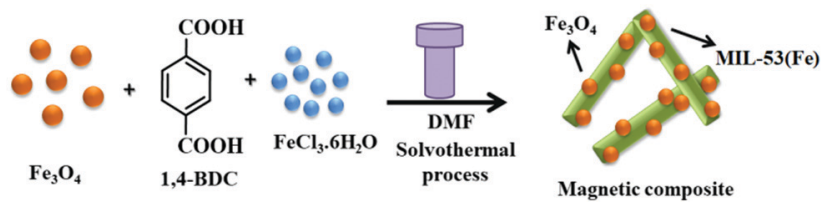

Scheme 5 Preparative route for MIL-53(Fe) hybrid magnetic composite.
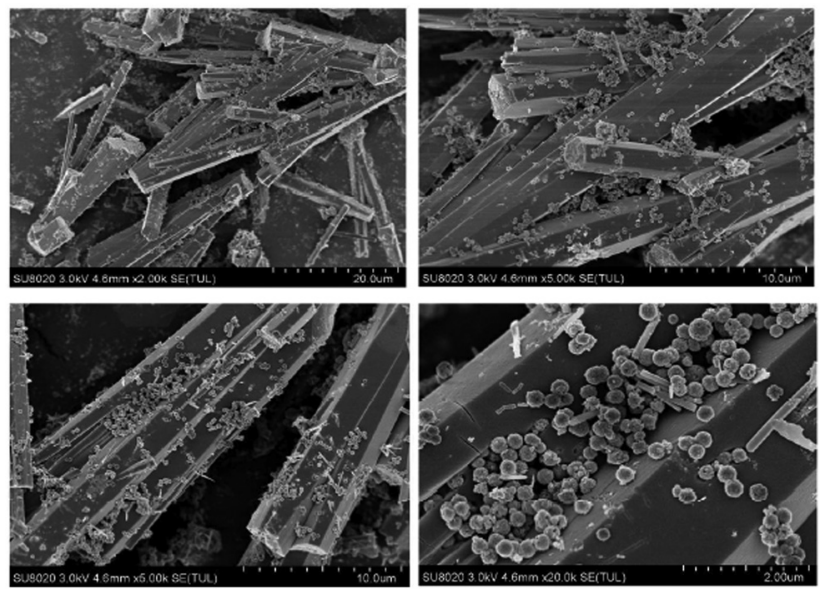

Fig. 4 SEM micrographs of $\mathrm{HPU}-13 \mathrm{aFe}_{3} \mathrm{O}_{4}$. Reproduced with permission from ref. 150. Copyright (2018) American Chemical Society.

along with their research group (Scheme 5). ${ }^{149}$ In this report, synthesized $\mathrm{Fe}_{3} \mathrm{O}_{4}$ nanospheres were added to a DMF solution containing ferric chloride and 1,4-BDC (1,4-benzene dicarboxylic acid) or $\mathrm{H}_{2}$ BDC under ultrasonication and then transferred into an autoclave for further heating at $150{ }^{\circ} \mathrm{C}$ for $12 \mathrm{~h}$. The resulting composite obtained after cooling was collected by centrifugation and denoted as $\mathrm{Fe}_{3} \mathrm{O}_{4} / \mathrm{MIL}-53(\mathrm{Fe})$.

Likewise, Wang and co-workers synthesized a novel magnetic HPU-13@ $\mathrm{Fe}_{3} \mathrm{O}_{4}$ composite by mixing of $\mathrm{Fe}_{3} \mathrm{O}_{4}$ with $\mathrm{CuSO}_{4}$ and 2-(5-pyridin-4-yl-2H-[1,2,4]triazol-3-yl)-pyrimidine as the organic linker for the selective adsorption of $\mathrm{Cr}(\mathrm{vI})$ from aqueous solution. ${ }^{150}$ The developed composite appeared in rod-like crystals of HPU-13 having uniformly dispersed $\mathrm{Fe}_{3} \mathrm{O}_{4}$ NPs (Fig. 4).

\section{Characterization}

Magnetic MOF composites can be characterized by various physicochemical analytical techniques, such as powder X-ray diffraction (PXRD), nitrogen adsorption-desorption isotherms, Fourier transform infrared spectroscopy (FTIR), thermogravimetric analysis (TGA), scanning electron microscopy (SEM), transmission electron microscopy (TEM), energy-dispersive X-ray spectroscopy (EDS), vibrating sample magnetometry (VSM), inductively coupled plasma optical emission spectroscopy (ICP-OES), single-crystal X-ray diffraction, nuclear magnetic resonance (NMR) and aqueous stability tests. PXRD bestows significant knowledge related to the chemical composition, crystallography and phase purity of the prepared composites. 
The phase purity of MOFs can also be effectively validated by matching the XRD pattern recorded experimentally with the simulated pattern derived from single-crystal X-ray data. Nitrogen $\left(\mathrm{N}_{2}\right)$ adsorption-desorption isotherms are used to determine the porosity, surface area, intrinsic pore volume as well as apparent pore size distributions of MOFs and magnetic materials. FTIR represents an indispensable technology to gain substantial information about the functional moieties present in the MOFs and MNPs. Besides, the changes and the occurrence of certain stretching frequencies in the FTIR spectra of the magnetic MOF composites help to deduce the type of bonding or the interactions that exist between the MOF and the magnetic material. TGA is performed to determine the thermal stability of the MOF and that of the MNPs too. Magnetic MOF composites offer certain applications in the field of catalysis and storage; therefore, their aqueous stability is also of prime importance. SEM is considered to be a wonderful technique for measuring various properties of magnetic MOF composites, such as their crystal size, morphology and elemental composition. Furthermore, SEM equipped with EDS reveals both quantitative as well as qualitative information about the involved metals and their distribution. VSM analysis is carried out to acquire information related to the magnetic characteristics of the resulting magnetic MOF composites. ICP-OES is executed to analyze the metal content and pristine nature of the sample. NMR spectroscopy is carried out to determine the purity of the MOF and the ratio of the linkers/ ligands involved in its synthesis. Single-crystal XRD is considered to be one of the highly sophisticated techniques to unambiguously determine the structure of a MOF. It gives absolute structural information about the material.

\section{Applications of magnetic MOF composites}

\subsection{Catalytic systems for various organic transformations}

Catalysis has been long considered a driver of innovation and progression and even today it continues to preserve its conspicuous position oriented towards fostering development in contemporary society. It is a foundation pillar of concrete modernization and holds significant potential for improvising antiquated or mature technology, thereby enhancing economic viability in chemical manufacturing industries along with ameliorating environmental impact. ${ }^{155,156}$ Moreover, with the advent of a novel class of recyclable heterogeneous materials, namely metal-organic frameworks, catalysis has reached new heights owing to their fascinating properties. In recent years, the role of supported MOFs has received substantial interest from the scientific fraternity for mediating a broad array of organic transformations. Several studies have been reported wherein MOFs have been effectively utilized as catalysts for a wide variety of reactions. ${ }^{18,157-160}$ Nevertheless, separation of the catalyst from reaction mixture post-catalysis requires additional processing steps, as a consequence of which core-shell structured MOF composites bearing magnetic functionality

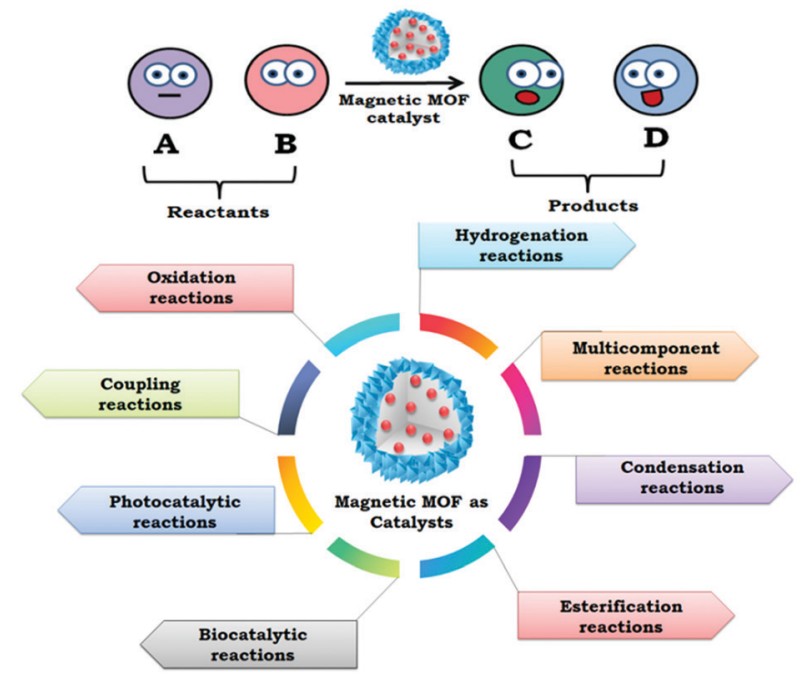

Fig. 5 Role of magnetic MOF composites as efficient catalysts for diverse industrially significant transformations.

have particularly grabbed the attention of material researchers. The combination of MOFs and magnetic materials is of huge interest because the flexibility of these cooperative functionalities allows their precise positioning and collection and also enables various applications within miniaturized platforms. Apart from that, superparamagnetic behavior facilitates rapid separation of catalysts from the solution media via an external static magnetic field. Driven by the constant demand for energy conservation, there has been an upsurge in interest towards the use of magnetic MOF composites as catalysts for diverse industrially challenging and demanding reactions (Fig. 5).

4.1.1 Oxidation reactions. The controlled oxidation of organic compounds to value-added chemicals and products is an indispensable transformation that has contributed immensely to the recent growth of organic synthesis at both the academic and industrial level. Traditionally, these oxidation reactions involve the use of stoichiometric amount of toxic heavy metal oxidants that generate large quantities of unwanted byproducts and also demonstrate poor selectivity. As a consequence of rising environmental cognizance, greener and environmentally benign processes yielding high atom economy are gaining widespread interest amongst the scientific community. Therefore, numerous heterogeneous catalysts like magnetic MOF composites are utilized for carrying out a wide range of oxidation reactions.

Nowadays, aerobic transition-metal-catalyzed selective oxidation of alcohols has been gaining huge momentum in fine and industrial organic chemistry. To date, several transition metal-based homogeneous catalysts, such as $\mathrm{Cu}, \mathrm{Mn}$, Co and Fe, have been utilized for the oxidation reactions. ${ }^{161,162}$ However, the difficulties in separation and recoverability hamper their large-scale applicability in industrial processes. To address these issues, Saikia et al. fabricated a $\mathrm{Fe}_{3} \mathrm{O}_{4} @ \mathrm{MIL}-$ $101(\mathrm{Cr})$ hybrid for carrying out the solvent-free oxidation of benzyl alcohol to benzaldehyde in the presence of tert-butyl hydroperoxide (TBHP). ${ }^{110}$ The experimental results revealed 
that the developed catalytic system exhibited $44 \%$ conversion and $98 \%$ selectivity towards the formation of benzaldehyde. In fact, a wide range of substituted benzyl alcohols were efficiently converted into the substituted benzaldehyde moieties. Moreover, the catalyst being magnetic in nature was facilely recovered and recycled for three consecutive runs without undergoing any deterioration and deactivation.

The concept of magnetic MOF composites was very well utilized by the Wang research group, wherein they fabricated a $\mathrm{Fe}_{3} \mathrm{O}_{4} / \mathrm{Fe}-\mathrm{MIL}-101$ catalyst for the oxidation of alcohols and epoxidation of olefins. ${ }^{137}$ Oxidation of alcohols was successfully executed in the presence of an $\mathrm{O}_{2}$ balloon as the sole oxidant, TEMPO as the co-catalyst and $\mathrm{KNO}_{2}$ as an additive. Additionally, the resulting material unveiled impressive activity as a wide series of primary, secondary, acrylic and allylic alcohols underwent reaction smoothly under the optimized reaction conditions with excellent conversion percentage and selectivity. Strikingly, it was observed that the polarity of the solvent significantly affected the conversion percentage during the oxidation of alcohols. Apart from this, the designed catalyst exhibited superior performance in the epoxidation of olefins. Indeed, cyclic olefins such as cyclopentene, cyclooctene and cyclododecene were efficaciously transformed into the preferred epoxides under ambient reaction parameters, i.e., at room temperature, and with short reaction times. Overall, the developed catalyst generated the desired products with high conversion percentages along with excellent selectivity.

Core-shell-structured magnetic MOF composites have emerged as an attractive platform for accomplishing various organic reactions. Recently, Yang and co-workers proposed an efficient strategy for developing a core-shell $\mathrm{Fe}_{3} \mathrm{O}_{4} / \mathrm{Cu}_{3}(\mathrm{BTC})_{2}$ catalyst, which displayed tremendous performance in the TEMPO-mediated aerobic oxidation of alcohols at $75{ }^{\circ} \mathrm{C}$ (Fig. 6). ${ }^{148}$ Fortunately, owing to the nanosized porous structure of the multifunctional MOF, effective adsorption of the organic reagents occurred, which intensified the contact between the active $\mathrm{Cu}^{2+}$ sites and the reactant molecules, thereby refining

(a)

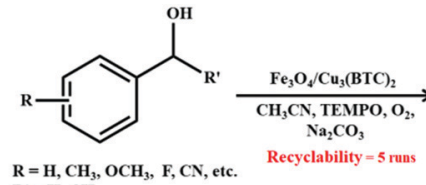
$\mathrm{R}=\mathrm{H}, \mathrm{CH}_{3}, \mathrm{OCH}_{3}, \mathbf{F}, \mathrm{CN}$, etc $\mathbf{R}^{\prime}=\mathbf{H}, \mathrm{CH}_{3}$

(b)
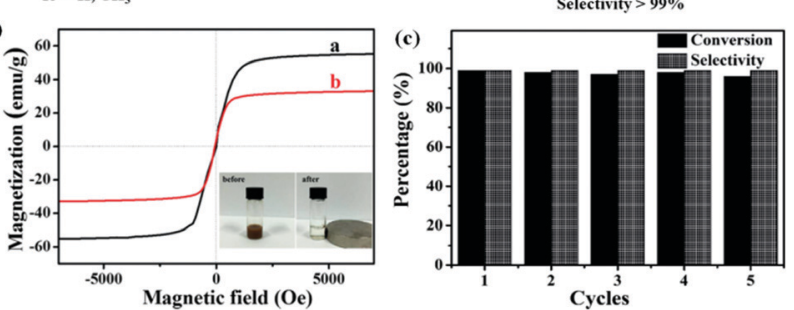

Fig. 6 (a) Scheme depicting $\mathrm{Fe}_{3} \mathrm{O}_{4} / \mathrm{Cu}_{3}(\mathrm{BTC})_{2}$-catalyzed oxidation of alcohols. (b) VSM curves of $\mathrm{Fe}_{3} \mathrm{O}_{4}$ and $\mathrm{Fe}_{3} \mathrm{O}_{4} / \mathrm{Cu}_{3}(\mathrm{BTC})_{2}$ at $25{ }^{\circ} \mathrm{C}$. (c) Recyclability runs of $\mathrm{Fe}_{3} \mathrm{O}_{4} / \mathrm{Cu}_{3}(\mathrm{BTC})_{2}$ catalyst in the oxidation of benzyl alcohol. Reproduced with permission from ref. 148. Copyright (2016) John Wiley and Sons.

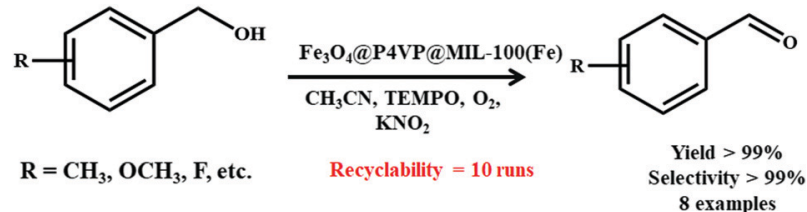

Scheme 6 Illustration showing aerobic oxidation of aromatic alcohols catalyzed by $\mathrm{Fe}_{3} \mathrm{O}_{4}$ @P4VPaMIL-100(Fe).

the escalated catalytic potential of the designed material. Some of the key intriguing characteristics of the developed methodology were negligible leaching of active species, easy magnetic recoverability of the catalyst along with good recyclability for five successive runs.

Another important investigation was made by Shu and co-workers. ${ }^{146}$ The authors designed a core-shell $\mathrm{Fe}_{3} \mathrm{O}_{4} @ \mathrm{P} 4 \mathrm{VP} @$ MIL-100(Fe) hybrid and evaluated its catalytic potential in the molecular $\mathrm{O}_{2}$-assisted selective oxidation of alcohols (Scheme 6). The intricately designed catalyst uncovered impressive potential in the concerned oxidation reaction. The hybrid catalyst showed promising prospects of facile recovery and exceptional recyclability for ten consecutive cycles without any considerable deterioration in its structural integrity and activity.

Selective oxidation of saturated $\mathrm{C}-\mathrm{H}$ bonds also symbolizes a major organic transformation in the fine and chemical industries as it invariably leads to the generation of numerous oxidized products that find extensive applications in the agricultural and domestic sectors. One of its key reactants is benzylic $\mathrm{C}-\mathrm{H}$ bonds, i.e., the benzylic hydrocarbon can be converted into corresponding alcohols, aldehydes or ketones, which serve as resourceful intermediates in the production of versatile generic drugs, pharmaceuticals, dyes and solvents. However, the extremely high activation energy of the inert $\mathrm{sp}^{3}$ $\mathrm{C}-\mathrm{H}$ bond has been identified as the foremost reason why its oxidation is quite challenging at lower temperatures. Numerous homogeneous catalysts have been reported in the literature for the oxidation of benzylic $\mathrm{C}-\mathrm{H}$ bonds; however, they suffer from difficulty in the recycling of the catalyst. Besides, several solid heterogeneous catalysts based on mesoporous $\mathrm{MnCeO}_{x}$, $\mathrm{Au}-\mathrm{Pd} / \mathrm{C}, \mathrm{CuFe} / \gamma-\mathrm{Al}_{2} \mathrm{O}_{3}$, and MIL-101(Cr) have been availed for the concerned reaction. ${ }^{163-166}$ Nevertheless, these protocols are accompanied with high energy inputs, elevated reaction temperature and $\mathrm{O}_{2}$ pressure, longer reaction times along with unrestrained selectivity and low conversion percentage. In view of the above-mentioned problems, Wang and co-workers presented the fabrication route for a hybrid magnetic MOF composite for the selective oxidation of benzylic $\mathrm{C}-\mathrm{H}$ bonds using TBHP as the oxidant (Scheme 7). ${ }^{48}$ The idea of covalently binding the active catalytic MOF nanostructure onto the magnetic component played a pivotal role in this report. The authors directly synthesized MOF nanolayers onto carboxylfunctionalized MNPs. Initially, carboxyl-functionalized MNPs capped with PVP were synthesized. Eventually, addition of copper ions and $\mathrm{H}_{3}$ BTC to the solution mixture led to the in situ generation of a HKUST framework onto ferrite NPs. The developed chemical bonding between the copper ions and 


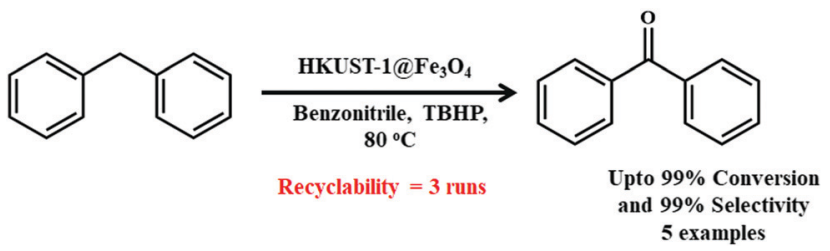

Scheme 7 HKUST-1 $\mathrm{aFe}_{3} \mathrm{O}_{4}$-catalyzed benzylic hydrocarbon oxidation

carboxylic groups was perceived to be the premier reason behind the MOF nanolayers remaining intact on the MNPs and also the integrity of the nanomaterial being maintained for repetitive catalytic cycles. The synthesized magnetic HKUST$1 @ \mathrm{Fe}_{3} \mathrm{O}_{4}$ core-shell nanomaterial exhibited incredible catalytic performance towards benzylic hydrocarbon oxidation with $99 \%$ conversion and selectivity. The diligently constructed material proved to be a stepping stone in the designing of MOF-based catalysts for continuous magnetic fluid bed purposes.

During the past few years, selective oxidation of benzylic $\mathrm{C}-\mathrm{H}$ bonds has reportedly been carried out using peroxide oxidants like TBHP and hydrogen peroxide $\left(\mathrm{H}_{2} \mathrm{O}_{2}\right)$. Nonetheless, these oxidizing agents are toxic and corrosive to equipment. Besides, tert-butanol formed after the utilization of TBHP gets left over in the reaction and demands further separation. Thus, use of molecular oxygen as a cheap and clean oxidant is highly demanded from an economic and environmental point of view. In this regard, Wang and Gao along with their research group rationally designed a $\mathrm{Cu}-\mathrm{CuFe}_{2} \mathrm{O}_{4} @ H K U S T-1$ heterostructure for carrying out selective oxidation of benzylic $\mathrm{C}-\mathrm{H}$ bonds (Scheme 8). ${ }^{167}$ For this, $\mathrm{Cu}-\mathrm{CuFe}_{2} \mathrm{O}_{4}$ NPs were initially synthesized using a solvothermal approach. The $\mathrm{Cu}(0)$ part of the $\mathrm{Cu}-\mathrm{CuFe}_{2} \mathrm{O}_{4}$ NPs acted as the key source of copper, which (a)

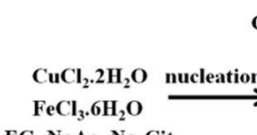

EG, $\mathrm{NaAc}, \mathrm{Na}_{3} \mathrm{Cit}$

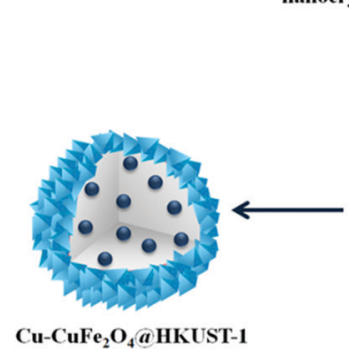

(b)

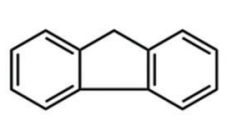

$\underset{\substack{0.1 \\ \mathrm{O}, 60^{\circ} \mathrm{C}}}{\stackrel{\mathrm{C}}{\mathrm{C}} \mathrm{CHPI}, \mathrm{CH}_{3} \mathrm{CN}}$

Recyclability $=\mathbf{1 0}$ runs
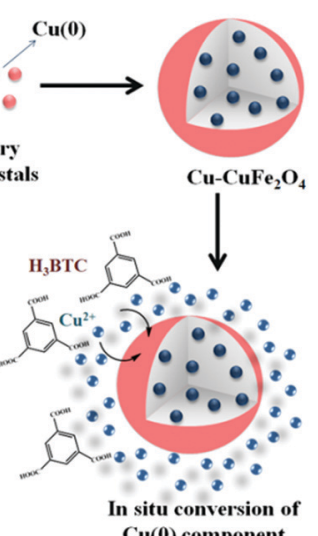

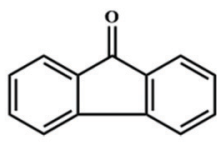

Upto $99 \%$ Conversion
and Selectivity 8 examples

Scheme 8 (a) Scheme depicting formation mechanism of $\mathrm{Cu}-\mathrm{CuFe}_{2} \mathrm{O}_{4} \mathrm{a}$ HKUST-1 heterostructure. (b) $\mathrm{Cu}-\mathrm{CuFe}_{2} \mathrm{O}_{4} \mathrm{OHKUST-1-catalyzed} \mathrm{selective}$ oxidation of benzylic $\mathrm{C}-\mathrm{H}$ bond.

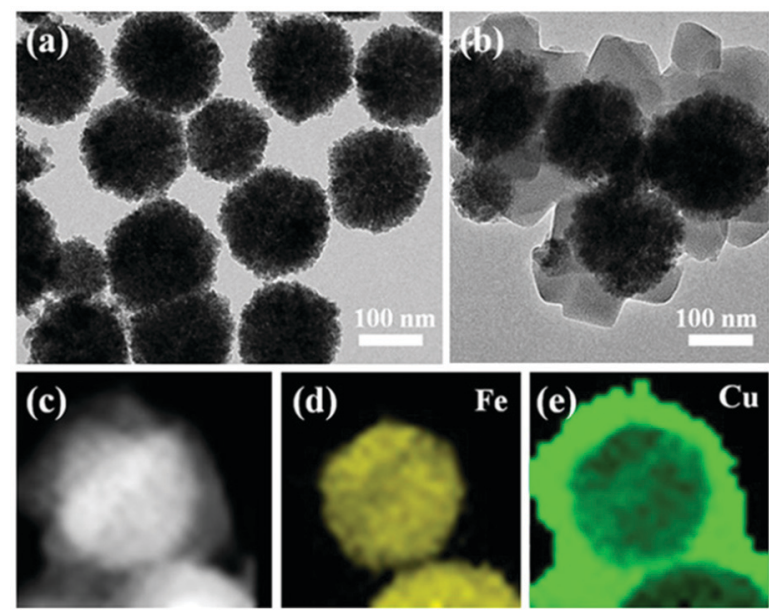

Fig. 7 TEM micrographs of (a) $\mathrm{Cu}-\mathrm{CuFe}_{2} \mathrm{O}_{4}$ and (b) $\mathrm{Cu}-\mathrm{CuFe}_{2} \mathrm{O}_{4} \mathrm{a}$ HKUST-1. HAADF-STEM micrograph of (c) $\mathrm{Cu}-\mathrm{CuFe}_{2} \mathrm{O}_{4}$ (aHKUST-1 and EDS mapping of (d) Fe and (e) $\mathrm{Cu}$ in the heterostructures. Reproduced with permission from ref. 167. Copyright (2017) American Chemical Society.

after the addition of an ethanolic solution of $\mathrm{H}_{3}$ BTC got readily transformed into a MOF shell.

Morphological and elemental characterization of the hybrid heterostructure was successfully accomplished through TEM and HAADF-STEM analysis (Fig. 7). Notably, the resulting multifaceted heterostructure possessing the integrated benefits of the $\mathrm{Cu}-\mathrm{CuFe}_{2} \mathrm{O}_{4}$ core and the MOF shell displayed distinct potential in the molecular $\mathrm{O}_{2}$ and $N$-hydroxyphthalimide (NHPI)-aided selective oxidation of benzylic $\mathrm{C}-\mathrm{H}$ bonds using fluorenone as a representative substrate. Conversion as well as selectivity of $99 \%$ were certainly achieved with acetonitrile as the solvent at $60{ }^{\circ} \mathrm{C}$. Furthermore, it was disclosed that during the catalytic procedure, the $\mathrm{Cu}-\mathrm{CuFe}_{2} \mathrm{O}_{4}$ component delivered multitudinous active sites while the MOF shell, i.e., HKUST-1, performed the role of attracting and preconcentrating the molecular oxygen. Besides, the protocol was also extended for executing selective oxidation of numerous substituted benzyl $\mathrm{C}-\mathrm{H}$ bonds. In addition, the magnetic core imparted sufficient stability and durability to the developed catalyst, as a result of which the catalyst was applied for 10 successive runs and did not exhibit any marked deterioration in catalytic efficacy.

4.1.2 Hydrogenation reactions. Hydrogenation reactions are amongst the most crucial transformations in the realm of organic chemistry, having prodigious commercial as well as industrial utility for producing fine and commodity chemicals. ${ }^{168-173}$ The hydrogenation of nitroarenes is a mild, simplistic and versatile reaction for the production of anilines. The large-scale industrial hydrogenation of nitrobenzenes to anilines is generally carried out in either gaseous or liquid phase. However, the gas-phase reactions are carried out at elevated temperatures, such as 553-573 K, and a very high $\mathrm{H}_{2}$ pressure of 0.1 to $0.5 \mathrm{MPa}$, which makes the overall methodology highly energy intensive. On the contrary, liquid-phase reactions enable significant reduction in temperature conditions. To date, several homogeneous catalytic systems based on transition metal complexes of $\mathrm{Rh}, \mathrm{Ir}, \mathrm{Ru}, \mathrm{Au}, \mathrm{Ag}, \mathrm{Pd}, \mathrm{Pt}$ have been 
reported in the literature. ${ }^{174-176}$ Nevertheless, these expensive catalytic systems are also accompanied by metal contamination and product purification problems. Therefore, the scientific fraternity has been aiming towards creating heterogeneous catalysts integrated with magnetic characteristics. Consequently, several attempts have been made towards designing magnetic MOF composites for hydrogenation reactions. To accomplish the prolific liquid-phase reduction of $p$-nitrophenol to $p$-aminophenol, $\mathrm{Fe}_{3} \mathrm{O}_{4} @ \mathrm{M} / \mathrm{MIL}-100(\mathrm{Fe})$ where $\mathrm{M}=\mathrm{Au}, \mathrm{Pt}$, Pd was synthesized by Chen and co-workers. ${ }^{177}$ In this regard, the authors prepared a sequence of hybrid magnetic MOF composites by simply altering the metal NPs, namely $\mathrm{Fe}_{3} \mathrm{O}_{4} @ \mathrm{Au} / \mathrm{MIL}-100(\mathrm{Fe}), \mathrm{Fe}_{3} \mathrm{O}_{4} @ \mathrm{Pt} /$ MIL-100(Fe) and $\mathrm{Fe}_{3} \mathrm{O}_{4} @ \mathrm{Pd} / \mathrm{MIL}-100(\mathrm{Fe})$ (Fig. 8). An assessment of the experimental results revealed that the developed microspheres exhibited remarkable catalytic reduction with turnover frequencies of 223, 3094 and 1343 for $\mathrm{Au}$, Pt and Pd, respectively. Amongst them, the $\mathrm{Fe}_{3} \mathrm{O}_{4} @ \mathrm{Pt} / \mathrm{MIL}-100(\mathrm{Fe})$ catalyst demonstrated the maximum conversion percentage and highest turnover frequency in the reduction reaction. Indeed, UV-visible absorption spectroscopy also conferred an encouraging corroboration for the catalytic reduction process. Several other nitrobenzenes were successfully reduced in the presence of $\mathrm{NaBH}_{4}$ using the $\mathrm{Fe}_{3} \mathrm{O}_{4} @ \mathrm{Pt} / \mathrm{MIL}-100(\mathrm{Fe})$ catalyst. The authors proposed an underlying plausible mechanistic route in which reduction phenomenon commenced with the adsorption of the substrate ( $p$-nitrophenol) onto the MOF shell. It is worth noting here that the $\pi-\pi$ stacking interactions amongst the aryl component of $p$-nitrophenol and the organic linker of the MOF along with coordination effects produced between the phenolic - $\mathrm{OH}$ of $p$-nitrophenol and the metal ions of the MOF triggered the adsorption process. Afterwards, reduction within the mesopores of the MOF proceeded via transference of electrons from
(A)

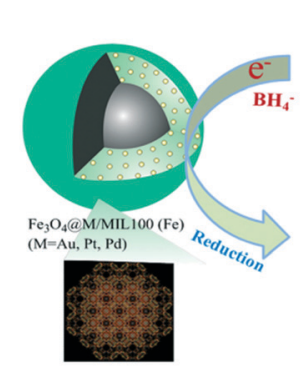

(B)

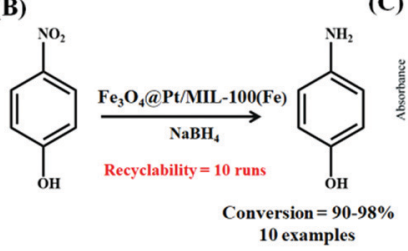

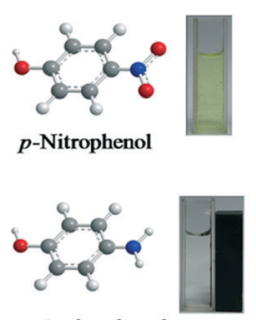

p-Aminophenol

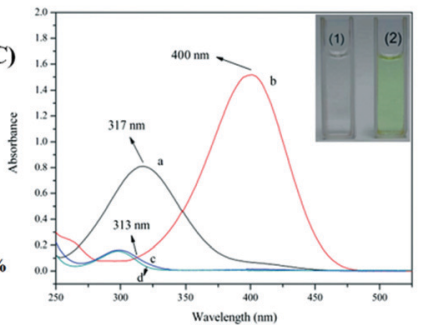

Fig. 8 (A) Diagrammatic and photographic presentation showing $\mathrm{Fe}_{3} \mathrm{O}_{4} \mathrm{OM} / \mathrm{MIL}-100(\mathrm{Fe})(\mathrm{M}=\mathrm{Au}$, $\mathrm{Pt}, \mathrm{Pd})$-catalyzed reduction of nitrophenol. (B) $\mathrm{Fe}_{3} \mathrm{O}_{4} \mathrm{aPt} / \mathrm{MIL}-100(\mathrm{Fe})$-mediated reduction of $p$-nitrophenol to $p$-aminophenol. (C) UV-visible spectra of $p$-nitrophenol before (a) and after (b) addition of $\mathrm{NaBH}_{4}$. (c) Spectrum obtained after complete reduction using catalyst and (d) spectrum of pure $p$-aminophenol. Reproduced with permission from ref. 177. Copyright 2014 Royal Society of Chemistry.
$\mathrm{NaBH}_{4}$ to noble metal NPs along with the concomitant generation of hydrogen atoms from hydride, which finally attacked $p$-nitrophenol and reduced it to $p$-aminophenol. It was deduced that the synergistic interaction produced as a result of enhanced contact between noble metal NPs and the MOF with a high concentration of $p$-nitrophenol in core-shell morphology substantially boosted the overall catalytic activity. More precisely, the uniform cavities present in the MOF shell acted as nanoreactors by delivering numerous docking sites for the substrates. Besides longer life, magnetic retrievability, high reusability and recyclability were some of the apparently striking features of the protocol.

Another $\mathrm{Au}-\mathrm{Fe}_{3} \mathrm{O}_{4} @ \mathrm{MIL}-100(\mathrm{Fe})$-based hybrid magnetic MOF composite for executing $\mathrm{NaBH}_{4}$-assisted 4-nitrophenol reduction was developed by $\mathrm{Zhu}$ et $a .^{178}$ In the synthesized composite, $\mathrm{Au}-\mathrm{Fe}_{3} \mathrm{O}_{4}$ acted as the superparamagnetic core and $\mathrm{Au}$ NPs were sandwiched betwixt the magnetic component and the porous MOF shell. As manifested from TEM analysis (Fig. 9), Au NPs were uniformly dispersed on ferrite NPs with subsequent development of a porous MOF shell outside the $\mathrm{Au}-\mathrm{Fe}_{3} \mathrm{O}_{4}$ particles. The synthesized porous magnetic material displayed exceptional activity even at room temperature. Furthermore, a time-dependent UV-visible study as well as the related spectra were obtained for examining the reduction kinetics. Moreover, results acquired from the extended X-ray absorption fine structure (XAFS) revealed MIL-100(Fe) to have higher or more prominent acidic character as a consequence of significant electron-donation phenomenon occurring from the MIL-100(Fe) to the Au NPs. The aforesaid process further enabled hydrogen molecule activation via Lewis acid-base interactions and facilitated faster production of 4-aminophenol.

On similar grounds, a remarkable $\mathrm{Cu}-\mathrm{BTC} @ \mathrm{Fe}_{3} \mathrm{O}_{4}$ composite for accomplishing $\mathrm{NaBH}_{4}$-mediated nitroarene reduction was synthesized by Zhang and Wang along with their research group (Scheme 9). ${ }^{179}$ A mixture of ethanol-water in $3: 1$ proportion was found to be the best solvent for achieving the complete transformation of nitrobenzene into aniline. Notably, the developed composite exhibited broad substrate scope and afforded the desired aniline derivatives in surprisingly good yields. Furthermore, the composite offered the additional advantage of recoverability and reusability for six multiple cycles via external magnetic forces.

Bian and co-workers smartly took advantage of a step-bystep assembly strategy for fabricating a core-shell $\mathrm{Fe}_{3} \mathrm{O}_{4} @$ @PDA$\mathrm{Pd} @\left[\mathrm{Cu}_{3}(\mathrm{btc})_{2}\right]$ composite for the reduction of 4-nitrophenol. ${ }^{49}$ The prudently designed composite consisted of a $\mathrm{Fe}_{3} \mathrm{O}_{4}$ core functionalized with polydopamine (PDA), an intermediate layer of Pd NPs and an outer or exterior shell of MOF. Advanced microscopic techniques such as TEM and HRTEM (Fig. 10) revealed the uniform and homogeneous dispersion of Pd NPs both on the interior and the exterior, i.e., on the surface of the PDA layer. The composite exhibited outstanding catalytic performance in the reduction of 4-nitrophenols and its excellent activity was accredited to the unique hierarchical core-shell structure of the composite. Existence of the PDA layer with numerous catechol and amine groups and strong affinity 

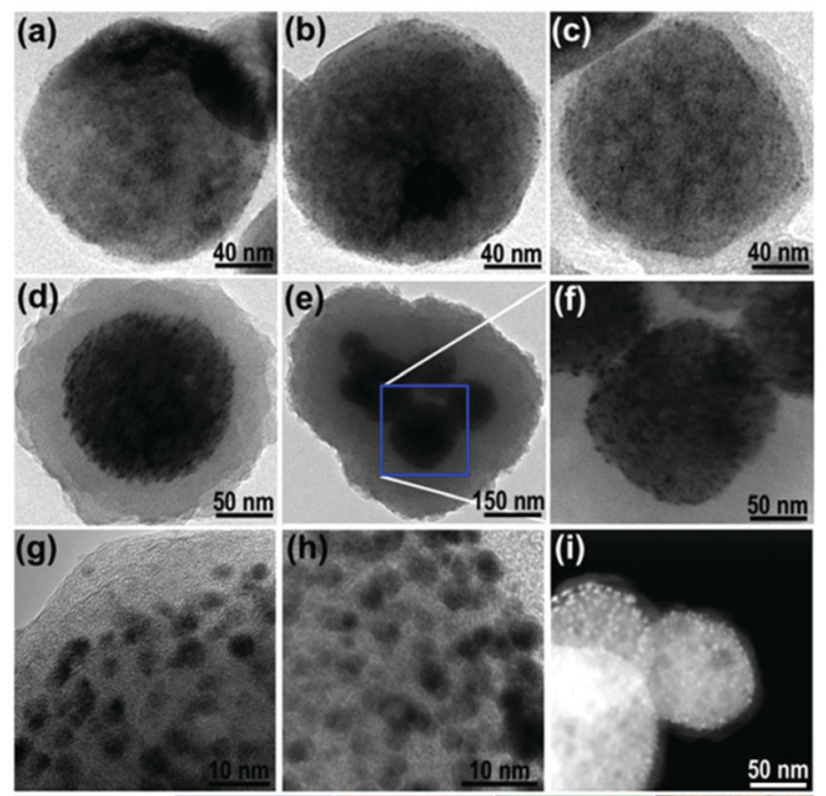

(i)
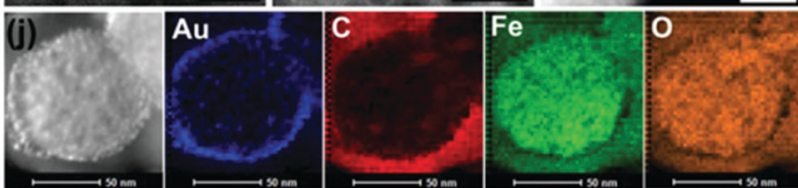

Fig. 9 TEM micrographs of (a) $\mathrm{Au}-\mathrm{Fe}_{3} \mathrm{O}_{4}$ and core-shell $\mathrm{Au}-\mathrm{Fe}_{3} \mathrm{O}_{4} \mathrm{C}$ MIL-100(Fe) obtained after (b) 5, (c) 10, (d) 20, and (e and f) 30 cycles. HRTEM and HAADF-STEM images of $\mathrm{Au}-\mathrm{Fe}_{3} \mathrm{O}_{4}(\mathrm{QMIL}-100(\mathrm{Fe})$ after ( $\mathrm{g}$ and i) 10 and ( $h$ and j) 20 cycles along with elemental mapping for $\mathrm{Au}, \mathrm{C}, \mathrm{Fe}$ and O elements in the composite. Reproduced with permission from ref. 178. Copyright 2015 Royal Society of Chemistry<smiles>O=[N+]([O-])C1=C[Te]=CC=C1</smiles>

$\mathrm{R}=\mathrm{CH}_{3}, \mathrm{OCH}_{3}, \mathrm{Cl}$ $\mathrm{Br}, \mathrm{F}, \mathrm{CH}_{2} \mathrm{OH}$, $\mathrm{NO}_{2}, \mathrm{COCH}_{3}$, etc.

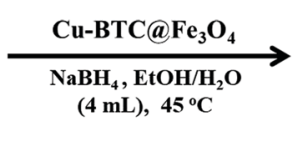

Recyclability $=6$ runs

Scheme anilines

towards organic molecules endowed the resultant material with good dispersibility in water and ethanol and rendered Pd-active sites accessible to the reactants. Besides, the MOF shell with added benefits of porosity facilitated the specific adsorption of the reactants through electrostatic, van der Waals and $\pi-\pi$ stacking interactions, thereby enhancing the contact between the reactants and the active species. Thus, the synergistic unification of each component played a decisive role in boosting the catalytic activity of the designed composite.

Very recently, Chen et al. designed a multifunctional [Fe $\left.\mathrm{F}_{4} @ \mathrm{Pt} @ M I L-100(\mathrm{Fe})\right]$ MNP-MOF composite by metamorphosing $\mathrm{Fe}_{3} \mathrm{O}_{4}$ nanospheres into MIL-100(Fe) and in situ encapsulating Pt NPs between the $\mathrm{Fe}_{3} \mathrm{O}_{4}$ core and the MIL-100(Fe)
(A)

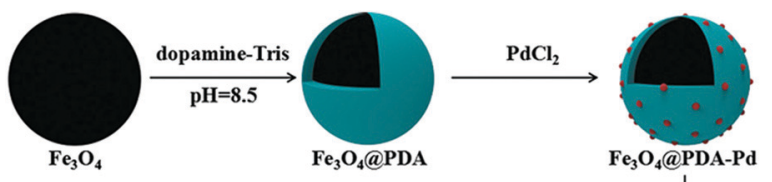

(B)

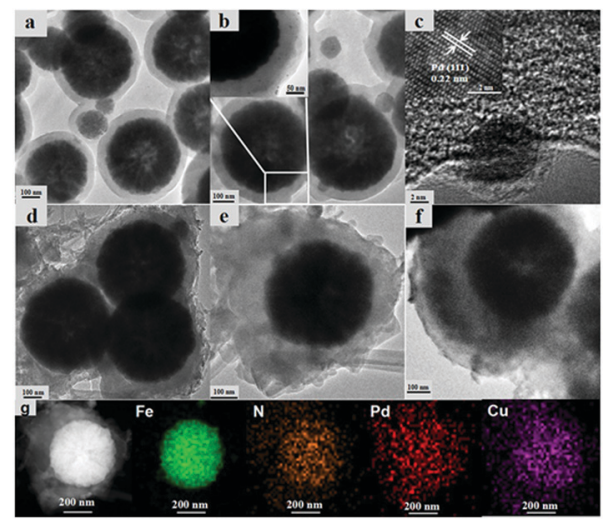

Fig. 10 (A) Fabrication route for $\mathrm{Fe}_{3} \mathrm{O}_{4} @ \mathrm{aPDA}-\mathrm{Pd} @ \mathrm{Cu}_{3}(\mathrm{btc})_{2}$. (B) TEM micrographs of (a) $\mathrm{Fe}_{3} \mathrm{O}_{4}\left(\mathrm{aPDA}\right.$, (b) $\mathrm{Fe}_{3} \mathrm{O}_{4}(\mathrm{aPDA}-\mathrm{Pd}$, (d and e) $\mathrm{Fe}_{3} \mathrm{O}_{4}\left(\mathrm{aPDA}-\mathrm{Pd} @ \mathrm{Cu}_{3}(\mathrm{btc})_{2}\right.$ when $n=5$ and (f) $\mathrm{Fe}_{3} \mathrm{O}_{4} @ \mathrm{aPDA}-\mathrm{Pd}\left(\mathrm{Cu}_{3}(\mathrm{btc})_{2}\right.$ when $n=15$, (c) HRTEM micrograph of $\mathrm{Fe}_{3} \mathrm{O}_{4}$ (QPDA-Pd, and (g) STEM image of $\mathrm{Fe}_{3} \mathrm{O}_{4} \mathrm{QPDA}-\mathrm{Pd}\left(\mathrm{Cu}_{3}(\mathrm{btc})_{2}\right.$ when $\mathrm{n}=5$ along with elemental mapping of $\mathrm{Fe}, \mathrm{N}, \mathrm{Pd}$ and $\mathrm{Cu}$ in the nanocomposite. Reproduced with permission from ref. 49. Copyright (2018) John Wiley and Sons.

shell for the reduction of $p$-nitrophenols. ${ }^{180}$ The core-shell heterostructure was fabricated by separately synthesizing $\mathrm{Fe}_{3} \mathrm{O}_{4}$ and PVP-modified Pt NPs, which were then consequently mixed with $\mathrm{H}_{3}$ btc under mechanical stirring and finally heated in an oven at $80{ }^{\circ} \mathrm{C}$ for $6 \mathrm{~h}$ (Scheme 10). During the course of the reaction, Pt NPs were first adsorbed onto the surface of the $\mathrm{Fe}_{3} \mathrm{O}_{4}$ and the oxidative dissolution of the $\mathrm{Fe}_{3} \mathrm{O}_{4}$ NPs in the mildly acidic conditions (formed after the dissociation of $\mathrm{H}_{3}$ btc) simultaneously generated $\mathrm{Fe}^{3+}$ ions, which further got coordinated with the carboxylate groups of the btc ligand, eventually leading to the formation of MIL-100(Fe) crystals. Meanwhile, some of the residual Pt NPs after being adsorbed on the $\mathrm{Fe}_{3} \mathrm{O}_{4}$ core also got adsorbed on the incessantly forming surface of the MIL-100(Fe) shell. The formation mechanism of the heterostructure was also deeply studied by carefully monitoring the morphologies obtained after discrete reaction periods. Synergistic cooperation between the Pt NPs and the MIL-100(Fe) shell (by imparting sufficient docking positions for $p$-nitrophenol) in the core-shell-structured composite led to astonishing results in the formation of $p$-aminophenol.

Chang et al. instantiated the fabrication of a magnetic MOF composite embedded with Ag NPs for establishing the reduction of 4-nitrophenol. ${ }^{181}$ The functional composite was 


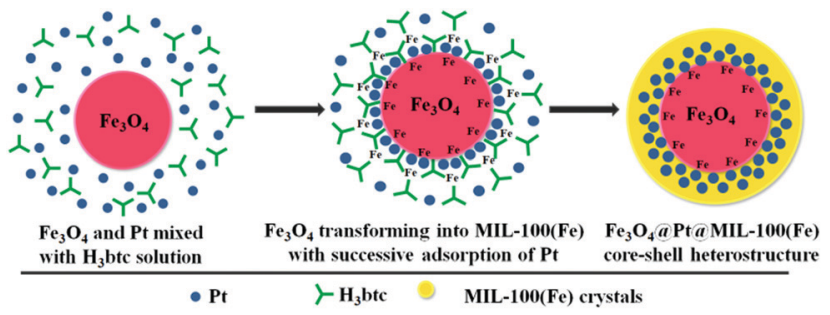

Scheme 10 Fabrication route for $\mathrm{Fe}_{3} \mathrm{O}_{4} @ \mathrm{QPt}(\mathrm{aMIL}-100(\mathrm{Fe})$ heterostructures.

prepared by initiating the layer-by-layer growth of an MIL$100(\mathrm{Fe})$ shell on a carboxyl-modified $\mathrm{Fe}_{3} \mathrm{O}_{4}$ core under mechanical agitation. The next step involved the preparation of Ag NPs via Co-60 gamma radiation-mediated reduction protocol and their uniform dispersion within the pores of MIL-100(Fe). The reduction processes of 4-nitrophenol with $\mathrm{NaBH}_{4}$ were monitored continuously using UV-visible spectroscopy. A representative reaction entailing $\mathrm{Fe}_{3} \mathrm{O}_{4} @ \mathrm{MIL}-100(\mathrm{Fe})$ without $\mathrm{Ag}$ was conducted and exhibited no significant change in peak intensity in UV analysis, thereby further signifying the crucial role of $\mathrm{Ag}$ NPs in nitrophenol reduction. The designed catalyst exhibited marvelous catalytic potency in the concerned reaction along with superb recyclability.

The polymerization of styrene via semihydrogenation of phenylacetylene has been extensively studied by the scientific fraternity. During the transformation, removal of even trace quantities of phenylacetylene represents the most crucial parameter that needs to be taken care of as it results in the poisoning of the catalyst. This reaction is generally carried out in semibatch stirred tank reactors. Recently, Zhou and Fang along with their research group synthesized a series of Pd-based magnetic core-shell catalysts, such as $\mathrm{Fe}_{3} \mathrm{O}_{4} @ \mathrm{SiO}_{2} /$ Pd, $\mathrm{Fe}_{3} \mathrm{O}_{4} @ A l O O H / \mathrm{Pd}, \mathrm{Fe}_{3} \mathrm{O}_{4} @ \mathrm{TiO}_{2} / \mathrm{Pd}, \mathrm{Fe}_{3} \mathrm{O}_{4} @ \mathrm{Cu}_{3}(\mathrm{BTC})_{2} / \mathrm{Pd}$ and $\mathrm{Fe}_{3} \mathrm{O}_{4} @$ @ZIF-8/Pd with Pd loading of 0.5 wt $\% .{ }^{182}$

Physicochemical characterization techniques like TEM and FTIR validated that the designed catalysts possessed core-shell morphological architecture. Besides this, X-ray photoelectron spectroscopic analysis of the catalyst validated the existence of the $\mathrm{PdO}_{2}$ group rather than $\mathrm{Pd}(0)$ or $\mathrm{PdO}$ as the active component involved in the semihydrogenation process. Amongst all the catalysts investigated for the concerned semihydrogenation process, the $\mathrm{Fe}_{3} \mathrm{O}_{4} @ \mathrm{ZIF}-8 / \mathrm{Pd}$ composite in the presence of ethanol gave the highest conversion percentage of 99.5 along with $90.5 \%$ selectivity towards styrene formation (Fig. 11). The magnificent activity was attributed to the influential electronic effects arising as a result of the donation of electrons from the ZIF-8 to $\mathrm{PdO}_{2}$. Moreover, after the successful formation of styrene, its desorption from the catalytic sites suppressed the further hydrogenation process.

Nowadays, there has been a paradigm shift towards constructing hollow MNPs@MOF composites. Owing to their high surface areas, significant lower density and efficient mass transfer, these hollow "yolk-shell" or "reverse bumpy ball" type composites are widely employed as catalysts for the synthesis of complex organic moieties. In this context, Zhao,

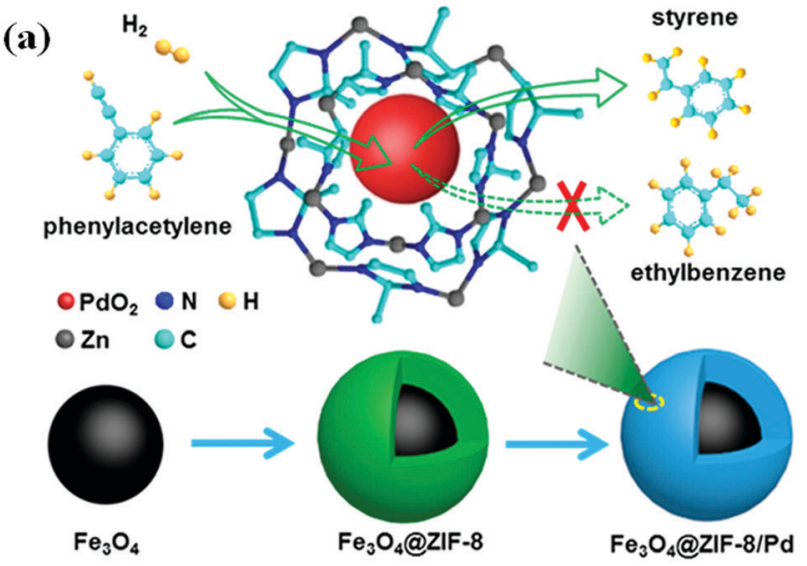

(b)

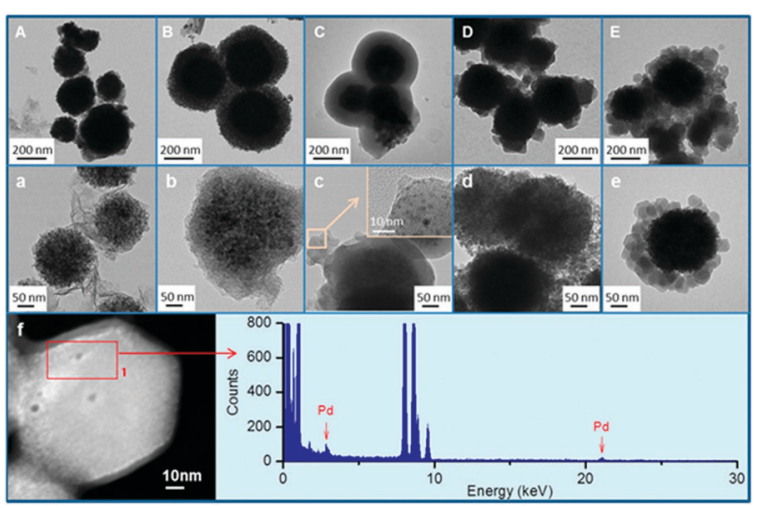

Fig. 11 (a) $\mathrm{Fe}_{3} \mathrm{O}_{4}$ (aZIF-8/Pd-catalyzed semihydrogenation of phenylacetylene to styrene. (b) HRTEM micrographs of support material (A-E) and catalyst (a-e). (A, a) $\mathrm{Fe}_{3} \mathrm{O}_{4} \mathrm{QAlOOH}$ and $\mathrm{Fe}_{3} \mathrm{O}_{4} @ \mathrm{AlOOH} / \mathrm{Pd},(\mathrm{B}, \mathrm{b}) \mathrm{Fe}_{3} \mathrm{O}_{4} \mathrm{Q}$ $\mathrm{TiO}_{2}$ and $\mathrm{Fe}_{3} \mathrm{O}_{4} @ \mathrm{aTiO}_{2} / \mathrm{Pd}$, (C, c) $\mathrm{Fe}_{3} \mathrm{O}_{4}\left(\mathrm{aSiO}_{2}\right.$ and $\mathrm{Fe}_{3} \mathrm{O}_{4} @ \mathrm{aSiO}_{2} / \mathrm{Pd}$, (D, d) $\mathrm{Fe}_{3} \mathrm{O}_{4} \mathrm{aCu}_{3}(\mathrm{BTC})_{2}$ and $\mathrm{Fe}_{3} \mathrm{O}_{4} \mathrm{aCu}_{3}(\mathrm{BTC})_{2} / \mathrm{Pd}$, (E, e) $\mathrm{Fe}_{3} \mathrm{O}_{4} \mathrm{QZIF}-8$ and $\mathrm{Fe}_{3} \mathrm{O}_{4} \mathrm{QZIF}-8 / \mathrm{Pd}$, and (f) HAADF-STEM and HAADF-EDS of $\mathrm{Fe}_{3} \mathrm{O}_{4} \mathrm{C}$ ZIF-8/Pd. Reproduced with permission from ref. 182. Copyright (2017) American Chemical Society.

Chen and research group saliently designed magnetic hollow double-shell-structured Pd/MOF nanospheres through a stepby-step assembly for the liquid-phase-assisted hydrogenation of styrene, cis-stilbene and tetraphenylethylene at room temperature (Fig. 12) ${ }^{183}$ In an attempt at fabricating the desired catalyst, polystyrene-co-acrylic acid nanospheres were first synthesized as a support material for depositing magnetic iron oxide NPs on its surface. After that, $\mathrm{Fe}_{3} \mathrm{O}_{4}$ /polystyrene (PS) nanospheres were covered with an outer shell of ZIF-8 followed by their successive encapsulation with Pd NPs in the interior part of ZIF-8 via a wet impregnation method to form $\mathrm{Fe}_{3} \mathrm{O}_{4} /$ PS@Pd/ZIF-8. In the next step, using the same solution of zinc nitrate and 2-methylimidazole, another outer shell of ZIF-8 was coated on the already synthesized sample to form $\mathrm{Fe}_{3} \mathrm{O}_{4} /$ PS@Pd/ZIF-8@ZIF-8 nanospheres. In the final step, the polystyrene-co-acrylic acid nanosphere template was removed to form hollow void $\mathrm{nFe}_{3} \mathrm{O}_{4} @ \mathrm{Pd} / \mathrm{ZIF}-8$ @ZIF-8 nanospheres. This novel architecture displayed outstanding efficacy in the hydrogenation of styrene, wherein it achieved a conversion percentage of 100 within a reaction time of 5 min along with excellent recyclability. It was ascertained that the internal hollow cavity 
(a)
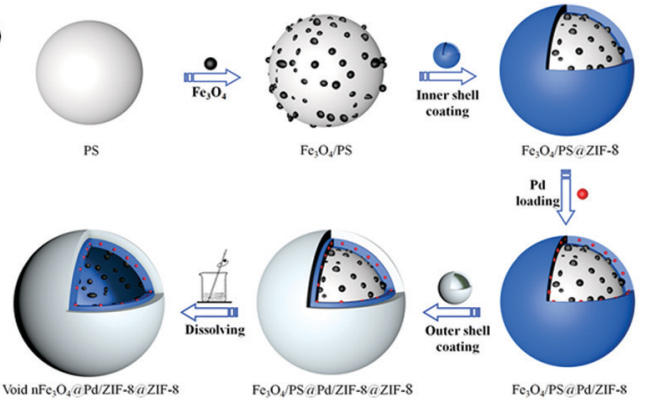
Pul.

(b)

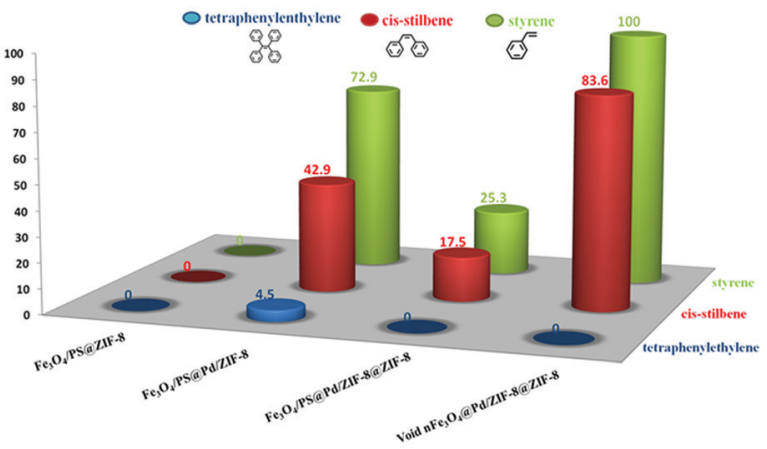

Fig. 12 (a) Diagrammatic representation showing synthesis of void $\mathrm{nFe}_{3} \mathrm{O}_{4} \mathrm{QPd} / \mathrm{ZIF}-8 \mathrm{QZIF}-8$. (b) Liquid-phase hydrogenation of styrene, cis-stilbene, and tetraphenylethylene catalyzed by $\mathrm{Fe}_{3} \mathrm{O}_{4} / \mathrm{PS} \mathrm{AZIF}-8$, $\mathrm{Fe}_{3} \mathrm{O}_{4} / \mathrm{PS} @ \mathrm{Pd} / \mathrm{ZIF}-8, \quad \mathrm{Fe}_{3} \mathrm{O}_{4} / \mathrm{PS} @ \mathrm{Pd} / \mathrm{ZIF}-8 \mathrm{aZIF}-8$ and void $\mathrm{nFe}_{3} \mathrm{O}_{4} @ \mathrm{aPd} /$ ZIF-8@ZIF-8 [reaction time: styrene $(5 \mathrm{~min})$, cis-stilbene $(6 \mathrm{~h})$ and tetraphenylethylene $(12 \mathrm{~h})]$. Reproduced with permission from ref. 183. Copyright (2019) American Chemical Society.

played a dominant factor in accelerating the diffusion rate of reactants, thereby enhancing the overall catalytic activity.

4.1.3 Coupling reactions. From the standpoint of energyefficient and sustainable processes, construction of ubiquitous $\mathrm{C}-\mathrm{C}, \mathrm{C}-\mathrm{N}$ and $\mathrm{C}-\mathrm{S}$ bonds ranks among the most versatile and appealing tool for carrying out organic synthesis, having numerous diverse applications in pharmaceuticals and materials science.

These transformations involve the coupling of two molecular fragments via the aid of a catalyst and most often result in the formation of stereospecific and regioselective products. ${ }^{184-187}$ The persistent development in this transformation can be directly observed from the continual rise in the number of publications each year. Despite remarkable success, ample reports present in literature demonstrate the use of homogeneous transition metal complexes as catalysts in these reactions. Nevertheless, transitionmetal-catalyzed reactions require an additional step of removing the leached metal ion and ligand after its decomposition from the reaction mixture. Besides, removal of trace amounts of transition metal to avoid product contamination is very crucial in the pharmaceutical and medicinal sectors. Therefore, the development of heterogeneous catalysts appears to be a viable solution for these reactions. The incessant expansion in these protocols has completely revolutionized the landscape of synthetic organic chemistry for the generation of natural products, organic materials and polymers. Recently, many magnetic MOF compositebased catalysts have been fabricated as outstanding reagents for accomplishing successful formation of $\mathrm{C}-\mathrm{C}, \mathrm{C}-\mathrm{N}$ and $\mathrm{C}-\mathrm{S}$ bonds in a simplistic and reliable manner.

Suzuki-Miyaura reaction involving coupling between aryl halides and arylboronic acids holds great promise for advancing synthetic methods in practical organic chemistry. In a quest to develop a novel catalyst that manifests ultrahigh efficacy for Suzuki-Miyaura coupling between aryl halides and arylboronic acids, a $\mathrm{Fe}_{3} \mathrm{O}_{4} @ P D A-\mathrm{Pd} @\left[\mathrm{Cu}_{3}(\mathrm{btc})_{2}\right]$ composite was designed by a research group. ${ }^{49}$ The catalytic performance of the synthesized composite was explored by taking bromobenzene and phenylboronic acid as model substrates in the presence of $\mathrm{K}_{2} \mathrm{CO}_{3}$ and a 1:1 ratio of ethanol-water as the optimized base and solvent, respectively (Scheme 11). The reported material was thereafter expanded for executing coupling between diverse aryl halides and arylboronic acids, which further uncovered excellent outcomes. In fact, encouraged by the obtained results, the catalyst was found to be active even towards coupling of highly challenging and perplexing aryl chlorides under ambient conditions. A fascinating attribute of the protocol was that because the catalyst is magnetic in nature, it could be recycled and reused eight times without undergoing any decomposition or decline in its catalytic activity.

Li et al. synthesized a MOF-5@SiO ${ }_{2} @ \mathrm{Fe}_{3} \mathrm{O}_{4}$ heterostructure for the Friedel-Crafts alkylation between benzyl chloride and toluene (Scheme 12). ${ }^{188} \mathrm{~A}$ simple solvothermal reaction resulted in the formation of magnetic $\mathrm{Fe}_{3} \mathrm{O}_{4}$ particles followed by their subsequent encapsulation within $\mathrm{a} \mathrm{SiO}_{2}$ layer via hydrolysis technique. Finally, an in situ strategy was utilized for coating MOF-5 on $\mathrm{SiO}_{2} @ \mathrm{Fe}_{3} \mathrm{O}_{4}$ particles. Initial screening was carried out by synthesizing catalysts with varying contents of MOF-5, i.e., 15.5 wt $\%$ MOF-5@SiO $\mathrm{SFF}_{3} \mathrm{O}_{4}, 26.8$ wt\% MOF-5@ $\mathrm{SiO}_{2} @ \mathrm{Fe}_{3} \mathrm{O}_{4}, 42.3 \mathrm{wt} \% \mathrm{MOF}-5 @ \mathrm{SiO}_{2} @ \mathrm{Fe}_{3} \mathrm{O}_{4}$ and $59.4 \mathrm{wt} \% \mathrm{MOF}-$ 5@SiO ${ }_{2} @ \mathrm{Fe}_{3} \mathrm{O}_{4}$. The synthesized 26.8 wt $\%$ MOF-5@SiO ${ }_{2} @ \mathrm{Fe}_{3} \mathrm{O}_{4}$ catalyst possessing plentiful active sites achieved $97 \%$ conversion in solvent-free conditions with greater selectivity towards the $p$-isomer instead of the $o$-isomer within $6 \mathrm{~h}$ at $120^{\circ} \mathrm{C}$. Moreover, the catalyst unveiled superb durability and recyclability for five consecutive runs.

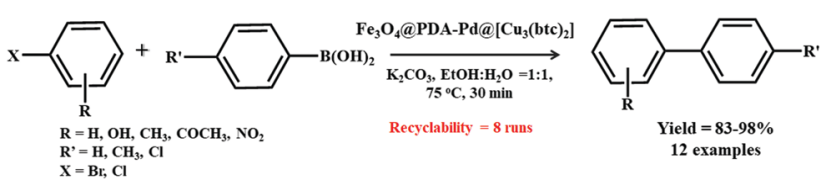

Scheme $11 \quad \mathrm{Fe}_{3} \mathrm{O}_{4} @ \mathrm{QPDA}-\mathrm{Pd} @\left[\mathrm{Cu}_{3}(\mathrm{btc})_{2}\right]$-catalyzed Suzuki-Miyaura coupling reaction.

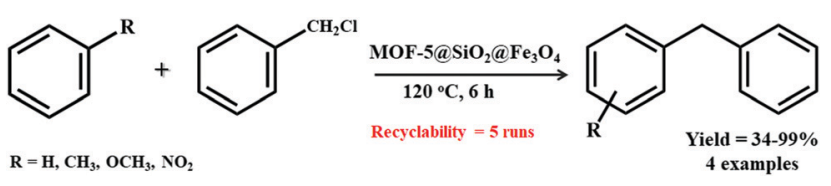

Scheme 12 MOF-5 $\mathrm{aSiO}_{2} \mathrm{CFe}_{3} \mathrm{O}_{4}$-mediated Friedel-Crafts alkylation reaction. 
A recent example of utilization of a magnetic MOF composite in the arena of catalysis was reported by Ji and co-workers. ${ }^{189}$ For the very first time, a MIL-53(Al)@SiO $\mathrm{SiFe}_{3} \mathrm{O}_{4}$ catalyst was in situ fabricated with different MIL-53(Al) contents by encapsulating a shell of $\mathrm{MIL}-53(\mathrm{Al})$ onto $\mathrm{SiO}_{2} @ \mathrm{Fe}_{3} \mathrm{O}_{4}$ particles under heating at $220{ }^{\circ} \mathrm{C}$ in an autoclave for $72 \mathrm{~h}$. Friedel-Crafts acylation between 2-methylindole and benzoyl chloride was chosen as the representative reaction for assessing the performance of the developed catalyst (Scheme 13). Close inspection of the assimilated results indicated that the catalyst possessed great surface area, apposite superparamagnetism and good catalytic activity and selectivity. MIL-53(Al)@SiO $\mathrm{SiFe}_{3} \mathrm{O}_{4}$ composite with $38.8 \%$ MIL-53(Al) content as a catalyst presented $98 \%$ conversion of 2-methylindole along with the selective formation of 3 -acetylindole and $N$-acetylindole with $81 \%$ and $18 \%$, respectively. Easy separability and reusability of the catalyst for five repeated cycles provided apparent certification of the immensely high activity and durability of the composite. Moreover, the catalyst was capable of maintaining over $90 \%$ 2-methylindole conversion and $80 \%$ selectivity towards 3-acetylindole even after five cycles, thereby proving its effectiveness after repeated reactions.

Indeed it is splendid to mention the work carried out by Zhang et al., where the authors smartly exploited an in situ selfassembled strategy for synthesizing a MIL-100(Fe)@SiO $\mathrm{S}_{2}$ $\mathrm{Fe}_{3} \mathrm{O}_{4}$ composite. ${ }^{190}$ Primarily, to obtain $\mathrm{SiO}_{2} @ \mathrm{Fe}_{3} \mathrm{O}_{4}$ particles, magnetic particles were synthesized via a solvothermal technique and thereafter modified with a silica layer to inhibit agglomeration and decomposition. The final catalyst was obtained by wrapping of pre-formed uniform $\mathrm{SiO}_{2} @ \mathrm{Fe}_{3} \mathrm{O}_{4}$ particles with a MIL-100(Fe) framework through the self-assembly of $\mathrm{Fe}\left(\mathrm{NO}_{3}\right)_{3}$ and $\mathrm{H}_{3} \mathrm{BTC}$ under refluxing conditions at $100{ }^{\circ} \mathrm{C}$ for $8 \mathrm{~h}$ and subsequently the catalytic activity of the core-shell-structured material was investigated in the liquid-phase acetalization processes involving benzaldehyde and glycol. The coupling reaction involving a 0.55 molar ratio of benzaldehyde to glycol proceeded well at $80{ }^{\circ} \mathrm{C}$ and was found to attain conversion of $73.2 \%$ within $2 \mathrm{~h}$. It was concluded that the composite possessing copious accessible Lewis acidic sites unveiled magnificent catalytic activity towards the acetalization reaction.

Considering the biological and optical activities of binuclear isoquinoline and pyridine-fused benzimidazoles as anticancer,

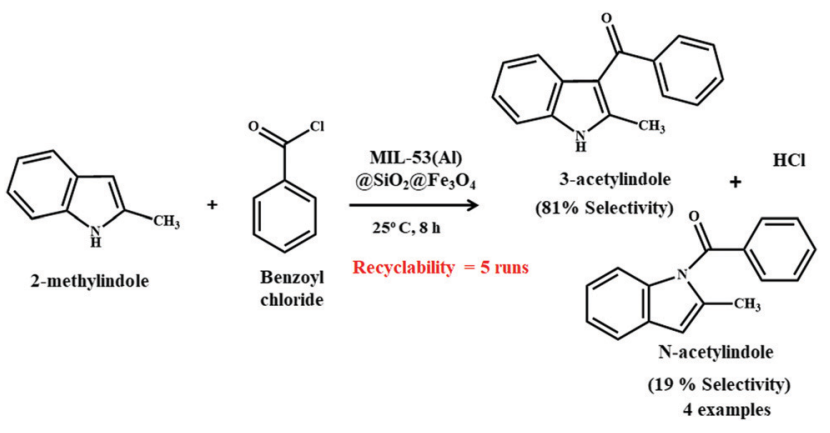

Scheme 13 Friedel-Crafts acylation between 2-methyl indole and benzoyl chloride mediated by MIL-53(Al)@SiO $2 \mathrm{aFe}_{3} \mathrm{O}_{4}$.

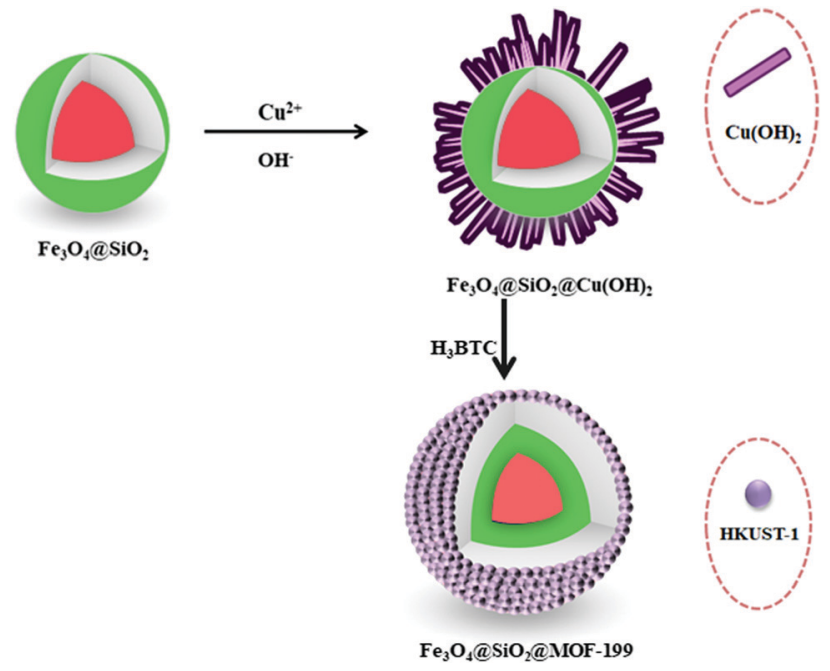

Scheme 14 Fabrication pathway for $\mathrm{Fe}_{3} \mathrm{O}_{4} \mathrm{CSiO}_{2} @ M O F-199$.

antitumor and anti-proliferative agents, Cho and colleagues described an efficient synthesis of these motifs by $\mathrm{Fe}_{3} \mathrm{O}_{4} @ \mathrm{SiO}_{2} @$ MOF-199. ${ }^{191}$ This magnetic MOF composite was prepared by growing a $\mathrm{Cu}(\mathrm{OH})_{2}$ shell on $\mathrm{Fe}_{3} \mathrm{O}_{4} @ \mathrm{SiO}_{2}$, and then the $\mathrm{Cu}(\mathrm{OH})_{2}$ was transformed into a Cu-BTC shell with the subsequent addition of $\mathrm{H}_{3} \mathrm{BTC}$ ligand (Scheme 14). The microwaveassisted reaction between 2-(2-bromoaryl)-4,7-dimethoxy-1- $\mathrm{H}^{-}$ benzo $[d]$ imidazoles and (Z)-2-(2-bromovinyl)-4,7-dimethoxy$1 H$-benzo $[d]$ imidazoles with 1,3-diketones led to the formation of binuclear $\mathrm{N}$-fused scaffolds 8,11-dimethoxybenzo[4,5]imidazo-[2,1-a]isoquinolines and 6,9-dimethoxybenzo[4,5]imidazo-[1,2-a]pyridines (Scheme 15a). Mechanistic studies revealed that the reaction proceeded via $\mathrm{C}-\mathrm{C}$ coupling, deacylation and finally cyclocondensation. The products obtained were subsequently oxidized in the presence of ceric ammonium nitrate in acetonitrile $/ \mathrm{H}_{2} \mathrm{O}$ or $\mathrm{HBr} / \mathrm{FeCl}_{3}$ in $\mathrm{H}_{2} \mathrm{O}$ to afford binuclear isoquinoline- and pyridine-fused benzimidazole4,7-diones (Scheme 15b). Furthermore, from the viewpoint of energy-efficient and environmentally sound protocols, the
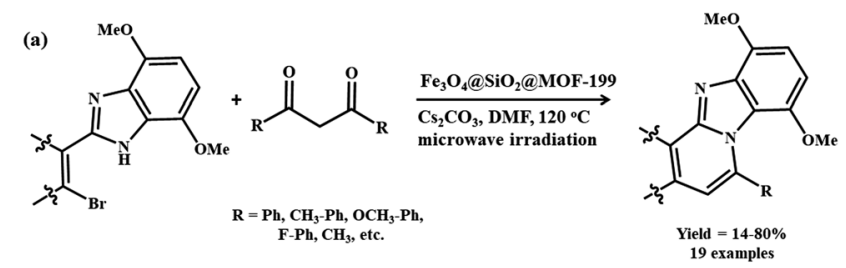

(b)
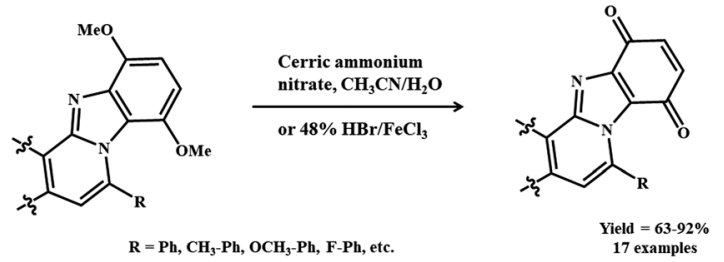

Scheme 15 (a) $\mathrm{Fe}_{3} \mathrm{O}_{4} \mathrm{CSiO}_{2} \mathrm{aMOF-199-catalyzed} \mathrm{synthesis} \mathrm{of} \mathrm{binuclear}$ isoquinoline- and pyridine-fused benzimidazoles. (b) Further oxidation of substituted benzimidazoles to substituted benzimidazole-4,7-diones. 


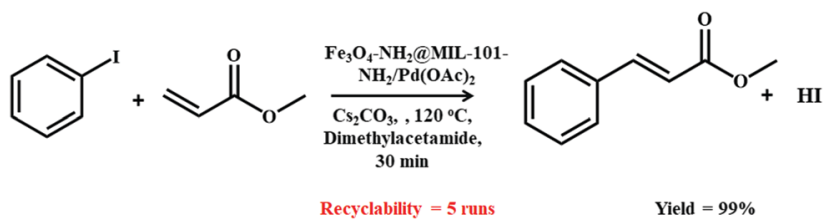

Scheme $16 \quad \mathrm{Fe}_{3} \mathrm{O}_{4}-\mathrm{NH}_{2} \mathrm{QMIL}-101-\mathrm{NH}_{2} / \mathrm{Pd}(\mathrm{OAc})_{2}$-mediated Heck-Mizoroki coupling reaction between iodobenzene and methyl acrylate.

designed methodology appeared to be an attractive platform for the synthesis of various bioreductive quinone based drugs.

Furthermore, the Heck-Mizoroki coupling reaction between olefins and aryl or vinyl halides for constructing $\mathrm{C}-\mathrm{C}$ bonds has played a crucial role in modern synthetic chemistry. In this connection, the Nuri research group devised a recyclable amine-modified magnetic MIL-101-Pd-based MOF composite for the Heck-Mizoroki reaction (Scheme 16). ${ }^{192}$ The catalyst preparation route began with the synthesis of amine (1,6-hexanediamine)-functionalized $\mathrm{Fe}_{3} \mathrm{O}_{4}$ NPs, which were eventually integrated with Cr-based MIL-101- $\mathrm{NH}_{2}$ MOF under solvothermal conditions with heating in an autoclave at $218{ }^{\circ} \mathrm{C}$ for $18 \mathrm{~h}$.

However, before loading $\mathrm{Pd}(\mathrm{OAc})_{2}$, the obtained $\mathrm{Fe}_{3} \mathrm{O}_{4}$ $\mathrm{NH}_{2} @ M I L-101-\mathrm{NH}_{2}$ MOF was first activated by dispersion in dichloromethane (DCM). With the assistance of the magnetic MOF composite-based catalyst, cross-coupling between iodobenzene and methyl acrylate in dimethylacetamide as the solvent proceeded smoothly at $120{ }^{\circ} \mathrm{C}$. In spite of the fact that the authors could not explore the substrate scope, the catalyst synthetic strategy offers promising potential for the further development of magnetic MOF composite-based catalysts.

The heteroatom $\mathrm{C}-\mathrm{N}$ and $\mathrm{C}-\mathrm{S}$ cross-coupling reactions have emerged as indispensable tools in the construction of a diverse range of products, having extensive utility in biological, pharmaceutical, agrochemical, biochemical and material sectors. The conventional methods employed by various research groups are highly discouraging owing to the involvement of harsh reaction conditions, such as use of strong reducing agents, polar solvents and elevated temperatures. Recently, the possibility of modifying the surface of a MOF, i.e., $\mathrm{NH}_{2}$ MIL53(Al), to obtain $\mathrm{Fe}_{3} \mathrm{O}_{4} @ A M C A-M I L 53$ (Al)- $\mathrm{NH}_{2}-\mathrm{Co}^{\mathrm{II}} \mathrm{NPs}$ was explored by Akhlaghinia and co-workers in $\mathrm{C}-\mathrm{N}$ and $\mathrm{C}-\mathrm{S}$ bond-forming reactions. ${ }^{193}$ In an attempt to obtain the desired catalyst, $\mathrm{NH}_{2}$-MIL53(Al) was synthesized using a one-pot solvothermal strategy and for further modifications it was subsequently activated in the presence of dicyclohexylcarbodiamide (DCC) and citric acid in acetonitrile to form AMCA-MIL53(Al). The resulting material was then integrated with the magnetic component under mechanical stirring at r.t., followed by functionalization with 2-chloroethylphosphonic (Ethephon) and amino guanidine nitrate to form $\mathrm{Fe}_{3} \mathrm{O}_{4}$ @AMCA-MIL53(Al)Ethephon and $\mathrm{Fe}_{3} \mathrm{O}_{4} @ A M C A-M I L 53(\mathrm{Al})-\mathrm{NH}_{2}$ composites, respectively. The product obtained was subsequently boiled in an ethanolic solution of cobalt chloride to form $\mathrm{Fe}_{3} \mathrm{O}_{4}$ @AMCAMIL53(Al)-NH $-\mathrm{No}_{2}{ }^{(\mathrm{II})} \mathrm{NPs}$ (Scheme 17).

Structural analysis was conducted well using various analytical and spectroscopic techniques, such as FTIR, TEM, FE-SEM,
BET, XRD and VSM analysis. The catalytic efficiency of the prudently constructed catalyst was investigated in the solventless $\mathrm{C}-\mathrm{N}$ cross-coupling of iodobenzene with aniline (Scheme 18a) and $\mathrm{C}-\mathrm{S}$ cross-coupling of iodobenzene with thiophenol (Scheme 18b). The protocol exhibited wide substrate scope, high functional group tolerance, exceptional yields and good recyclability owing to the magnetic nature of the catalyst. Scheme 19 depicts the synthetic pathway of the cross-coupling reactions, which begins with the in situ reduction of $\mathrm{Co}$ (II) species (present in $\mathrm{Fe}_{3} \mathrm{O}_{4}$ @AMCA-MIL53 (Al)- $\mathrm{NH}_{2}-\mathrm{Co}^{\mathrm{II}}$ ) to $\mathrm{Co}(\mathrm{I})$ in the presence of base $\left(\mathrm{KOH} / \mathrm{K}_{3} \mathrm{PO}_{4}\right)$. In the next step, oxidative addition of aryl halide to $\mathrm{Co}$ (I) generates intermediate (II), which later on coordinates with heteroatom to afford intermediate (IV). Meanwhile, intermediate (IV) undergoes reductive elimination to yield the anticipated products in excellent yields along with the regeneration of $\mathrm{Co}(\mathrm{II})$ from $\mathrm{Co}(\mathrm{I})$. The high catalytic performance of the catalyst was further accredited to its nanosized crystalline nature and simultaneous existence of active cobalt species. Furthermore, to assess the heterogeneous nature of the catalyst, various experiments like hot filtration and poisoning tests were carried out.

4.1.4 Multicomponent coupling reactions. Multicomponent reactions (MCRs), owing to their ability to generate diversity-oriented synthesis of structurally complicated scaffolds, have witnessed revitalization in the field of synthetic organic chemistry. The concept of MCRs involves the incorporation of three or more reactants in a one-pot fashion to sequentially furnish new chemical entities that contain all the atoms of the starting materials. Thus, MCRs, by reducing the number of individual synthetic steps or preserving the atom and step economy, reduce the reaction time and solvents, typically pursuing the principles of green chemistry. ${ }^{194-196}$ The aforementioned integral benefits of these reactions provide an efficient way for the synthesis of combinatorial libraries of bioactive heterocyclic motifs whose construction has been considered a milestone in medicinal chemistry, natural product synthesis, bioconjugation and artificial drug synthesis.

In this direction, a novel bifunctional catalyst entailing use of a magnetic MIL-101- $\mathrm{SO}_{3} \mathrm{H}$ MOF composite was reported for the preparation of 1,3,5-triarylbenzene scaffolds (Scheme 20a) from acetophenone as the precursor reagent and 2,4,6-triarylpyridine moieties (Scheme 20b) obtained via coupling between acetophenone, aromatic aldehydes and ammonium acetate. ${ }^{113}$ In both the reactions, wide arrays of functional groups were well tolerated and the targeted products were obtained in splendid yields. Scheme 21 illustrates the mechanistic route through which cooperative interaction between the magnetic MIL-101- $\mathrm{SO}_{3} \mathrm{H}$-based catalyst and the substrates furnish 1,3,5triphenylbenzene motifs. The initial step involves the protonation of acetophenone through acidic sites present in MIL-101- $\mathrm{SO}_{3} \mathrm{H}$ to generate the enol form. The subsequent reaction between the protonated forms ( $\mathbf{A}$ and $\mathbf{B}$ ) and further dehydration leads to the formation of the $\alpha, \beta$-unsaturated carbonyl moiety $\mathbf{C}$, which again activates by the catalyst and undergoes reaction with another protonated acetophenone to form $\mathbf{D}$. The compound $\mathbf{D}$ then undergoes dehydrogenation and prototrophic shift followed 


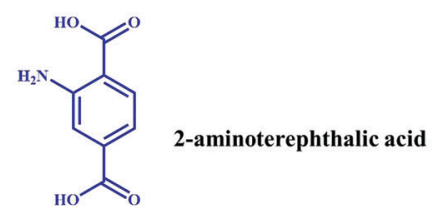

\begin{tabular}{l|l}
$\mathrm{AICl}_{3} \cdot 6 \mathrm{H}_{2} \mathrm{O}$ & $\begin{array}{l}\text { DMF: } \mathrm{H}_{2} \mathrm{O}=9: 1 \\
150{ }^{\circ} \mathrm{C}, 24 \mathrm{~h}\end{array}$
\end{tabular}

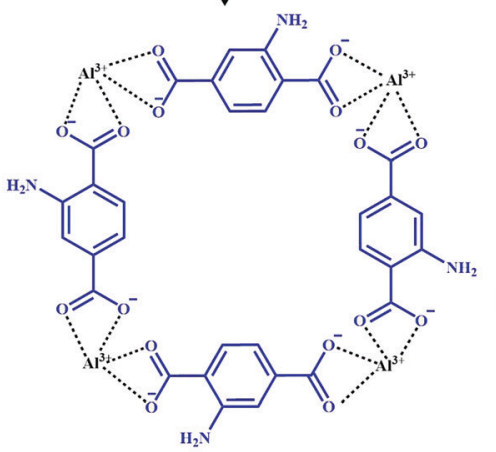

$\mathrm{NH}_{2}$-MIL53(AI)<smiles>CC(=O)CC(CC(=O)O)(CC(=O)O)C(=O)O</smiles>

DCC, Acetonitrile, $80^{\circ} \mathrm{C}, 24 \mathrm{~h}$

Citric acid

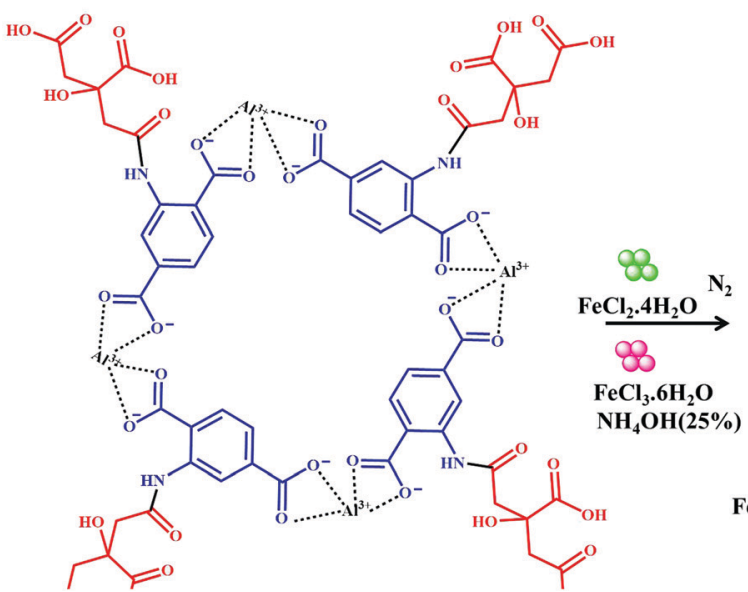

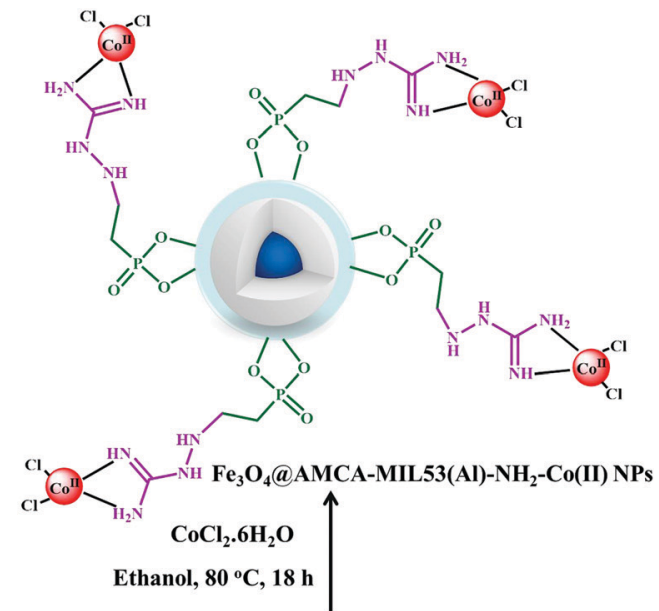
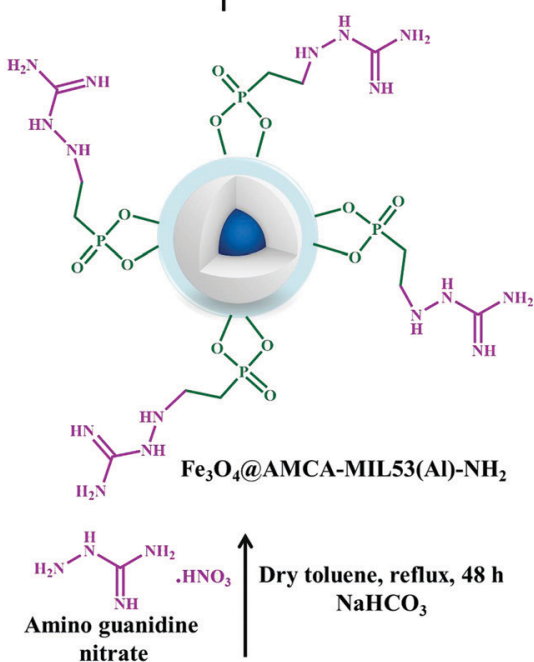

nitrate

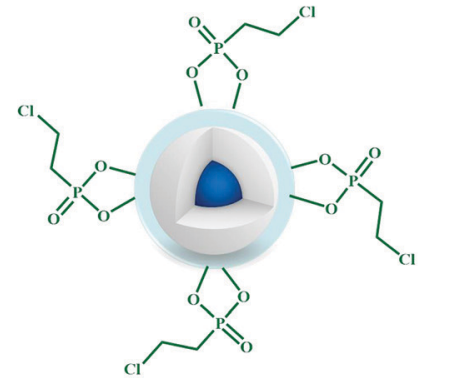

$\mathrm{Fe}_{3} \mathrm{O}_{4} @$ AMCA-MIL53(AI) Ethephon

Scheme 17 Scheme depicting formation of $\mathrm{Fe}_{3} \mathrm{O}_{4}$ (aAMCA-MIL53(Al)- $\mathrm{NH}_{2}-\mathrm{CO}^{\text {(II) }}$.

by electrocyclization and dehydrogenation to yield the desired product.

A synthetic pathway involving the critical role of MIL-101$\mathrm{SO}_{3} \mathrm{H}$ towards accelerating the formation of 2,4,6-triaryl pyridines is demonstrated in Scheme 22. The scheme depicts the protonation of acetophenone via magnetic MIL-101- $\mathrm{SO}_{3} \mathrm{H}$ catalyst to produce the enol form, which undergoes nucleophilic addition with benzaldehyde to afford product $\mathbf{C}$ through Aldol condensation. Meanwhile, the enamine moiety generated after reaction between ammonium acetate and acetophenone interacts with $\mathbf{C}$ via Michael addition to form complex E, which eventually cyclizes and undergoes oxidation to form 2,4,6-triphenylpyridines. The synergistic effect between the Lewis acidic sites of $\mathrm{Cr}^{\mathrm{III}}$ and the active sites of $\mathrm{Fe}_{3} \mathrm{O}_{4}$ NPs was uncovered to have a positive and profound influence on the reaction kinetics. Additionally, the Brønsted acidic sites, due to the $\mathrm{SO}_{3} \mathrm{H}$ groups, were also responsible for achieving exceptional catalytic performance. Some of the startling attributes of the projected catalytic protocol encompassed high efficiency, good chemical stability, high recyclability, high functional group tolerance, magnetic retrievability and high product yield. All these features collectively rendered the proposed methodology to be highly beneficial from economic and environmental concerns. 


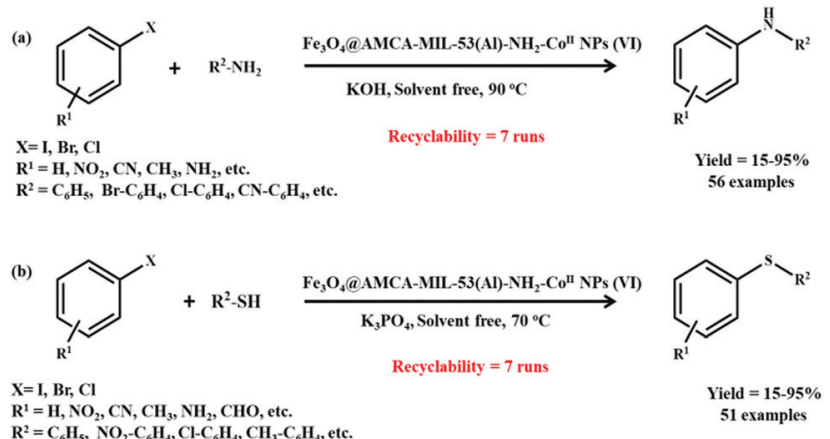

$\mathrm{R}^{2}=\mathrm{C}_{6} \mathrm{H}_{5}, \mathrm{CO}_{2}-\mathrm{C}_{6} \mathrm{H}_{4}, \mathrm{Cl}_{-} \mathrm{C}_{6} \mathrm{H}_{4}, \mathrm{CH}_{3}-\mathrm{C}_{6} \mathrm{H}_{4}$, ete.

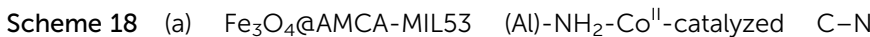
cross-coupling reaction (b) $\mathrm{Fe}_{3} \mathrm{O}_{4}$ (aAMCA-MIL53 (Al)-NH $\mathrm{C}-\mathrm{S}$ cross-coupling reaction.

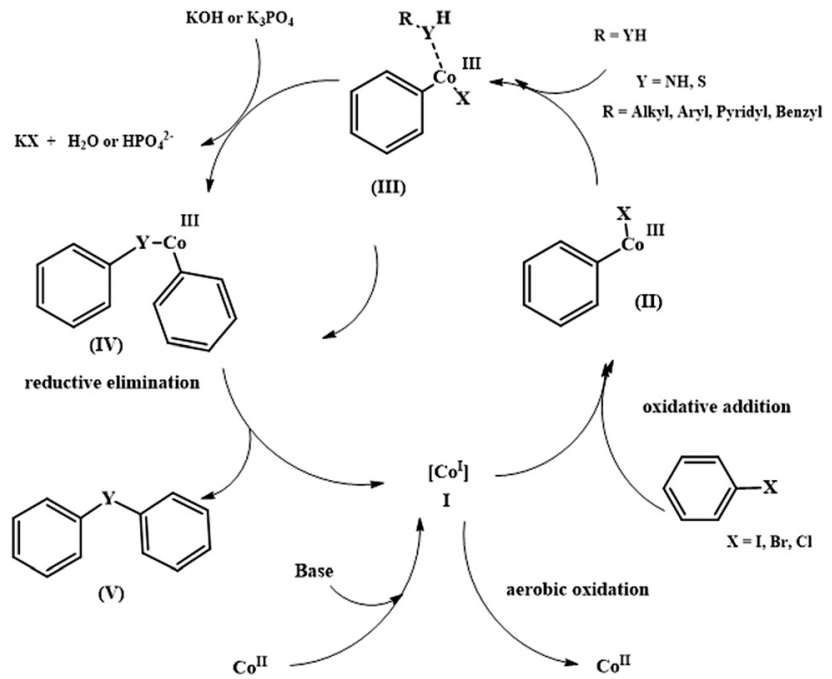

Scheme 19 Mechanistic route for $\mathrm{Fe}_{3} \mathrm{O}_{4}$ (aAMCA-MIL53(Al)- $\mathrm{NH}_{2}-\mathrm{CO}^{(\text {(II) }}$ assisted $\mathrm{C}$-heteroatom $(\mathrm{N}, \mathrm{S})$ cross-coupling reactions.

(a)

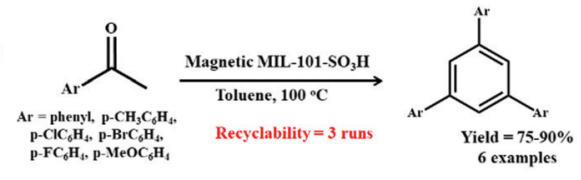

(b)

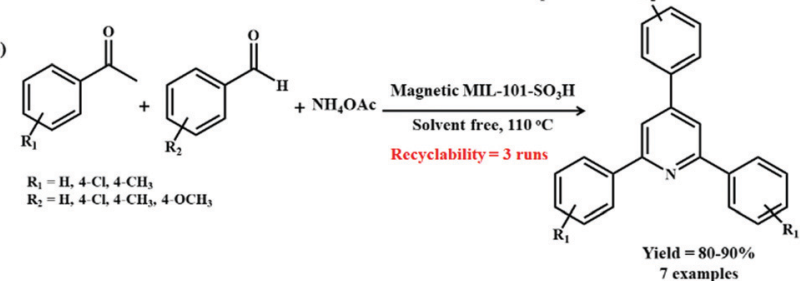

Scheme 20 (a) Preparation of 1,3,5-triarylbenzenes mediated by magnetic MIL-101- $\mathrm{SO}_{3} \mathrm{H}$ catalyst. (b) Preparation of 2,4,6-triaryl pyridines mediated by magnetic MIL-101- $\mathrm{SO}_{3} \mathrm{H}$ catalyst.

Given the tremendous potential of multicomponent coupling reactions in shaping our current industrial and academic sectors, Zhang et al. recently designed a magnetic $\mathrm{NiFe}_{2} \mathrm{O}_{4}$ @MOF-5 heterostructure for executing successful solventless multicomponent

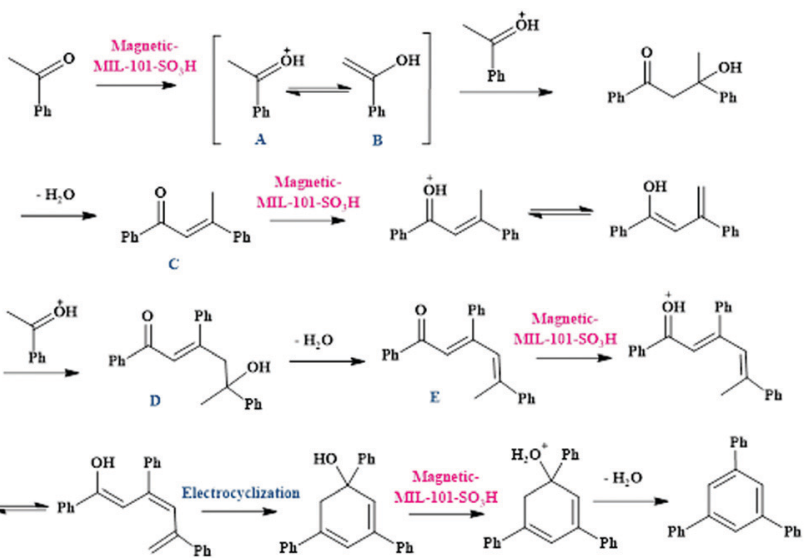

Scheme 21 Mechanistic pathway for the synthesis of 1,3,5-triphenylbenzene motifs in the presence of magnetic MIL-101- $\mathrm{SO}_{3} \mathrm{H}$ composite.

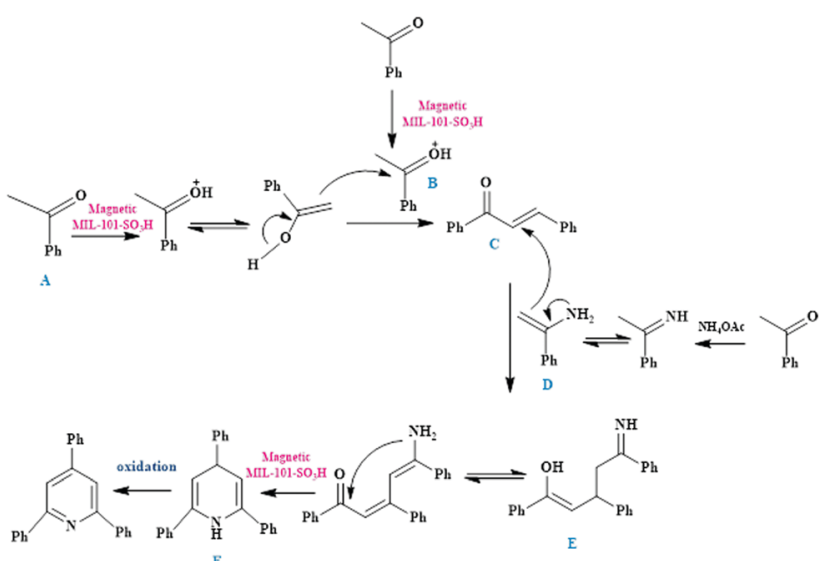

Scheme 22 Mechanistic pathway for the synthesis of 2,4,6-triaryl pyridines in the presence of magnetic MIL-101- $\mathrm{SO}_{3} \mathrm{H}$ composite.

coupling between benzaldehyde, indole, and kojic acid to yield 2-substituted alkyl and aryl(indolyl) kojic acid derivatives (Scheme 23). ${ }^{197}$ The final catalyst was synthesized in three steps having a $\mathrm{NiFe}_{2} \mathrm{O}_{4}$ magnetic core, zinc ions as connectors and terephthalic acid $\left(\mathrm{H}_{2} \mathrm{BDC}\right)$ as linkers. Firstly, $\mathrm{NiFe}_{2} \mathrm{O}_{4} \mathrm{NPs}$ prepared via a co-precipitation method were eventually functionalized using sodium citrate and later on the MOF-5 layer was grown onto the citrate-functionalized NPs after the $\mathrm{NiFe}_{2} \mathrm{O}_{4}$ particles were heated in an autoclave containing a mixture of zinc nitrate and $\mathrm{H}_{2} \mathrm{BDC}$ in $\mathrm{DMF}$ at $130{ }^{\circ} \mathrm{C}$ for $24 \mathrm{~h}$.

The MOF-assimilated magnetic component possessed sufficient magnetic susceptibility to permit facile separation of the catalyst from the reaction media via external magnetic forces rather than cumbersome filtration and centrifugation techniques. Divergent and distinctive aldehyde and indole moieties were coupled effectively to afford 2-substituted alkyl and aryl(indolyl)kojic acid scaffolds in astonishing and remarkable yields. Scheme 24 portrays a mechanistic route that highlights the synergistic interplay of the $\mathrm{NiFe}_{2} \mathrm{O}_{4} @ \mathrm{MOF}-5$-based catalyst and substrates in stimulating the multicomponent reaction. The reaction commences with the activation of the carbonyl group 
(a)

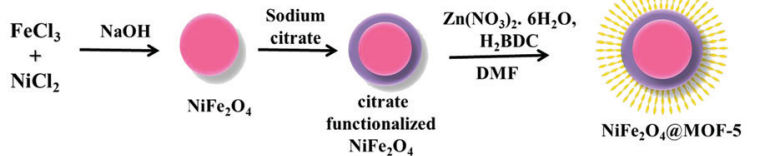

(b)

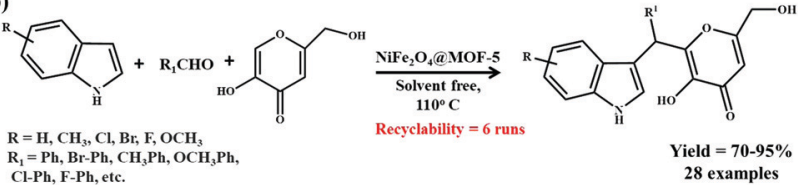

$\mathrm{R}_{1}=\mathrm{Ph}, \mathrm{Br}-\mathrm{Ph}, \mathrm{CH}_{3} \mathrm{Ph}, \mathrm{OCH}_{3} \mathrm{PH}$

Scheme 23 (a) Synthesis of $\mathrm{NiFe}_{2} \mathrm{O}_{4} \mathrm{aMOF}-5$. (b) NiFe $\mathrm{O}_{4} \mathrm{aMOF-5-}$ mediated coupling reaction between aldehyde, indole and kojic acid.

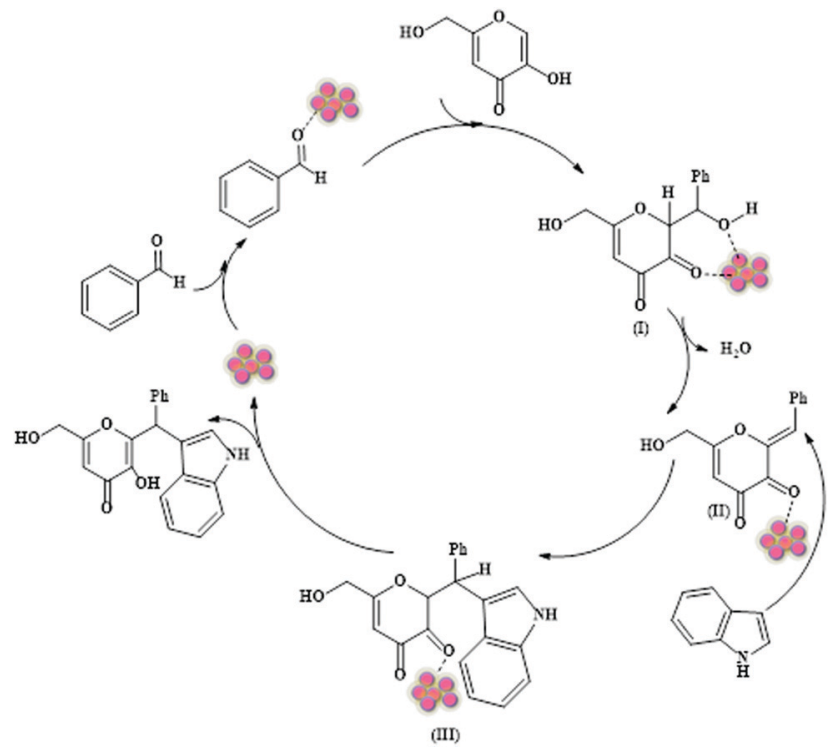

Scheme $24 \mathrm{NiFe}_{2} \mathrm{O}_{4} @ M O F-5$-catalyzed fabrication of 2-substituted alkyl and aryl(indolyl) kojic acid moieties.

of benzaldehyde via interaction with $\mathrm{NiFe}_{2} \mathrm{O}_{4} @ \mathrm{MOF}-5$, which further reacts with kojic acid to form intermediate I. This intermediate then undergoes dehydration to give intermediate II, which further interacts with indole through conjugate addition and subsequent enolization yields the final product.

Similarly, a magnetic $\mathrm{CoFe}_{2} \mathrm{O}_{4} / \mathrm{TMU}-17-\mathrm{NH}_{2}$ MOF composite fabricated via an embedding approach was successfully investigated as a catalyst in the multicomponent coupling between 1,3-diketone, aromatic aldehydes and urea or thiourea to form bis-3,4-dihydropyrimidin-2(1H)-one and 3,4-dihydropyrimidin$2(1 H)$-one derivatives. ${ }^{119}$ The reaction proceeded smoothly under mild conditions, without the use of solvent and completed within 10-30 min with good to excellent yields.

A magnetically retrievable $\mathrm{CoFe}_{2} \mathrm{O}_{4} @ \mathrm{SiO}_{2} @ \mathrm{NH}_{2} @ \mathrm{Cu}(5-\mathrm{NIPA})$ heterostructure possessing immense thermal stability was fabricated via a covalent bonding strategy, which exhibited unprecedented catalytic activity in the multicomponent oxidative coupling between primary alkyl/aryl amines, substituted anilines and sodium azides to form 2-substituted benzimidazole moieties (Fig. 13). ${ }^{56}$ The authors proposed a possible mechanistic route (Scheme 25) in which cooperative interaction between (a)

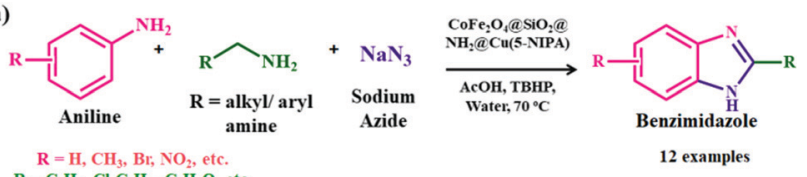

$\mathbf{R}=\mathrm{C}_{6} \mathrm{H}_{5}, \mathrm{Cl}-\mathrm{C}_{6} \mathrm{H}_{5}, \mathrm{C}_{4} \mathrm{H}_{3} \mathrm{O}$, etc.

(b)

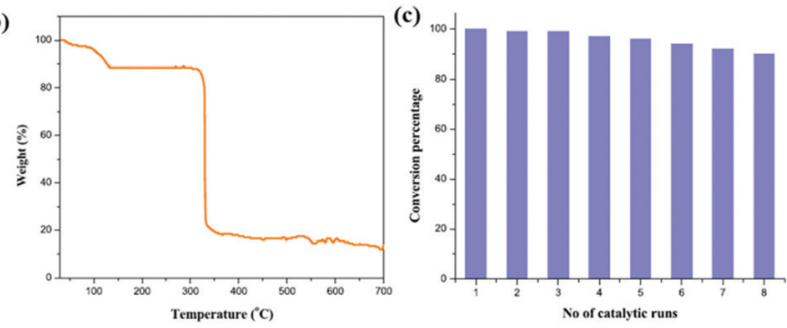

Fig. 13 (a) $\mathrm{CoFe}_{2} \mathrm{O}_{4} \mathrm{aSiO}_{2} \mathrm{aNH}_{2}(\mathrm{aCu}(5-\mathrm{NIPA})$-catalyzed multicomponent coupling reaction to afford benzimidazole scaffolds. (b) TGA curve of $\mathrm{CoFe}_{2} \mathrm{O}_{4} @ \mathrm{aSiO}_{2} @ \mathrm{aNH}_{2} @ \mathrm{aCu}(5-\mathrm{NIPA})$. (c) Recyclability studies for $\mathrm{CoFe}_{2} \mathrm{O}_{4}\left(\mathrm{aSiO}_{2}\left(\mathrm{aNH}_{2} @ \mathrm{aCu}(5-\mathrm{NIPA})\right.\right.$-mediated benzimidazole synthesis. Reproduced with permission from ref. 56. Copyright (2018) American Chemical Society.

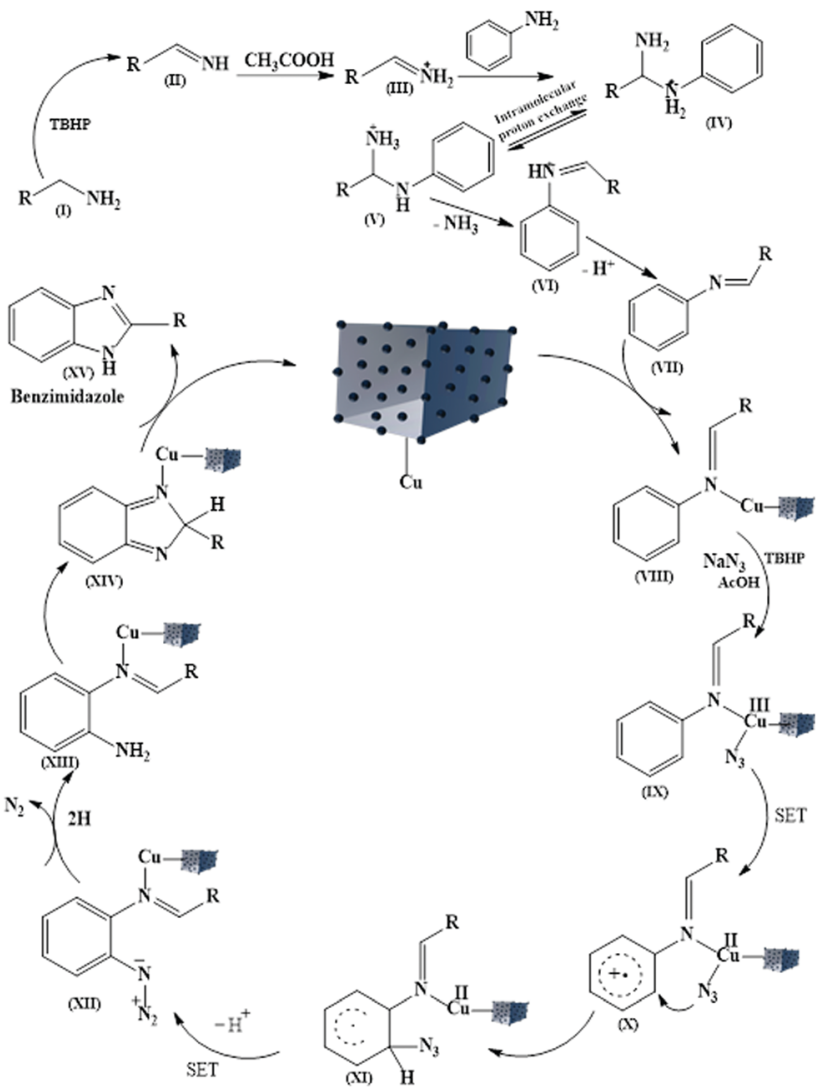

Scheme $25 \mathrm{CoFe}_{2} \mathrm{O}_{4} \mathrm{aSiO}_{2} \mathrm{aNH}_{2} \mathrm{aCu}(5-\mathrm{NIPA})$-assisted synthesis of 2substituted benzimidazoles.

$\mathrm{CoFe}_{2} \mathrm{O}_{4} @ \mathrm{SiO}_{2} @ \mathrm{NH}_{2} @ \mathrm{Cu}(5-\mathrm{NIPA})$ and reactants successfully afforded 2-substituted benzimidazoles in good to excellent conversion percentages. Oxidation of benzylamine generates an imine moiety, which further reacts with aryl amine to produce an intermediate complex that coordinates with $\mathrm{Cu}$ (present in $\left.\mathrm{CoFe}_{2} \mathrm{O}_{4} @ \mathrm{SiO}_{2} @ \mathrm{NH}_{2} @ \mathrm{Cu}(5-\mathrm{NIPA})\right)$. Meanwhile, acetic acid reacts 
with sodium azide to generate hydrazoic acid, which in the presence of TBHP forms $\mathrm{N}_{3}$ radical, which consequently interacts with the $\mathrm{Cu}-\mathrm{MOF}$ coordinated complex. The subsequent single electron transfer process followed by loss of $\mathrm{N}_{2}$, intramolecular oxidative cyclization and aromatization forms the anticipated benzimidazole moiety. The protocol permitted the fruitful synthesis of a diverse range of benzimidazoles with good conversion percentages. The plentiful coordinatively unsaturated metal centers inside the MOF structure was asserted to be the prime parameter behind the impressive catalytic potential of the designed composite. Besides, the incorporation of green reaction conditions (water as solvent), wide substrate applicability and the excellent recyclability and durability of the catalyst owing to its magnetic characteristics made the protocol highly valuable for addressing industrial and environmental concerns.

Synthesis of $S$-aryl phosphorothioates via phosphorylation of aryl thiols has been rated as one of the most poignant transformations in organic synthesis as the resulting products find extensive usage as versatile intermediates in the generation of biologically active compounds. For accomplishing the preferred phosphorylation process, these protocols employ chlorine or bromine along with aryl thiols, which are highly toxic along with foul smelling. Additionally, the reported methodologies not only incorporate homogeneous transition metal salts but also involve unfavourable starting reagents and additives. A recent report wherein phosphorothiolation of aryl boronic acids was carried out using sulfur powder persuaded Zhang and co-workers to formulate a three-component coupling reaction between aniline as the aryl source, $\mathrm{H}$-phosphonates $[\mathrm{P}(\mathrm{O}) \mathrm{H}]$ and sulfur powder to form $\mathrm{C}_{(\operatorname{aryl})}-\mathrm{S}-\mathrm{P}$ bonds catalyzed by a Cu-BTC@Fe $\mathrm{O}_{4}$ composite (Scheme 26). ${ }^{198}$ The catalyst was fabricated via a secondary growth approach in which carboxylmodified $\mathrm{Fe}_{3} \mathrm{O}_{4}$ NPs were added into an ethanol-water solution containing copper ions and PVP followed by the stepwise addition of more copper ions and $\mathrm{H}_{3}$ BTC under mechanical stirring for $12 \mathrm{~h}$. Proper nucleation and growth of MOF onto $\mathrm{Fe}_{3} \mathrm{O}_{4} \mathrm{NPS}$ was controlled by fine-tuning the precursor reagent ratios and the manner or series in which reagents were added. In the presence of the developed $\mathrm{Cu}-\mathrm{BTC} @ \mathrm{Fe}_{3} \mathrm{O}_{4}$ composite, a broad array of anilines (to in situ generate aryl diazonium salts) and H-phosphonates underwent reaction smoothly to afford the desired scaffolds in remarkable yields. Furthermore, the magnetic retrievability of the catalyst favored its repetitive use for six repeated runs and without any considerable decrease in the catalytic performance.
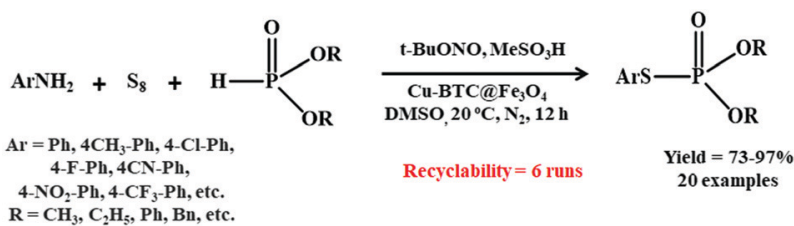

Scheme $26 \mathrm{Cu}$-BTC $\mathrm{aFe}_{3} \mathrm{O}_{4}$-catalyzed synthesis of S-aryl phosphorothioates.

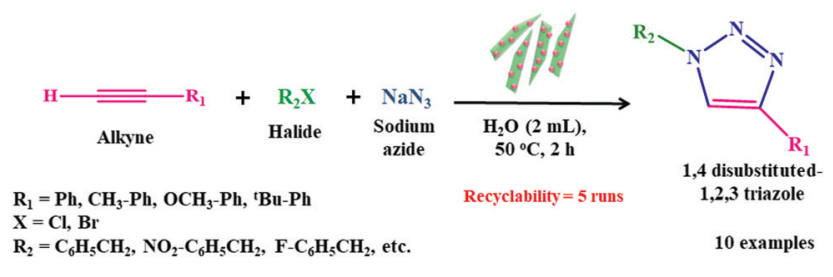

Scheme $27 \mathrm{CoFe}_{2} \mathrm{O}_{4} / \mathrm{Mn}$-BDC-mediated click coupling reaction.

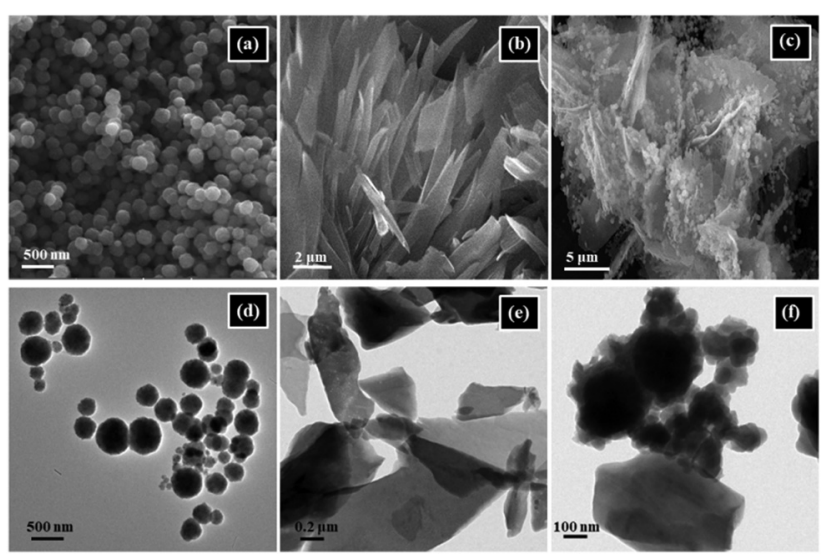

Fig. 14 SEM micrographs of (a) $\mathrm{CoFe}_{2} \mathrm{O}_{4}$, (b) $\mathrm{Mn}-\mathrm{BDC}$ and (c) $\mathrm{CoFe}_{2} \mathrm{O}_{4} /$ $\mathrm{Mn}-\mathrm{BDC}$. TEM micrographs of (d) $\mathrm{CoFe}_{2} \mathrm{O}_{4}$, (e) $\mathrm{Mn}-\mathrm{BDC}$ and (f) $\mathrm{CoFe}_{2} \mathrm{O}_{4} /$ $\mathrm{Mn}-\mathrm{BDC}$. Reproduced with permission from ref. 154. Copyright (2020) American Chemical Society.

Very recently, Sharma and co-workers fabricated a $\mathrm{CoFe}_{2} \mathrm{O}_{4} /$ Mn-BDC hybrid heterostructure for carrying out multicomponent click coupling of alkyl/aryl halides, terminal alkynes and sodium azide to afford 1,4-disubstituted 1,2,3-triazoles (Scheme 27). ${ }^{154}$ As substantiated through SEM and TEM analysis (Fig. 14), the composite synthesized by a mixing approach contained Mn-BDC possessing microflake morphology with homogeneous dispersion of $\mathrm{CoFe}_{2} \mathrm{O}_{4}$ NPs. The developed catalyst, apart from presenting impressive catalytic performance towards the synthesis of a broad array of 1,4-disubstituted triazoles, was also magnetically retrievable and recyclable for five runs, which further added mystique to the designed methodology. Scheme 28 elucidates the crucial role of $\mathrm{CoFe}_{2} \mathrm{O}_{4} / \mathrm{Mn}-\mathrm{BDC}$ in promoting the multicomponent click coupling to afford 1,2,3-triazole scaffolds under ambient reaction conditions. The primary step entails the coordination of Mn species (present in $\mathrm{CoFe}_{2} \mathrm{O}_{4} / \mathrm{Mn}$-BDC) with a terminal alkyne to generate $\mathrm{Mn}$ coordinated complex I. Meanwhile, the in situ formed alkyl azide reacts with complex I and subsequently undergoes 1,3-dipolar cycloaddition to generate the final product.

Benzodiazepine moieties encompassing a triazole framework are biologically active heterocyclic compounds with immense pharmaceutical significance. In view of this, $\mathrm{CuFe}_{2} \mathrm{O}_{4} @ \mathrm{MIL}$ $101(\mathrm{Cr})$ was lately investigated as a recyclable material in the synthesis of benzodiazepines comprising a triazole skeleton in the eco-friendly solvent of water (Scheme 29). ${ }^{199}$ Chalcones with acetylene groups, $o$-phenylene diamine and substituted phenyl azides were taken as multicomponent reaction partners to 


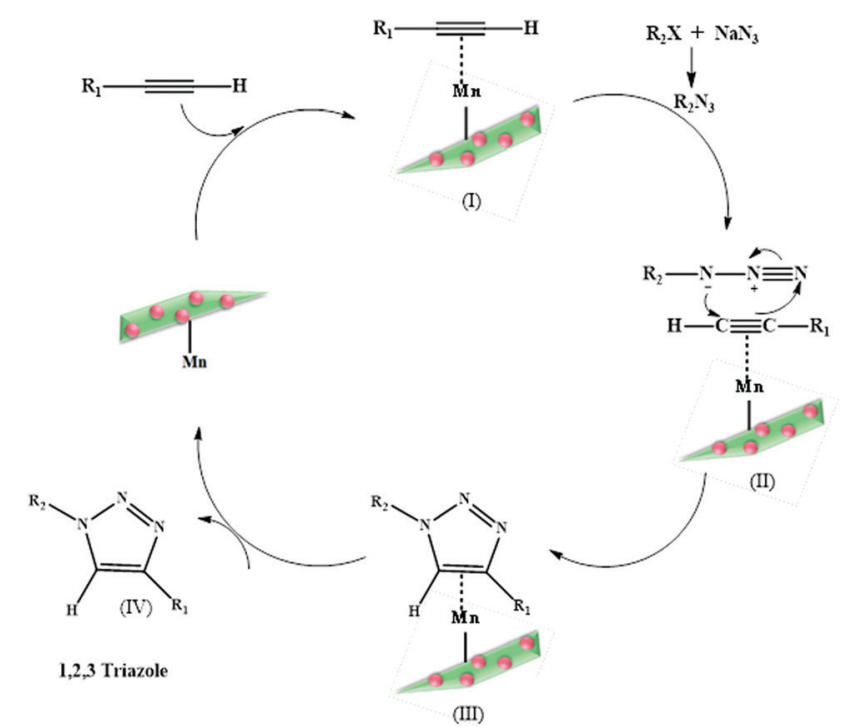

Scheme 28 Scheme depicting $\mathrm{CoFe}_{2} \mathrm{O}_{4} / \mathrm{Mn}$-BDC-mediated preparation of 1,4-disubstituted 1,2,3-triazoles.

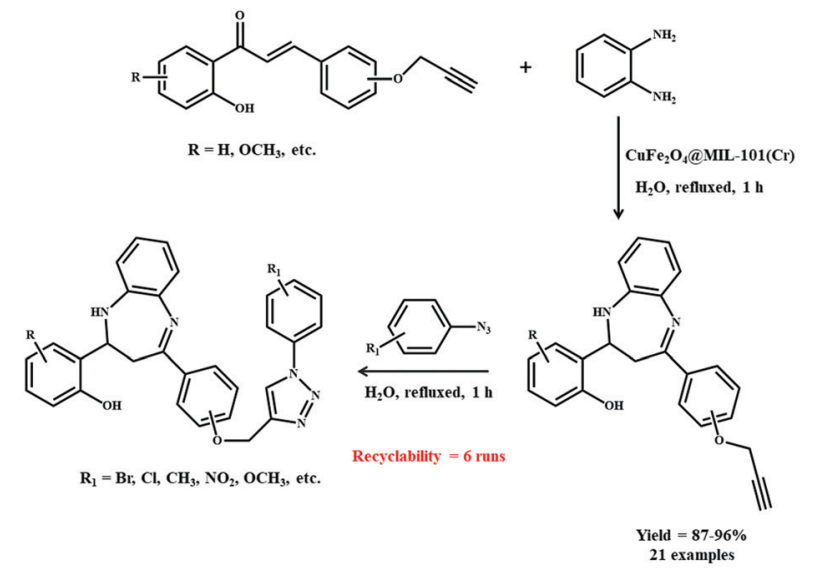

Scheme 29 Synthesis of benzodiazepines containing triazole skeletons using $\mathrm{CuFe}_{2} \mathrm{O}_{4} @ \mathrm{aMIL}-101(\mathrm{Cr})$ catalyst.

afford the desired benzodiazepines in excellent yields. The engaged protocol was found to be effective even for gram scale synthesis. Furthermore, magnetic retrievability and reusability for six consecutive runs without any significant decrement in catalytic performance were some added benefits of the methodology.

4.1.5 Condensation reactions. A condensation reaction is a type of organic transformation in which two or more reactants undergo chemical reaction via the loss of smaller molecules, such as water, ethanol, methanol, hydrogen chloride or acetic acid. These reactions are known to have wider applications in combinatorial organic synthesis as it yields numerous bulk platform chemicals and fine medical intermediates. Knoevenagel condensation between an aromatic aldehyde or an aromatic ketone moiety and malonic ester, malonic acid, cyanoacetic ester having an active methylene group is one of the most versatile and appealing reactions for obtaining complex organic scaffolds.
Considering the widespread importance of this reaction in synthetic organic chemistry, Ji and co-workers demonstrated a successful reaction between $p$-chlorobenzaldehyde and malononitrile catalyzed by recyclable ZIF-8@SiO $\mathrm{S}_{2} @ \mathrm{Fe}_{3} \mathrm{O}_{4} \cdot{ }^{200}$ By taking different contents of ZIF-8, the authors synthesized a series of ZIF-8@SiO ${ }_{2} @ \mathrm{Fe}_{3} \mathrm{O}_{4}$-based composites through simply encapsulating $\mathrm{SiO}_{2} @ \mathrm{Fe}_{3} \mathrm{O}_{4}$ into ZIF-8 via an in situ approach. The synthesized catalyst achieved an incredible approximately $100 \%$ conversion and selectivity within $4 \mathrm{~h}$. Besides, the protocol delivered fairly excellent results with both electron-donating and -withdrawing functionalities and the anticipated products were efficaciously attained in high yield.

Another research group led by $\mathrm{Ge}$ also reported the Knoevenagel reaction between benzaldehyde and cyanoacetamide using a potent $\mathrm{Fe}_{3} \mathrm{O}_{4} / \mathrm{ZIF}-8$ catalyst. ${ }^{201}$ The synthesis of the $\mathrm{Fe}_{3} \mathrm{O}_{4} /$ ZIF-8 composite was an encapsulation process compelled by the electrostatic interactions between the positive components of ZIF-8 and the negatively charged $\mathrm{Fe}_{3} \mathrm{O}_{4}$ (Scheme 30a). Moreover, by simply adjusting the amount of $\mathrm{Fe}_{3} \mathrm{O}_{4}$ and $\mathrm{Zn}\left(\mathrm{NO}_{3}\right)_{2}$, the particle size and surface charge of the overall composite was controlled effectively. The high catalytic activity of the designed composite in the Knoevenagel reaction was attributed to the existence of active basic sites on its external surface (Scheme 30b).

In this context, a prolific attempt was made by Schneider et al., wherein the authors synthesized a porous $\mathrm{Fe}_{3} \mathrm{O}_{4} @ Z I F-8$ composite by dispersing smaller sized citrate-modified $\mathrm{Fe}_{3} \mathrm{O}_{4}$ NPs within the cavities or pores of the ZIF-8. ${ }^{202}$ The carboxyl functionalities on $\mathrm{Fe}_{3} \mathrm{O}_{4}$ interacted with $\mathrm{Zn}^{2+}$ ions coordinated with 2-methylimidazole, eventually driving the growth of ZIF-8 around the $\mathrm{Fe}_{3} \mathrm{O}_{4}$ core. Microscopic studies (Fig. 15) divulged the formation of rhombic dodecahedral shaped ZIF-8 with spherical $\mathrm{Fe}_{3} \mathrm{O}_{4} \mathrm{NPs}$ assimilated into the framework. The catalytic potency of developed architecture was assessed in the Knoevenagel condensation between benzaldehyde and malononitrile using toluene as a solvent at room temperature (Scheme 31). The protocol was even further stretched to $\mathrm{Cu}^{2+}$-doped $\mathrm{Fe}_{3} \mathrm{O}_{4} / \mathrm{ZIF}-8$ for catalyzing the cycloaddition reaction between phenyl azides and terminal acetylenes to afford triazole scaffolds.

The Li research group prepared a $\mathrm{Fe}_{3} \mathrm{O}_{4} / \mathrm{IRMOF}-3$ composite and analyzed its catalytic potential in the Knoevenagel condensation of benzaldehyde and ethyl cyanoacetate. ${ }^{203}$

(a)
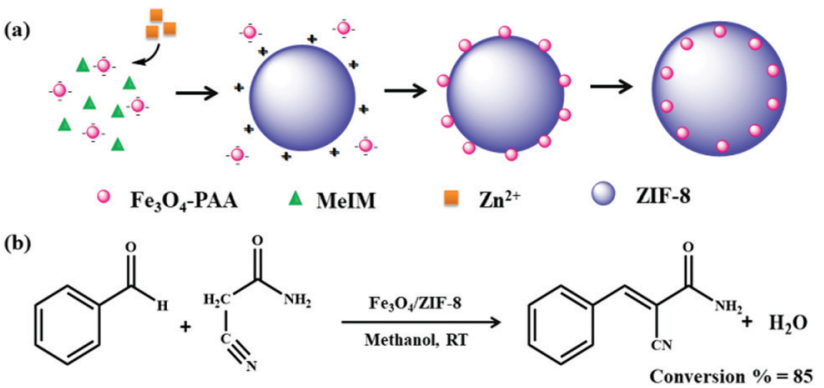

Scheme 30 (a) Formation pathway of $\mathrm{Fe}_{3} \mathrm{O}_{4} / \mathrm{ZIF}-8$. (b) $\mathrm{Fe}_{3} \mathrm{O}_{4} / \mathrm{ZIF}-8$ mediated Knoevenagel condensation of benzaldehyde and cyanoacetamide. 

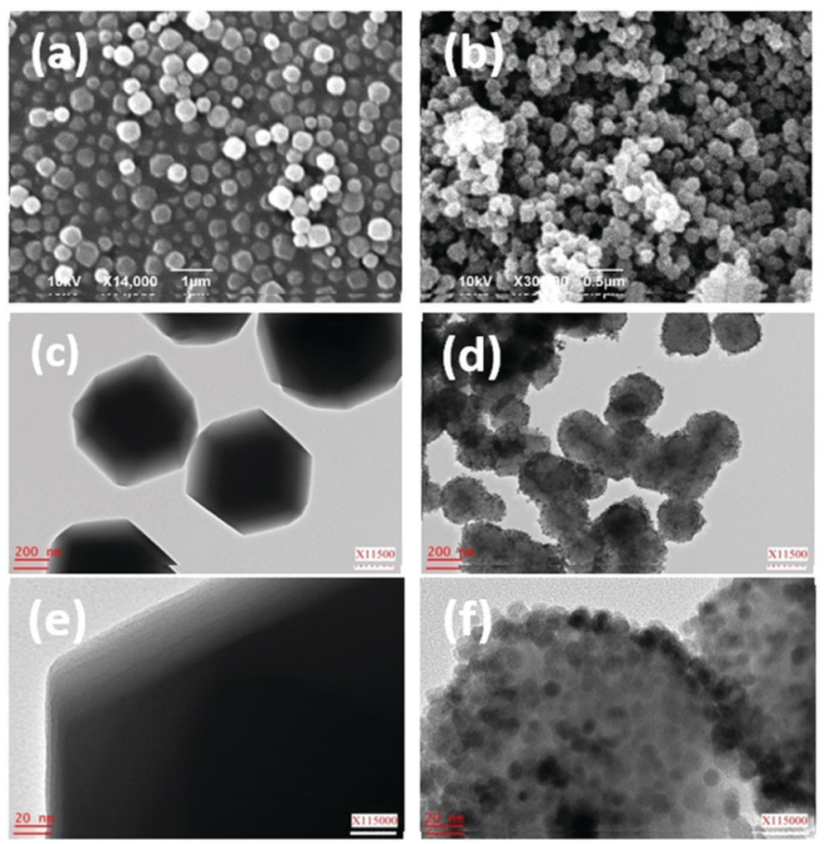

Fig. 15 SEM micrographs of (a) ZIF-8 and (b) $\mathrm{Fe}_{3} \mathrm{O}_{4}$ @ZIF-8. TEM micrographs of (c and e) $\mathrm{ZIF}-8$ and (d and f) $\mathrm{Fe}_{3} \mathrm{O}_{4} \mathrm{aZIF-8}$. Reproduced with permission from ref. 202. Copyright 2015 Royal Society of Chemistry.

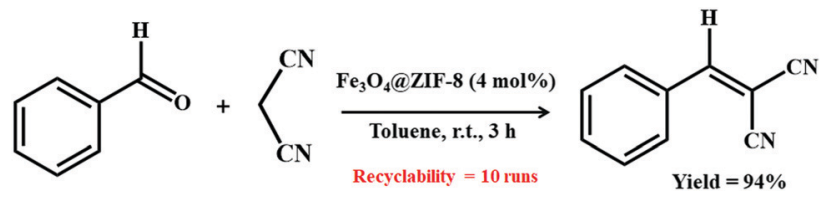

Scheme 31 Knoevenagel condensation of benzaldehyde and malononitrile mediated by $\mathrm{Fe}_{3} \mathrm{O}_{4} \mathrm{QZZIF}-8$.

The material was synthesized by coating $\mathrm{Fe}_{3} \mathrm{O}_{4}$ with a layer of PVP that, apart from acting as a promoter, also ensured implicit encapsulation of $\mathrm{Fe}_{3} \mathrm{O}_{4}$ within the MOF matrix. Electrostatic interactions between the $\mathrm{Zn}^{2+}$ ions of the MOF and the pyrrolidone groups of PVP in conjunction with hydrophobic interactions between PVP and the organic linker of the MOF served as the basis for the growth of the overall composite. The authors further illuminated the fact that this MOF-based catalyst attained a marvelous ethyl cyanoacetate conversion of 98.3\% within $4 \mathrm{~h}$.

Another magnetically recyclable $\mathrm{Fe}_{3} \mathrm{O}_{4} @ U$ UiO-66- $\mathrm{NH}_{2}$ composite possessing a core-shell structure was employed in the Knoevenagel condensation between benzaldehyde and ethyl cyanoacetate. ${ }^{204}$ The developed catalyst was found to be highly active in the concerned reaction due to the bifunctional characteristics of UiO-66- $\mathrm{NH}_{2}$ along with the superior mass transfer phenomenon commendably eventuating due to its nanosized core-shell morphology. Moreover, the catalyst showed appreciable recycling stability for four consecutive runs due to facile recovery via magnetic forces. In fact, the protocol was further extended for the reaction between numerous larger aromatic aldehydes, like 1-naphthaldehyde and 9-anthraldehyde with ethyl cyanoacetate.
Likewise, another research group also explored $\mathrm{Fe}_{3} \mathrm{O}_{4}$ @MIL$100(\mathrm{Fe})-\mathrm{NH}_{2}$ as a potent catalyst in the Knoevenagel condensation between ethyl cyanoacetate and benzaldehyde. ${ }^{205}$ The high catalytic efficiency of the catalyst was attributed not only to the simultaneous presence of Lewis acidic metal sites and amino groups but also due to the existence of a mesoporous MOF shell.

Recently, a one-pot sequential deacetalization-Knoevenagel cascade condensation reaction was reported by Matsuoka and co-workers using $\mathrm{Fe}_{3} \mathrm{O}_{4} @$ @HKUST-1 as the catalyst. ${ }^{206}$ The catalyst was fabricated by embedding $\mathrm{Fe}_{3} \mathrm{O}_{4}$ NPs into the copper-based ceramic material $\mathrm{Cu}_{2}(\mathrm{OH})_{3} \mathrm{NO}_{3}$. At room temperature, this ceramic material in an ethanolic solution of $\mathrm{H}_{3} \mathrm{BTC}$ was converted into HKUST-1. The cascade reaction between benzaldehyde dimethylacetal and malononitrile occurred smoothly at $363 \mathrm{~K}$ in the presence of 1,4-dioxane as the solvent with the successful formation of benzylidene malononitrile. It is worth noting here that the Brønsted and Lewis acidic sites along with coordinatively unsaturated metal centers inside the structure of MOF were mainly responsible for its high catalytic activity. In fact, the newly developed catalyst $\left(\mathrm{Fe}_{3} \mathrm{O}_{4} @ H K U S T-1\right)$ exhibited high catalytic performance in comparison to the traditional heterogeneous catalysts such as alumina, $\mathrm{SiO}_{2}$ and $\mathrm{MgO}$ in the concerned reaction. The authors further explored the scope and versatility of the fabricated magnetic MOF composite towards the hydrogenation of olefin-like 1-octene. For this, Pd NPs were incorporated by mixing in $\mathrm{Fe}_{3} \mathrm{O}_{4} @ \mathrm{Cu}_{2}(\mathrm{OH})_{3} \mathrm{NO}_{3}$ solution and with the successive addition of linker (BTC), $\mathrm{Pd} / \mathrm{Fe}_{3} \mathrm{O}_{4}$ @ HKUST-1 composite was formed which resulted in octane formation with $98 \%$ yield.

The Claisen-Schmidt condensation between a nucleophilic ketone donor and an electrophilic aldehyde acceptor is also considered to be a powerful multicomponent reaction that finds extensive usage in medicinal and synthetic organic chemistry. This reaction generates numerous pharmacologically significant compounds that possess anticancer, anti-inflammatory and antimalarial properties. Chalcones, an important structural motif in organic synthesis and a progenitor of biologically active scaffolds such as flavonoids, benzothiazepines and pyrazolines can be synthesized via this reaction in acidic or basic conditions. ${ }^{207,208}$ In view of this, a magnetically recyclable core-shell $\mathrm{Fe}_{3} \mathrm{O}_{4}$ @ MIL-100(Fe) heterostructure fabricated by utilizing a multistep assembly strategy was explored for its ability to catalyze the Claisen-Schmidt reaction affording chalcone motifs (Scheme 32). ${ }^{108}$ Under optimal reaction conditions and taking benzaldehyde and acetophenone as model substrates, the catalyst demonstrated noteworthy catalytic activity. The high activity was further

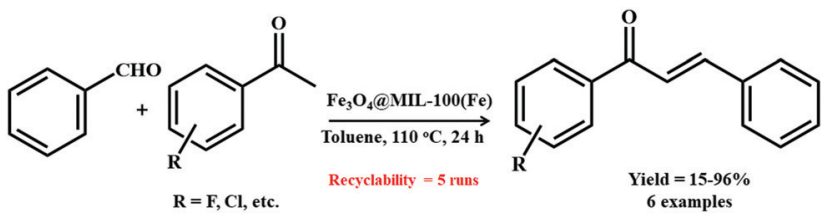

Scheme $32 \mathrm{Fe}_{3} \mathrm{O}_{4} \mathrm{OMIL-100}(\mathrm{Fe})$-catalyzed Claisen-Schmidt reaction of benzaldehyde and acetophenone. 
attributed to the exceptionally high surface area, well-defined pore size and Lewis acidic sites in the structure of the overall composite.

Coumarins, a significant class of oxygen heterocycles, have garnered increasing attention in the agrochemicals, insecticides, cosmetics and fragrance industries. Coumarin and its derivatives possess numerous biological activities, such as anticancer, antimicrobial, anti-HIV, and antithrombotic, that are in high demand in the pharmaceutical sector. Owing to the involvement of milder reaction conditions, simple starting reagents, and shorter reaction times, these motifs can be synthesized easily via Pechmann condensation reaction..$^{209,210}$ Taking into account the aforementioned benefits offered by these moieties, Ji and co-workers fabricated a series of newer Cu-BTC@SiO ${ }_{2} @ \mathrm{Fe}_{3} \mathrm{O}_{4}$ materials via ultrasonic-assisted method by varying the mass percent of Cu-BTC in the composite and subsequently utilized them as catalysts in the Pechmann reaction between 1-naphthol and ethyl acetoacetate (Scheme 33). ${ }^{211}$ Amongst the various synthesized catalysts, 50.8\% Cu-BTC@SiO $\mathrm{SFe}_{3} \mathrm{O}_{4}$ unveiled an outstanding conversion of $96 \%$ along with $98 \%$ selectivity. Besides this, the ease of catalyst separation and reusability for five consecutive runs without any appreciable loss in efficiency further enhanced the significance of this protocol.

Discovered in 1850, the Strecker reaction represents one of the most efficient strategies in the synthesis of $\alpha$-amino nitriles. It is a multicomponent reaction in which an amine group, a carbonyl moiety and alkaline metal cyanides effectively crosscouple to form the desired biologically important synthones. ${ }^{212}$ Considering the sizeable interest in these molecules in synthetic organic chemistry, a porous magnetic $\mathrm{Fe}_{3} \mathrm{O}_{4} / \mathrm{MIL}-101(\mathrm{Fe})$ material was examined as a potent catalyst towards accomplishing three-component Strecker condensation of aldehydes/ ketones, amines and trimethylsilyl cyanide to afford $\alpha$-amino nitriles (Scheme 34). ${ }^{213}$ A broad range of substituted aldehydes and substituted anilines reacted smoothly in ethanol at room temperature. The protocol generated highly demanded products in exceptional yields, further highlighting the presence of Lewis acidic sites in the catalyst, which were responsible for its high activity.

4.1.6 Esterification reactions. The heavy reliance on and increasing consumption of fossil fuels have prompted researchers to develop alternative greener fuels that not only benefit society by curtailing fuel usage but also reduce atmospheric pollution to a greater extent. To remediate the above-mentioned problem, biodiesel has emerged as an attractive alternative fuel that is

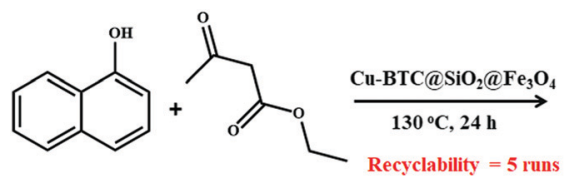

Scheme $33 \mathrm{Cu}$-BTCaSiO $\mathrm{aFe}_{3} \mathrm{O}_{4}$-catalyzed between 1-naphthol and ethyl acetoacetate.
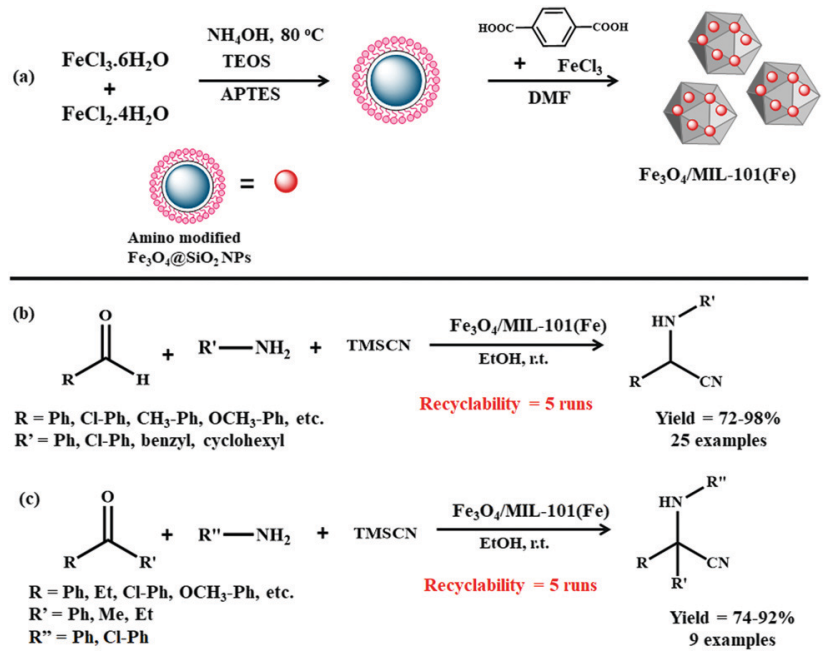

Scheme 34 (a) Fabrication of $\mathrm{Fe}_{3} \mathrm{O}_{4} / \mathrm{MIL}-101$ (Fe) composite. (b) $\mathrm{Fe}_{3} \mathrm{O}_{4} /$ MIL-101(Fe)-mediated Strecker reaction between aldehydes, amines and TMSCN. (c) $\mathrm{Fe}_{3} \mathrm{O}_{4} / \mathrm{MIL}-101(\mathrm{Fe})$-mediated Strecker reaction between ketones, amines and TMSCN.

sustainable, biodegradable and non-toxic. The transesterification reactions for the production of biodiesel are among the most attractive research areas in the academic and industrial sectors. Moreover, due to mounting demand for an economically sustainable environment, transesterification reactions provide a unique platform for designing more acceptable processes in organic synthesis. It is splendid to introduce here the work carried out by Guan et al. for establishing esterification of oleic acid with ethanol. ${ }^{214}$ The authors ingeniously designed a profitable strategy in which an ionic liquid (1,4-butanediyl-3,3'-bis(3-sulfopropyl)imidazolium) dihydrogen sulfate (DAIL) with abundant acidic sites was constricted inside the framework of $\mathrm{Fe}_{3} \mathrm{O}_{4} @ \mathrm{NH}_{2}-\mathrm{MIL}$ $88 \mathrm{~B}(\mathrm{Fe})$ (Fig. 16A). The structure of the resulting catalyst was identified and ascertained productively using FT-IR, TGA, VSM and $\mathrm{N}_{2}$ adsorption-desorption isotherms. Additionally, welldeveloped microscopic tools like SEM and TEM revealed the spindle morphology of the synthesized catalyst (Fig. 16B). The ionic liquid-grafted magnetic MOF composite with a significantly high concentration of acidic sites $\left(1.76 \mathrm{mmol} \mathrm{H}^{+} \mathrm{g}^{-1}\right)$ gave

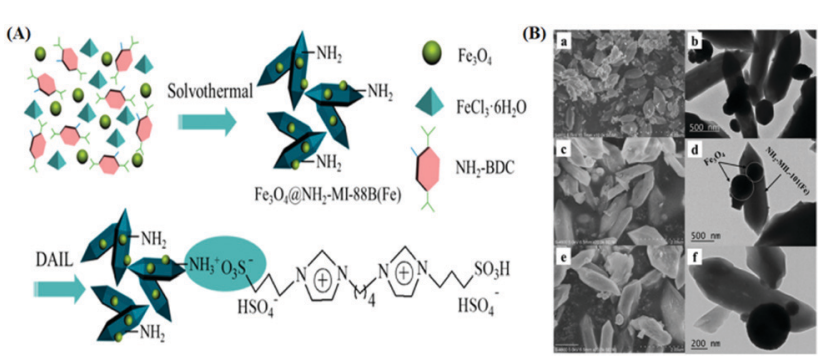

Fig. 16 (A) Illustration showing synthesis of ionic liquid-based magnetic MOF composite DAIL- $\mathrm{Fe}_{3} \mathrm{O}_{4}\left(\mathrm{QNH}_{2}-\mathrm{MIL}-88(\mathrm{Fe})\right.$. (B) SEM and TEM micrographs of $\mathrm{Fe}_{3} \mathrm{O}_{4} @ \mathrm{ONH}_{2}-\mathrm{MIL}-88\left(\mathrm{Fe}\right.$ ) (a and b), DAIL-Fe $\mathrm{O}_{4} @ \mathrm{NNH}_{2}-\mathrm{MIL}-88$ (Fe) (c and d) and recovered DAIL- $\mathrm{Fe}_{3} \mathrm{O}_{4} \mathrm{aNH}_{2}-\mathrm{MIL}-88$ (Fe) (e and f). Reproduced with permission from ref. 214. Copyright (2016) American Chemical Society. 
biodiesel in $93.2 \%$ yield. The catalyst was found to be separated easily via an external magnet and was reused for six consecutive runs, demonstrating good potential for large-scale industrial applicability.

Another neoteric magnetic MOF composite as a potential prospect for carrying out esterification reaction was delineated by Wang et al. ${ }^{215}$ The $\mathrm{Fe}_{3} \mathrm{O}_{4} / \mathrm{MIL}-100(\mathrm{Fe})$ heterostructure was fabricated under ambient reaction conditions, i.e., low temperature without the need for HF (hydrofluoric acid) and high pressure. The catalytic efficiency of the resulting composite was investigated in the esterification of rosin with glycerol. Rosin majorly consists of tricyclic diterpene resin acid and its esterification with alcohols is considered to be highly challenging in industry. Surprisingly, the designed catalyst achieved a notable rosin conversion of $94.8 \%$ at $240{ }^{\circ} \mathrm{C}$ within a $2.5 \mathrm{~h}$ reaction time. Elimination of free, adsorbed water molecules from the structure of $\mathrm{Fe}_{3} \mathrm{O}_{4} / \mathrm{MIL}-100$ (Fe) significantly boosted its catalytic efficiency, as evident through the experimental results. Besides, the magnetic retrievability of the catalyst permitted its facile removal via an external magnet, which further enhanced the economic competitiveness of the protocol.

\subsection{Photocatalysts}

Technological changes and innovation are the thrust of industrialization and development but it comes at the cost of a mounting and invisible water pollution crisis. Water is not only crucial for human survival but also forms the basis of certain socio-economic developments. The persistent cocktail of pollutants like dyes, pesticides, aromatic hydrocarbons and pharmaceuticals are to blame for the water quality deterioration. Thus, the ever-increasing release of these pollutants into the water streams is of prime international concern and has attracted the attention of the scientific fraternity. The discharged wastewater not only damages the ecosystem but also causes serious harm to mankind and aquatic life. Therefore, the need of the hour is to design lucrative, eco-friendly and sustainable technologies that completely remove or degrade these organic pollutants from water. Much of the research endeavors of scientists working in the bourgeoning arena of environmental remediation have been directed in this area. ${ }^{216,217}$ In this regard, magnetic MOF composite-based catalysts have appeared as a viable solution for accomplishing the proper and absolute degradation of organic pollutants into non-toxic groups. In light of this, Cai and co-workers fabricated a yolk-shell structured composite in which core-shell Pd@ $\mathrm{Fe}_{3} \mathrm{O}_{4}$ NPs were wrapped with a hollow Fe-MOF shell under solvothermal conditions with heating at $100{ }^{\circ} \mathrm{C}$ for 6 h. $^{218}$ They subsequently investigated its catalytic prospects in the $\mathrm{H}_{2} \mathrm{O}_{2}$-assisted Fenton-like degradation of chlorophenols and phenols from water samples. Use of HR-TEM indicated the uniform distribution of $\mathrm{Fe}_{3} \mathrm{O}_{4}$ and Pd NPs in the Fe-MOF shell. It was further revealed that the presence of cavities in the yolkshell structure of $\mathrm{Pd@Fe} \mathrm{O}_{4} @ \mathrm{MOF}$ enabled a faster reactant diffusion rate, thereby enhanced the overall catalytic efficiency of the composite. The reactive oxygen species in the sample were detected using electron spin resonance spin-trap and continuousflow chemiluminescence techniques. Besides, the outstanding catalytic activity of the composite was ascribed to the faster and continuous production of hydroxyl radicals, which led to the complete degradation and mineralization of pollutants.

Nevertheless, use of solar energy irradiation has emerged as a potentially promising solution for tackling water pollutionrelated issues. Since Fujishima and Honda reported the earliest example of an artificial photocatalytic system, numerous photoactive materials, such as $\mathrm{ZnO}, \mathrm{CdS}$, and $\mathrm{ZnS}$, have been reported for the photodegradation of organic pollutants. ${ }^{219}$ Nonetheless, these conventional inorganic semiconductorbased photomaterials not only suffer from low solar energy conversion efficiency, photocorrosion, and agglomeration but also lead to difficulty in separation and recycling. In recent years, use of MOFs as active photocatalysts has garnered considerable attention from scientists across the globe as evident from some critical reviews already reported in the literature. ${ }^{12,26}$ In order to drive photocatalytic reactions, different functional units are incorporated into MOFs, which apart from harvesting light energy also simultaneously catalyze the reaction. MOFs offer an additional advantage of excitation via metal-oxo clusters and ligand-to-metal charge transfer. ${ }^{220-222}$ Furthermore, integrating the superb properties of MOFs with magnetic materials smartly overcomes the post-separation problems via magnetic attraction.

Considering the immense benefits of MOFs in the field of photocatalysis, Qiu and co-workers reported a novel and magnetic recyclable $\mathrm{Fe}_{3} \mathrm{O}_{4} @ \mathrm{MIL}-100(\mathrm{Fe})$-based photocatalyst (Fig. 17A) and studied its photocatalytic activity in methylene blue degradation. ${ }^{223}$ Firstly, ferrite NPs prepared solvothermally were modified using MAA. Then, MAA-functionalized ferrite NPs were dispersed in a solution containing ferric chloride and $\mathrm{H}_{3} \mathrm{BTC}$ under ultrasonication. After repeating a number of cycles, core-shell-structured $\mathrm{Fe}_{3} \mathrm{O}_{4} @ \mathrm{MIL}-100(\mathrm{Fe})$ was obtained. SEM and TEM analysis clearly showed the

(A)

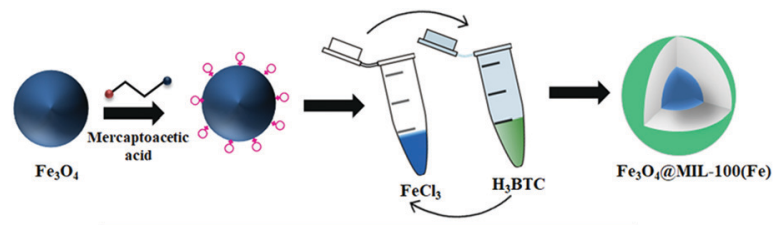

(B)

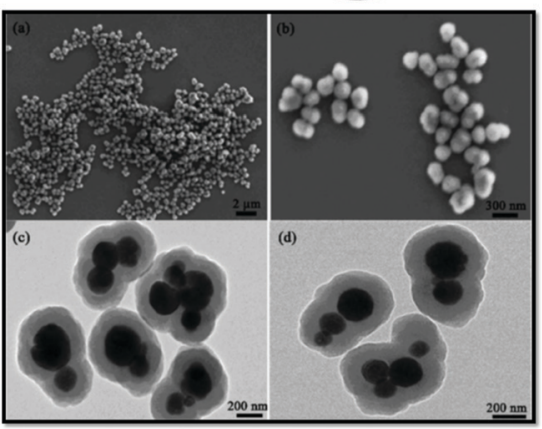

Fig. 17 (A) Schematic representation showing construction of $\mathrm{Fe}_{3} \mathrm{O}_{4} \mathrm{C}$ MIL-100(Fe)-based photocatalyst. (B) SEM and TEM micrographs of core-shell $\mathrm{Fe}_{3} \mathrm{O}_{4} \mathrm{QMIL}-100$ (Fe) acquired after 50 cycles. Reproduced with permission from ref. 223. Copyright 2013 Royal Society of Chemistry. 


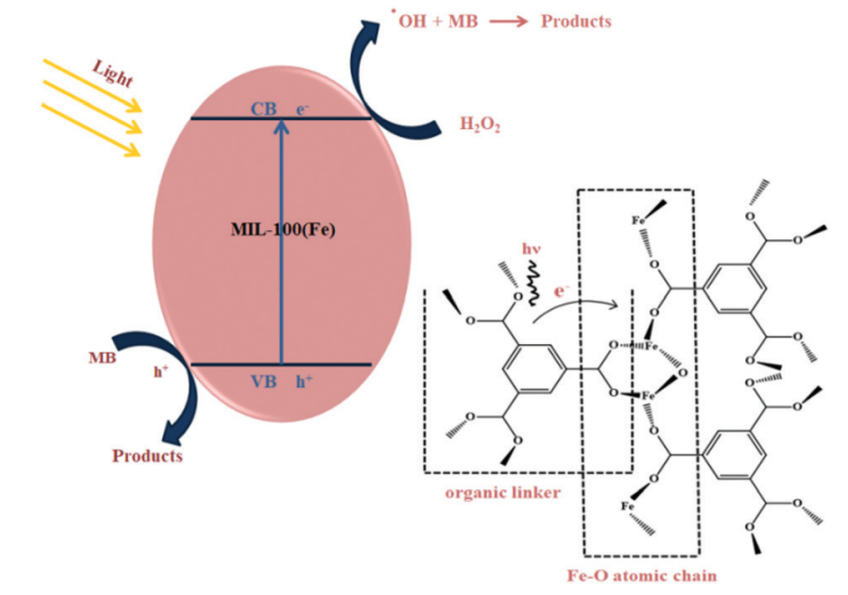

Scheme 35 Diagrammatic representation exhibiting MIL-100(Fe) photocatalyst-assisted methylene blue (MB) degradation along with electron transfer phenomenon under light irradiation.

spherical and monodisperse nature of the ferrite NPs (Fig. 17B). Additionally, these micrographs also revealed the core-shell morphological structure of the synthesized nanocatalyst as having a ferrite core and a MOF shell. The results disclosed the astonishing photocatalytic activity of $\mathrm{Fe}_{3} \mathrm{O}_{4} @$ @IL-100(Fe) in both visible and UV-visible irradiation (Scheme 35). It was perceived that the photodegradation efficiency of methylene blue increased when $\mathrm{Fe}_{3} \mathrm{O}_{4} @ \mathrm{MIL}-100(\mathrm{Fe})$ was used in conjunction with $\mathrm{H}_{2} \mathrm{O}_{2}$. The obtained results were ascribed to the electron acceptor properties of $\mathrm{H}_{2} \mathrm{O}_{2}$ suppressing the electron-hole pair recombination tendency and increasing the overall photodegradation efficiency. MIL-100(Fe) functioned like a semiconductor as it possesses an empty d metal orbital that mixes with the LUMO of the organic ligand to yield the conduction band. The overall mechanism was inferred on the basis of the electron excitation from valence to conduction band on irradiation with light and holes got automatically generated in the valence band. The photoinduced transference of electrons transformed $\mathrm{H}_{2} \mathrm{O}_{2}$ into hydroxyl radicals $(\mathrm{OH})$, thereby hampering the recombination phenomenon of electrons and holes. The generated holes and hydroxyl radicals altogether possessed strong oxidizing ability and further reacted to oxidize adsorbed methylene molecules. Additionally, the designed composite presented favorable magnetic properties, as a consequence of which it was facilely separated via an external magnet, thus making it an admirable prospect for developing active photocatalysts working within the visible light range for organic pollutant degradation.

A new multifunctional MOF heterostructure (MHMC) comprising of 1-D MIL-53(Fe) microrods and $\mathrm{Fe}_{3} \mathrm{O}_{4}$ nanospheres was fabricated and achieved impressive photocatalytic performance for the degradation of Rhodamine $\mathrm{B}$ and $p$-nitrophenol. ${ }^{149} \mathrm{H}_{2} \mathrm{O}_{2}$-assisted photodegradation studies were conducted using a $500 \mathrm{~W}$ halogen tungsten lamp in a cylindrical Pyrex vessel reactor. Experimental results revealed that with the addition of just a small amount of $\mathrm{H}_{2} \mathrm{O}_{2}$, the developed heterostructure resulted in outstanding photocatalytic efficiency for
Rhodamine B and $p$-nitrophenol degradation under visible light irradiation. The results with MOF-based materials were much superior to those with $\mathrm{Fe}_{2} \mathrm{O}_{3^{-}}$and $\mathrm{Fe}_{3} \mathrm{O}_{4}$-based photocatalysts, further providing a perfect exemplar for large-scale industrial applications.

Amongst emerging contaminants, diclofenac sodium (DCF), a non-steroidal anti-inflammatory drug (NSAID), has been massively sold across the globe. Due to its high consumption, it is often detected at high levels in surface, ground and waste water. Considering the alarming situation, effective materials are required for its complete elimination from water streams. Within this perspective, Hou et al. described the fabrication of an $\mathrm{Fe}_{3} \mathrm{O}_{4} @ \mathrm{MIL}-100(\mathrm{Fe})$ composite for the adsorptive removal and photocatalytic degradation of diclofenac sodium from water. ${ }^{224}$ The overall composite was synthesized by taking $\mathrm{Fe}_{3} \mathrm{O}_{4}$ NPs as the metal antecedent and $\mathrm{H}_{3} \mathrm{BTC}$ as the organic linker. After irradiating the overall solution by microwave at $150{ }^{\circ} \mathrm{C}$ for $30 \mathrm{~min}$, an orange-brown solid material was formed, which after washing with water yielded the final $\mathrm{Fe}_{3} \mathrm{O}_{4} @ M I L-$ $100(\mathrm{Fe})$. The developed material not only demonstrated outstanding adsorption capacity for DCF, but also resulted in its 99\% degradation with $\mathrm{H}_{2} \mathrm{O}_{2}$ under visible light. The high photocatalytic efficacy was accredited to the distinctive structure of $\mathrm{Fe}_{3} \mathrm{O}_{4} @ \mathrm{MIL}-100(\mathrm{Fe})$ and the simultaneous presence of $\mathrm{H}_{2} \mathrm{O}_{2}$. The metal centers or nodes present in the MOF behaved as semiconductor dots while the charges (holes and electrons) formed in the separation state in visible light migrated to the surface of the MOF. The as produced electrons and holes further reacted with DCF and catalyzed its degradation. It is worth appreciating that the authors proposed a plausible degradation route for diclofenac degradation using the $\mathrm{Fe}_{3} \mathrm{O}_{4}$ @ MIL-100(Fe) $/ \mathrm{H}_{2} \mathrm{O}_{2}$ system in visible light.

In another report, the He research group described the onepot fabrication of a magnetic MIL-100(Fe) composite at room temperature. ${ }^{225}$ The catalytic potency of the resulting material was evaluated in the industrially demanding degradation of sodium sulfadiazine. Degradation experiments were conducted in the presence of $\mathrm{H}_{2} \mathrm{O}_{2}$ under a solar simulator with a $300 \mathrm{~W}$ xenon lamp. The experimental results highlighted the fact that the morphology of the designed catalyst, i.e., $\mathrm{Fe}_{3} \mathrm{O}_{4}$ nanorods, considerably accelerated its catalytic efficiency. Besides this, the designed photocatalyst was facilely retrieved and recycled for five photodegradation runs without undergoing any diminution in its activity. Thus, the saliently designed magnetic MOF composites that combine activity, selectivity and magnetic retrievability on a single platform appear to be a practicable and sustainable solution for large-scale environmental remediation. Song et al. for the very first time introduced a ternary $\mathrm{Fe}_{3} \mathrm{O}_{4} @ \mathrm{Au} @ M I L-100(\mathrm{Fe})$ catalyst for the photoinduced oxidation of 3,3,5,5-tetramethylbenzidine (TMB) and $o$-phenylene diamine. ${ }^{226}$ Fabrication of the overall catalyst commenced with the seed-mediated growth of Au NPs on amine-terminated $\mathrm{Fe}_{3} \mathrm{O}_{4}$ NPs (generated using APTES), which after modification with MAA were repeatedly dispersed in $\mathrm{FeCl}_{3}$ and $\mathrm{H}_{3} \mathrm{BTC}$ solution for 10 cycles to produce $\mathrm{Fe}_{3} \mathrm{O}_{4} @ A u @ M I L-100(\mathrm{Fe})$ composite (Scheme 36). The $\mathrm{H}_{2} \mathrm{O}_{2}$-mediated photocatalytic 


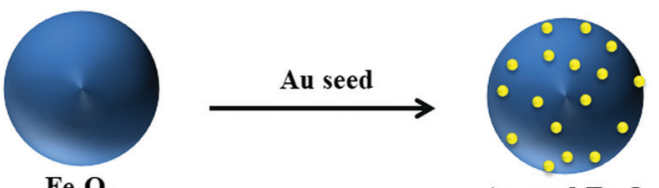

$\mathrm{Fe}_{3} \mathrm{O}_{4}$

Au-seed $\mathrm{Fe}_{3} \mathrm{O}_{4}$

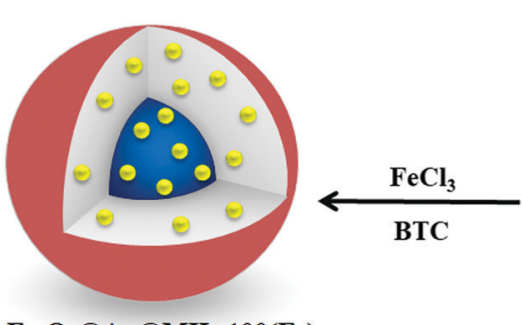

$\mathrm{Fe}_{3} \mathrm{O}_{4} @ \mathrm{Au} @ \mathrm{MIL}-100(\mathrm{Fe})$

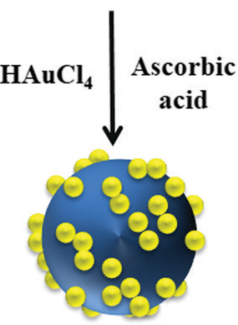

$\mathrm{Fe}_{3} \mathrm{O}_{4} @ \mathrm{Au}$

Scheme 36 Schematic representation showing fabrication pathway for magnetic MOF composite-based nanocatalyst.

oxidation of both the substrates was successfully accomplished via the aid of ascorbic acid and photoirradiation for $60 \mathrm{sec}$. Furthermore, the complete catalytic process was effectively monitored through UV-visible and surface-enhanced Raman scattering (SERS) spectroscopic studies. Additionally, comparative studies devoid of a photo-assisted route for the oxidation of TMB were also conducted and splendidly highlighted the enhanced and accelerated oxidation rate achieved in the case of the photoinduced process.

\subsection{Biocatalysts}

The development of greener and environmentally sound synthetic protocols is one of the major goals to be accomplished in modern organic synthesis. Use of natural enzymes as biocatalysts for catalyzing various organic reactions appears to be a rational solution for switching towards energy-efficient and sustainable processes. Biocatalysis using enzymes is an attractive strategy that not only combines high selectivity and reactivity on a single platform but also minimizes energy input and waste. However, working with natural enzymes in organic solvents is not only challenging but also sometimes problematic. Besides this, poor thermal stability, short-term operational stability, and difficulty in recovering these enzymes further aggravate the problem to a large extent. ${ }^{227}$ Thus, immobilization of enzymes onto solid support materials, such as magnetic MOF composites, has proven to be an appealing strategy that smartly outwits the shortcomings associated with working with natural enzymes. The encapsulation or immobilization methodology renders the resulting material with enhanced activity and stability necessary to withstand the reaction conditions during catalytic processes.

It is worth mentioning here that Bradshaw and co-workers designed a synthetic route for stabilizing functional molecules such as Candida antarctica lipase B (CalB) enzyme within hierarchically porous MOF capsules. ${ }^{228}$ In this approach, both UiO-66 and $\mathrm{Fe}_{3} \mathrm{O}_{4}$ functionalized with heptanoic acid were synthesized using a post-ligand exchange strategy. Afterwards, Hep-UiO-66 and $\mathrm{Hep}-\mathrm{Fe}_{3} \mathrm{O}_{4}$ were dispersed under ultrasonication

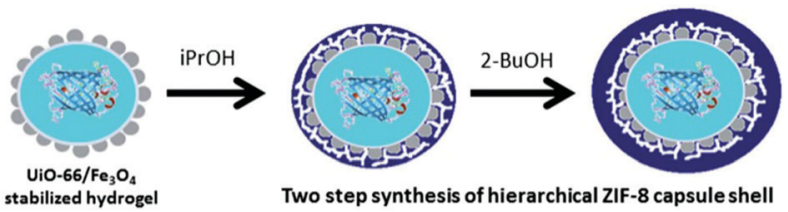

Scheme 37 Illustration depicting fabrication of magnetic MOF composite-based microcapsules. Reproduced with permission from ref. 228 . Copyright 2015 Royal Society of Chemistry.

in liquid paraffin and then mixed with agarose solution in PBS (phosphate-buffered saline) under stirring for $2 \mathrm{~min}$. It was perceived that both UiO-66 and $\mathrm{Fe}_{3} \mathrm{O}_{4}$ acted as templates for stabilizing agarose hydrogel droplets around which another shell of ZIF-8 was deposited. A secondary ZIF-8 shell was then formed by immersing UiO-66/ $/ \mathrm{Fe}_{3} \mathrm{O}_{4} /$ agarose solution in an isopropanol solution of zinc nitrate and 2-methylimidazole and keeping the stock solution at $-20{ }^{\circ} \mathrm{C}$ for $2 \mathrm{~h}$. The aforesaid protocol was repeated again using 2-butanol instead of isopropanol, which led to the formation of a dense ZIF- 8 microcapsule shell on the exterior of the UiO-66/ $\mathrm{Fe}_{3} \mathrm{O}_{4}$ hydrogel core (Scheme 37).

The hydrogel core served the purpose of encapsulating enzymes required to carry out biocatalysis while the MNPs resulted in facile separation via external magnetic forces. Various biomolecules or enzymes, such as green fluorescent protein (GFP), Candida antarctica lipase B (CalB) and galactosidase, were encapsulated by the authors in agarose hydrogels before establishment of the shell. The catalytic potential of CalB loaded on microcapsules was investigated in size-selective biocatalytic transesterification between pairs of small substrates (1-butanol and vinyl acetate to form butyl acetate) and pairs of large substrates (3-(4-hydroxyphenyl)propan-1-ol and vinyl laurate to form 3-(4hydroxyphenyl)propyl dodecanoate). The presented structural magnetic MOF-enzyme composite paved the way for designing such newer materials with wider prospects in chemoenzymatic catalysis, drug delivery, bioseparation and biodegradation fields.

Lv et al. also fabricated three recyclable multienzyme magnetic MOF composites by employing a layer-by-layer assembly approach in which glucose oxidase (GOx) and horseradish peroxidase (HRP) were spatially confined within the pores of a magnetic HKUST-1 MOF heterostructure. ${ }^{100}$ The catalytic potency of three designed nanocomposites, GOx@HRP@HKUST-1@ $\mathrm{Fe}_{3} \mathrm{O}_{4}$, GOx-HRP@HKUST-1@Fe $\mathrm{O}_{4}$ and HRP@GOx@HKUST-1@Fe $\mathrm{O}_{4}$, was further evaluated in the cascade catalysis of glucose and $o$-phenylenediamine as representative substrates. In the cascade reaction, GOx first executed glucose oxidation to gluconic acid and $\mathrm{H}_{2} \mathrm{O}_{2}$ followed by the decomposition of $\mathrm{H}_{2} \mathrm{O}_{2}$ into water and oxygen mediated by HRP. Amongst the three systems, GOx@ HRP@HKUST-1@ $\mathrm{Fe}_{3} \mathrm{O}_{4}$ exhibited the highest catalytic activity with 100\% glucose conversion within $15 \mathrm{~h}$ while HRP@GOx@ HKUST-1@Fe $\mathrm{O}_{3}$ demonstrated higher thermal and chemical stability. Besides, magnetic retrievability and high operational stability were some of the fascinating features of the designed magnetic MOF-enzyme composite that make it particularly attractive for use in artificial biomimetic reactor-driven processes in intracellular and extracellular biosynthesis. 
a)
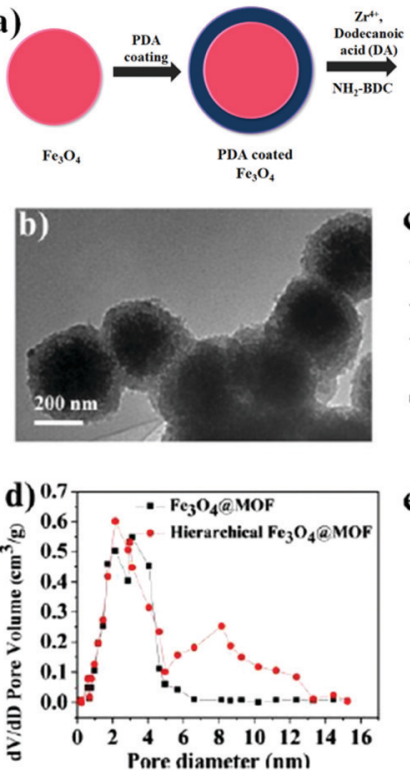
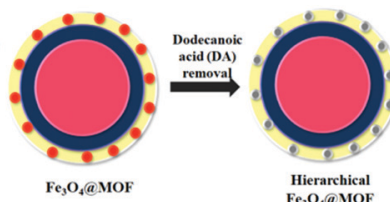

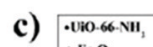

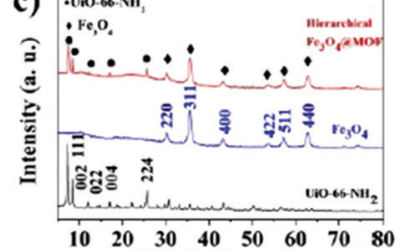

e)

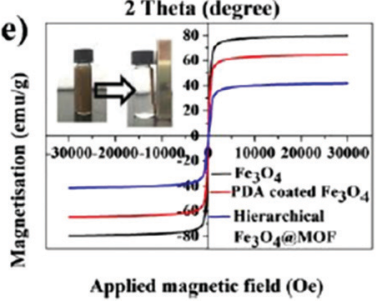

Fig. 18 (a) Fabrication of hierarchical $\mathrm{Fe}_{3} \mathrm{O}_{4}$ (aMOF, (b) TEM image of $\mathrm{Fe}_{3} \mathrm{O}_{4} \mathrm{QMOF}$, (c) XRD patterns, (d) pore size distribution and (e) VSM curves of synthesized materials. Reproduced with permission from ref. 229. Copyright 2019 Royal Society of Chemistry.

Zheng and his colleagues synthesized a novel porous magnetic MOF-enzyme composite using a modular-induced defectformation approach. ${ }^{229}$ In this, $\mathrm{Fe}_{3} \mathrm{O}_{4}$ NPs synthesized via a solvothermal approach were first coated with PDA to induce the growth of the UiO-66- $\mathrm{NH}_{2}$ MOF shell by the addition of $\mathrm{ZrCl}_{4}$ as the metal progenitor, 2-aminoterephthalic acid as the ligand and dodecanoic acid (DA) as the modulator. The subsequent heat treatment at $100{ }^{\circ} \mathrm{C}$ for $3 \mathrm{~h}$ and $130{ }^{\circ} \mathrm{C}$ for $24 \mathrm{~h}$ generated $\mathrm{Fe}_{3} \mathrm{O}_{4} @ \mathrm{MOF}$, which after the elimination of the competitive ligand, i.e., dodecanoic acid, under $\mathrm{HCl}$ treatment at $90{ }^{\circ} \mathrm{C}$ for $24 \mathrm{~h}$ led to the formation of hierarchical $\mathrm{Fe}_{3} \mathrm{O}_{4} @ \mathrm{MOF}$ with numerous mesopores (Fig. 18). Once the core-shell $\mathrm{Fe}_{3} \mathrm{O}_{4} @$ MOF was synthesized, an enzyme amidase was covalently immobilized on it using phosphate buffer and glutaraldehyde as the cross linking agent with continuous stirring at $25{ }^{\circ} \mathrm{C}$ for $3 \mathrm{~h}$.

The developed catalyst was systematically characterized using sophisticated XRD, TEM, $\mathrm{N}_{2}$ adsorption-desorption and VSM techniques. The catalytic potency of the resulting material was investigated in the synthesis of $(S)$-4-fluorophenylglycine from varying concentrations of N-phenylacetyl-4-fluorophenylglycine. When the reaction was performed at $\mathrm{pH} 9$ for $2 \mathrm{~h}$ at $40{ }^{\circ} \mathrm{C}$ and at variable substrate concentrations of 60,80 and $100 \mathrm{mM}$, a good conversion of $49.9 \%$ with $99.9 \%$ enantiomeric excess (ee) was obtained. Apart from this, the authors also prepared a sequence of controlled magnetic MOF composites, namely $\mathrm{Fe}_{3} \mathrm{O}_{4} @\left[\mathrm{Cu}_{3}(\mathrm{btc})_{2}\right], \mathrm{Fe}_{3} \mathrm{O}_{4} @$ @IL-100(Fe) and $\mathrm{Fe}_{3} \mathrm{O}_{4} @ \mathrm{ZIF}-8$, and examined their enzyme loading potential under similar conditions. High thermal and storage stability, good catalytic activity, better organic solvent tolerance, strong magnetic responsiveness, reusability and retention of relative activity

up to $98.2 \%$ even after 15 runs further added to the significance of the protocol.

\section{Conclusions and future outlook}

Designing intriguing and multifunctional architectures such as magnetic MOF composites is a burgeoning field of importance. The superb integration of MNPs with the remarkable characteristics of MOFs promotes the successful fabrication of newer synthetic composites that possess innovative, additive and complementarily enhanced properties in comparison to the one-component counterparts. Despite a short history, impressive advancements related to the construction of magnetic MOF composites have been witnessed during the past few years. Furthermore, magnetic MOF composites have evolved as a brilliant star in modern material science and engineering owing to their broad and extensive applications in catalysis, environmental remediation, drug delivery, sensing and device fabrication. Amongst various arenas, catalysis represents one of the most vibrant and dynamic sectors for magnetic MOF composites and has become an exciting research area. Driven by the global drive towards energy miniaturization, particular efforts of the research fraternity are made towards designing novel magnetic MOF composites as effectual catalysts for several industrially significant organic transformations. This review showcased scientific research-based progression attained in the domain of magnetic MOF composites by compiling all the routes employed to date for their fabrication. The synthetic section provided a detailed overview of these methodologies, including layer-by-layer, embedding, encapsulation and mixing along with a brief description of characterizations. Reports on the utilization of magnetic MOF composites for successfully establishing a broad array of organic reactions, including oxidation, hydrogenation, coupling, condensation, esterification and multicomponent coupling, have also been summarized. In addition, recent progress in the budding and proliferating field of photocatalysis and biocatalysis has also been reviewed. It is noteworthy that promising catalytic efficacy with facile recovery and recyclability has been achieved on a single platform by the design of these phenomenal magnetic MOF composites. Although striking and noteworthy results have been achieved in terms of their fabrication, characterization and catalytic applications, a few obstacles still need to be conquered to unveil their full potential in other industrially important processes. Firstly, magnetic MOF composites with ameliorated water stability, shelf life and recyclability are highly pertinent in industrial settings while at the same moment reaction kinetics in magnetic MOF composite-catalyzed processes also warrant deep investigation. Furthermore, intricate synthetic procedures, expensive organic ligands and lower production yields make the overall protocols highly exorbitant and thus confine their utility to laboratory scale. Henceforth, their translation from laboratory to industrial scale requires the earnest efforts of material engineers. Taking sustainability into account, future research should focus upon optimization of synthetic routes so that 
magnetic MOF composites can be prepared in a simpler, greener and more lucrative manner. Additionally, an in-depth understanding of their formation processes is highly crucial. Though this challenge is not trivial, cutting-edge systematic studies related to the fundamental growth mechanism are imperative for scrutinizing structure-property relationships as well as for engineering complex magnetic MOF composites that find extensive uses in multifaceted applications. We foresee that computational modeling and simulation studies will also help in understanding and predicting the interaction of magnetic materials with the organic and inorganic components of MOF, which will further help in elucidating the exact mechanism responsible for their formation. Besides, advanced spectroscopic techniques like synchrotron X-ray absorption spectroscopy (STXM) and synchrotron X-ray photoelectron spectroscopy (XPS) in combination with in-operando catalytic experiments can further help in probing the behavior of the active molecular species in the composite material. Magnetic MOF composites is an evolving field with enticing prospects and interfacing it with several frontier areas of biology, medicine, energy, and the environment will certainly broader its horizon in the future. It is believed that with the collective and joint efforts of chemists and industrial engineers, these versatile and hybrid materials could offer advanced platforms for future innovative applications in the areas of imaging, drug delivery, luminescent materials, microoptics, micro-electronics, device fabrication and clinical therapies. Furthermore, it has been rightly said that "Rome was not built in a day", so the scientific community needs to devote immense efforts and additional time to unleash the concealed fascinating properties of magnetic MOF composites that may provide new perspectives for future societal development.

\section{Author contributions}

The manuscript was written by Sneha Yadav and Dr Ranjana Dixit. Editing of the manuscript was done by Shivani Sharma, Sriparna Dutta and Kanika Solanki. Prof. Rakesh K. Sharma designed the framework of the review article, edited the manuscript and provided constructive suggestions. All authors have read and approved the final manuscript.

\section{Conflicts of interest}

There are no conflicts to declare.

\section{Acknowledgements}

Sneha Yadav gratefully acknowledges the Council of Scientific \& Industrial Research, New Delhi, India for the award of a Senior Research Fellowship.

\section{Notes and references}

1 D. J. Tranchemontagne, J. L. Mendoza-Cortés, M. O'Keeffe and O. M. Yaghi, Chem. Soc. Rev., 2009, 38, 1257-1283.
2 K. E. Cordova and O. M. Yaghi, Mater. Chem. Front., 2017, 1, 1304-1309.

3 N. R. Catarineu, A. Schoedel, P. Urban, M. B. Morla, C. A. Trickett and O. M. Yaghi, J. Am. Chem. Soc., 2016, 138, 10826-10829.

4 D. Zacher, R. Schmid, C. Woell and R. A. Fischer, Angew. Chem., Int. Ed., 2011, 50, 176-199.

5 J. Lee, O. K. Farha, J. Roberts, K. A. Scheidt, S. T. Nguyen and J. T. Hupp, Chem. Soc. Rev., 2009, 38, 1450-1459.

6 A. U. Czaja, N. Trukhan and U. Müller, Chem. Soc. Rev., 2009, 38, 1284-1293.

7 A. Aijaz, T. Akita, N. Tsumori and Q. Xu, J. Am. Chem. Soc., 2013, 135, 16356-16359.

8 P. Hu, J. V. Morabito and C.-K. Tsung, ACS Catal., 2014, 4, 4409-4419.

9 H. Fei, M. D. Sampson, Y. Lee, C. P. Kubiak and S. M. Cohen, Inorg. Chem., 2015, 54, 6821-6828.

10 X. Zhu, B. Li, J. Yang, Y. Li, W. Zhao, J. Shi and J. Gu, ACS Appl. Mater. Interfaces, 2015, 7, 223-231.

11 J.-R. Li, J. Sculley and H.-C. Zhou, Chem. Rev., 2012, 112, 869-932.

12 A. López-Magano, A. Jiménez-Almarza, J. Alemán and R. Mas-Ballesté, Catalysts, 2020, 10, 720.

13 M. Liu, J. Wu and H. Hou, Chem. - Eur. J., 2019, 25, 2935-2948.

14 A. Dhakshinamoorthy, Z. Li and H. Garcia, Chem. Soc. Rev., 2018, 47, 8134-8172.

15 V. Pascanu, G. González Miera, A. K. Inge and B. n. MartínMatute, J. Am. Chem. Soc., 2019, 141, 7223-7234.

$16 \mathrm{~J}$. Gascon, A. Corma, F. Kapteijn and F. X. Llabres i Xamena, ACS Catal., 2014, 4, 361-378.

17 S. M. Rogge, A. Bavykina, J. Hajek, H. Garcia, A. I. OlivosSuarez, A. Sepúlveda-Escribano, A. Vimont, G. Clet, P. Bazin, F. Kapteijn, M. Daturi, E. V. Ramos-Fernandez, F. X. Llabrés i Xamena, V. V. Speybroeck and J. Gascon, Chem. Soc. Rev., 2017, 46, 3134-3184.

18 J. Liu, L. Chen, H. Cui, J. Zhang, L. Zhang and C.-Y. Su, Chem. Soc. Rev., 2014, 43, 6011-6061.

19 R. J. Kuppler, D. J. Timmons, Q.-R. Fang, J.-R. Li, T. A. Makal, M. D. Young, D. Yuan, D. Zhao, W. Zhuang and H.-C. Zhou, Coord. Chem. Rev., 2009, 253, 3042-3066.

20 Q. Yang, Q. Xu and H.-L. Jiang, Chem. Soc. Rev., 2017, 46, 4774-4808.

21 J.-S. Qin, S. Yuan, C. Lollar, J. Pang, A. Alsalme and H.-C. Zhou, Chem. Commun., 2018, 54, 4231-4249.

22 S. Yang, L. Peng, D. T. Sun, M. Asgari, E. Oveisi, O. Trukhina, S. Bulut, A. Jamali and W. L. Queen, Chem. Sci., 2019, 10, 4542-4549.

23 A. Dhakshinamoorthy, A. M. Asiri and H. Garcia, Chem. Commun., 2017, 53, 10851-10869.

24 L. Chen and Q. Xu, Matter, 2019, 1, 57-89.

25 S. Yuan, L. Feng, K. Wang, J. Pang, M. Bosch, C. Lollar, Y. Sun, J. Qin, X. Yang and P. Zhang, Adv. Mater., 2018, 30, 1704303.

26 X. Deng, Z. Li and H. García, Chem. - Eur. J., 2017, 23, 11189-11209. 
27 N. C. Burtch, J. Heinen, T. D. Bennett, D. Dubbeldam and M. D. Allendorf, Adv. Mater., 2018, 30, 1704124.

28 Y. J. Ma, X. X. Jiang and Y. K. Lv, Chem. - Asian J., 2019, 14, 3515-3530.

29 Q.-L. Zhu and Q. Xu, Chem. Soc. Rev., 2014, 43, 5468-5512.

30 M. Aghayi-Anaraki and V. Safarifard, Eur. J. Inorg. Chem., 2020, 1916-1937.

31 R. Ricco, L. Malfatti, M. Takahashi, A. J. Hill and P. Falcaro, J. Mater. Chem. A, 2013, 1, 13033-13045.

32 P. Silva, S. M. Vilela, J. P. Tomé and F. A. A. Paz, Chem. Soc. Rev., 2015, 44, 6774-6803.

33 G. M. Espallargas and E. Coronado, Chem. Soc. Rev., 2018, 47, 533-557.

34 P. Falcaro, R. Ricco, A. Yazdi, I. Imaz, S. Furukawa, D. Maspoch, R. Ameloot, J. D. Evans and C. J. Doonan, Coord. Chem. Rev., 2016, 307, 237-254.

35 R. Lin, L. Ge, H. Diao, V. Rudolph and Z. Zhu, J. Mater. Chem. A, 2016, 4, 6084-6090.

36 C. Jo, H. J. Lee and M. Oh, Adv. Mater., 2011, 23, 1716-1719.

37 J. Nan, X. Dong, W. Wang, W. Jin and N. Xu, Langmuir, 2011, 27, 4309-4312.

38 A. Huang, W. Dou and J. r. Caro, J. Am. Chem. Soc., 2010, 132, 15562-15564.

39 S. Zhang, Q. Yang, W. Wang, C. Wang and Z. Wang, J. Agric. Food Chem., 2016, 64, 2792-2801.

40 X. Qiu, X. Wang and Y. Li, Chem. Commun., 2015, 51, 3874-3877.

41 L.-Q. Yu and X.-P. Yan, Chem. Commun., 2013, 49, 2142-2144.

42 J. K. Bristow, K. T. Butler, K. L. Svane, J. D. Gale and A. Walsh, J. Mater. Chem. A, 2017, 5, 6226-6232.

43 Y. Yang, F. Xia, Y. Yang, B. Gong, A. Xie, Y. Shen and M. Zhu, J. Mater. Chem. B, 2017, 5, 8600-8606.

44 T. Wehner, K. Mandel, M. Schneider, G. Sextl and K. Müller-Buschbaum, ACS Appl. Mater. Interfaces, 2016, 8, 5445-5452.

45 L. M. Rossi, N. J. Costa, F. P. Silva and R. Wojcieszak, Green Chem., 2014, 16, 2906-2933.

46 S. Singamaneni, V. N. Bliznyuk, C. Binek and E. Y. Tsymbal, J. Mater. Chem., 2011, 21, 16819-16845.

47 N. A. Frey, S. Peng, K. Cheng and S. Sun, Chem. Soc. Rev., 2009, 38, 2532-2542.

48 Y. Chen, X. Huang, X. Feng, J. Li, Y. Huang, J. Zhao, Y. Guo, X. Dong, R. Han, P. Qi, Y. Han, H. Li, C. Hu and B. Wang, Chem. Commun., 2014, 50, 8374-8377.

49 R. Ma, P. Yang, Y. Ma and F. Bian, ChemCatChem, 2018, 10, 1446-1454.

50 M. B. Gawande, P. S. Branco and R. S. Varma, Chem. Soc. Rev., 2013, 42, 3371-3393.

51 I. Ahmed and S. H. Jhung, Mater. Today, 2014, 17, 136-146.

52 M. Iranmanesh and J. Hulliger, Chem. Soc. Rev., 2017, 46, 5925-5934.

53 P. Falcaro, F. Lapierre, B. Marmiroli, M. Styles, Y. Zhu, M. Takahashi, A. J. Hill and C. M. Doherty, J. Mater. Chem. C, 2013, 1, 42-45.
54 G. M. Lari, G. Pastore, M. Haus, Y. Ding, S. Papadokonstantakis, C. Mondelli and J. Pérez-Ramírez, Energy Environ. Sci., 2018, 11, 1012-1029.

55 M. Babazadeh, R. Hosseinzadeh-Khanmiri, J. Abolhasani, E. Ghorbani-Kalhor and A. Hassanpour, $R S C A d v$., 2015, 5, 19884-19892.

56 R. K. Sharma, S. Yadav, S. Sharma, S. Dutta and A. Sharma, ACS Omega, 2018, 3, 15100-15111.

57 G. Gao, J.-Q. Di, H.-Y. Zhang, L.-P. Mo and Z.-H. Zhang, J. Catal., 2020, 387, 39-46.

58 A. Ghorbani-Choghamarani and Z. Taherinia, ACS Comb. Sci., 2020, 22, 902-909.

59 C. S. Yan, H. Y. Gao, L. F. Ma, L. L. Dang, L. Zhang, P. P. Meng and F. Luo, J. Mater. Chem. A, 2016, 4, 13603-13610.

60 W. Li, K. Wang, X. Yang, F. Zhan, Y. Wang, M. Liu, X. Qiu, J. Li, J. Zhan, Q. Li and Y. Liu, Chem. Eng. J., 2020, 379, 122256.

61 Y. Xiong, F. Ye, C. Zhang, S. Shen, L. Su and S. Zhao, RSC Adv., 2015, 5, 5164-5172.

62 T. Saemian, M. Gharagozlou, M. H. Sadr and S. Naghibi, Polyhedron, 2019, 174, 114163.

63 M. Attia, N. McMahon, H. Li, R.-B. Lin, F. DeLuna, Y. Shi, B. Chen and J. Y. Ye, J. Solid State Chem., 2020, 283, 121127.

64 L. Nirumand, S. Farhadi, A. Zabardasti and A. Khataee, J. Taiwan Inst. Chem. Eng., 2018, 93, 674-685.

65 F. Siadatnasab, S. Farhadi, A.-A. Hoseini and M. Sillanpää, New J. Chem., 2020, 44, 16234-16245.

66 L. Melag, M. M. Sadiq, K. Konstas, F. Zadehahmadi, K. Suzuki and M. R. Hill, RSC Adv., 2020, 10, 40960-40968.

67 M. Heydari, M. Gharagozlou, M. Ghahari and S. Naghibi, Appl. Organomet. Chem., 2020, 34, e5994.

68 S. Bahrani, M. Ghaedi, K. Dashtian, A. Ostovan, M. J. K. Mansoorkhani and A. Salehi, J. Chromatogr. B: Anal. Technol. Biomed. Life Sci., 2017, 1067, 45-52.

69 J. J. Lenders, C. L. Altan, P. H. Bomans, A. Arakaki, S. Bucak, G. de With and N. A. Sommerdijk, Cryst. Growth Des., 2014, 14, 5561-5568.

70 H.-J. Song, X.-H. Jia and X.-Q. Zhang, J. Mater. Chem., 2012, 22, 22699-22705.

71 N. R. Jana, Y. Chen and X. Peng, Chem. Mater., 2004, 16, 3931-3935.

72 R. Abu-Much and A. Gedanken, J. Phys. Chem. C, 2008, 112, 35-42.

73 H. Cui, Y. Liu and W. Ren, Adv. Powder Technol., 2013, 24, 93-97.

74 T. J. LaTempa, X. Feng, M. Paulose and C. A. Grimes, J. Phys. Chem. C, 2009, 113, 16293-16298.

75 O. Pascu, E. Carenza, M. Gich, S. n. Estradé, F. Peiró, G. Herranz and A. Roig, J. Phys. Chem. C, 2012, 116, 15108-15116.

76 T. Parandhaman, N. Pentela, B. Ramalingam, D. Samanta and S. K. Das, ACS Sustainable Chem. Eng., 2017, 5, 489-501.

77 K. Wongwailikhit and S. Horwongsakul, Mater. Lett., 2011, 65, 2820-2822. 
78 W. Wu, C. Z. Jiang and V. A. Roy, Nanoscale, 2016, 8, 19421-19474.

79 Q. Zhang, X. Yang and J. Guan, ACS Appl. Nano Mater., 2019, 2, 4681-4697.

80 R. K. Sharma, S. Dutta, S. Sharma, R. Zboril, R. S. Varma and M. B. Gawande, Green Chem., 2016, 18, 3184-3209.

81 Y. Liu, J. Goebl and Y. Yin, Chem. Soc. Rev., 2013, 42, 2610-2653.

82 O. Bomatí-Miguel, L. Mazeina, A. Navrotsky and S. Veintemillas-Verdaguer, Chem. Mater., 2008, 20, 591-598.

83 B. S. Kwon, W. Zhang, Z. Li and K. M. Krishnan, Adv. Mater. Interfaces, 2015, 2, 1400511.

84 T. Togashi, S. Takami, K. Kawakami, H. Yamamoto, T. Naka, K. Sato, K. Abe and T. Adschiri, J. Mater. Chem., 2012, 22, 9041-9045.

85 C. Blanco-Andujar, D. Ortega, P. Southern, Q. Pankhurst and N. Thanh, Nanoscale, 2015, 7, 1768-1775.

86 Y. Zhang, M. Liu, B. Peng, Z. Zhou, X. Chen, S.-M. Yang, Z.-D. Jiang, J. Zhang, W. Ren and Z.-G. Ye, Sci. Rep., 2016, 6, 1-8.

87 A. Shelemin, O. Kylián, J. Hanuš, A. Choukourov, I. Melnichuk, A. Serov, D. Slavínská and H. Biederman, Vacuum, 2015, 120, 162-169.

88 H. Aali, S. Mollazadeh and J. V. Khaki, Ceram. Int., 2018, 44, 20267-20274.

89 H. Kloust, R. Zierold, J.-P. Merkl, C. Schmidtke, A. Feld, E. Pöselt, A. Kornowski, K. Nielsch and H. Weller, Chem. Mater., 2015, 27, 4914-4917.

90 M. Jiao, J. Zeng, L. Jing, C. Liu and M. Gao, Chem. Mater., 2015, 27, 1299-1305.

91 E. C. Vreeland, J. Watt, G. B. Schober, B. G. Hance, M. J. Austin, A. D. Price, B. D. Fellows, T. C. Monson, N. S. Hudak, L. Maldonado-Camargo, A. C. Bohorquez, C. Rinaldi and D. L. Huber, Chem. Mater., 2015, 27, 6059-6066.

92 R. Costo, V. Bello, C. Robic, M. Port, J. F. Marco, M. Puerto Morales and S. Veintemillas-Verdaguer, Langmuir, 2012, 28, 178-185.

93 Z. Kozakova, I. Kuritka, N. E. Kazantseva, V. Babayan, M. Pastorek, M. Machovsky, P. Bazant and P. Sáha, Dalton Trans., 2015, 44, 21099-21108.

94 X. Jing, T. Liu, D. Wang, J. Liu and L. Meng, CrystEngComm, 2017, 19, 5089-5099.

95 D. Bonvin, J. A. Bastiaansen, M. Stuber, H. Hofmann and M. M. Ebersold, RSC Adv., 2017, 7, 55598-55609.

96 M. Ognjanović, B. Dojčinović, M. Fabian, D. M. Stanković, J. F. Mariano and B. Antić, Ceram. Int., 2018, 44, 13967-13972.

97 K. V. Manukyan, Y.-S. Chen, S. Rouvimov, P. Li, X. Li, S. Dong, X. Liu, J. K. Furdyna, A. Orlov, G. H. Bernstein, W. Porod, S. Roslyakov and A. S. Mukasyan, J. Phys. Chem. C, 2014, 118, 16264-16271.

98 Y. Chen, Z. Xiong, L. Peng, Y. Gan, Y. Zhao, J. Shen, J. Qian, L. Zhang and W. Zhang, ACS Appl. Mater. Interfaces, 2015, 7, 16338-16347.

99 F. Ke, L.-G. Qiu, Y.-P. Yuan, X. Jiang and J.-F. Zhu, J. Mater. Chem., 2012, 22, 9497-9500.
100 S. Chen, L. Wen, F. Svec, T. Tan and Y. Lv, RSC Adv., 2017, 7, 21205-21213.

101 J. Li, J. Wang, Y. Ling, Z. Chen, M. Gao, X. Zhang and Y. Zhou, Chem. Commun., 2017, 53, 4018-4021.

102 H. Duo, X. Lu, S. Wang, L. Wang, Y. Guo and X. Liang, New J. Chem., 2019, 43, 12563-12569.

103 J.-C. Yang and X.-B. Yin, Sci. Rep., 2017, 7, 1-15.

104 X. Zhao, S. Liu, Z. Tang, H. Niu, Y. Cai, W. Meng, F. Wu and J. P. Giesy, Sci. Rep., 2015, 5, 1-10.

105 C. Hou, Y. Wang, Q. Ding, L. Jiang, M. Li, W. Zhu, D. Pan, H. Zhu and M. Liu, Nanoscale, 2015, 7, 18770-18779.

106 I. A. Senosy, Z.-H. Lu, T. M. Abdelrahman, M.-N. O. Yang, H.-M. Guo, Z.-H. Yang and J.-H. Li, Environ. Sci.: Nano, 2020, 7, 2087-2101.

107 Y. Tao, G. Huang, H. Li and M. R. Hill, ACS Sustainable Chem. Eng., 2019, 7, 13627-13632.

108 F. Ke, L.-G. Qiu and J. Zhu, Nanoscale, 2014, 6, 1596-1601. 109 F. Ke, Y.-P. Yuan, L.-G. Qiu, Y.-H. Shen, A.-J. Xie, J.-F. Zhu, X.-Y. Tian and L.-D. Zhang, J. Mater. Chem., 2011, 21, 3843-3848.

110 M. Saikia, D. Bhuyan and L. Saikia, New J. Chem., 2015, 39, 64-67.

111 A. Mehdinia, D. Jahedi Vaighan and A. Jabbari, ACS Sustainable Chem. Eng., 2018, 6, 3176-3186.

112 M. Bellusci, P. Guglielmi, A. Masi, F. Padella, G. Singh, N. Yaacoub, D. Peddis and D. Secci, Inorg. Chem., 2018, 57, 1806-1814.

113 M. B. Boroujeni, A. Hashemzadeh, M.-T. Faroughi, A. Shaabani and M. M. Amini, RSC Adv., 2016, 6, 100195-100202.

114 H. Li, M. M. Sadiq, K. Suzuki, R. Ricco, C. Doblin, A. J. Hill, S. Lim, P. Falcaro and M. R. Hill, Adv. Mater., 2016, 28, 1839-1844.

115 A. R. Chowdhuri, D. Bhattacharya and S. K. Sahu, Dalton Trans., 2016, 45, 2963-2973.

116 X. Min, W. Yang, Y.-F. Hui, C.-Y. Gao, S. Dang and Z.-M. Sun, Chem. Commun., 2017, 53, 4199-4202.

117 S. Venkateswarlu, A. Panda, E. Kim and M. Yoon, ACS Appl. Nano Mater., 2018, 1, 4198-4210.

118 H. S. Far, M. Hasanzadeh, M. S. Nashtaei, M. Rabbani, A. Haji and B. Hadavi Moghadam, ACS Appl. Mater. Interfaces, 2020, 12, 25294-25303.

119 M. Yadollahi, H. Hamadi and V. Nobakht, Appl. Organomet. Chem., 2019, 33, e4629.

120 Y. Li, Q. Xie, Q. Hu, C. Li, Z. Huang, X. Yang and H. Guo, Sci. Rep., 2016, 6, 1-11.

121 Y. Yan, Y. Lu, B. Wang, Y. Gao, L. Zhao, H. Liang and D. Wu, ACS Appl. Mater. Interfaces, 2018, 10, 26539-26545.

122 Y. Yan, Z. Zheng, C. Deng, X. Zhang and P. Yang, Chem. Commun., 2013, 49, 5055-5057.

123 R. K. Sharma, R. Gaur, M. Yadav, A. Goswami, R. Zbořil and M. B. Gawande, Sci. Rep., 2018, 8, 1-12.

124 D. Zhang, R. Chung, A. B. Karki, F. Li, D. P. Young and Z. Guo, J. Phys. Chem. C, 2010, 114, 212-219.

125 H.-Y. Lee, S.-H. Lee, C. Xu, J. Xie, J.-H. Lee, B. Wu, A. L. Koh, X. Wang, R. Sinclair and S. X. Wang, Nanotechnology, 2008, 19, 165101. 
126 Y. Zhang, J.-Y. Liu, S. Ma, Y.-J. Zhang, X. Zhao, X.-D. Zhang and Z.-D. Zhang, J. Mater. Sci.: Mater. Med., 2010, 21, 1205-1210.

127 H. Liu, P. Hou, W. Zhang and J. Wu, Colloids Surf., A, 2010, 356, 21-27.

128 G. Unsoy, S. Yalcin, R. Khodadust, G. Gunduz and U. Gunduz, J. Nanopart. Res., 2012, 14, 1-13.

129 L. Zang, J. Qiu, X. Wu, W. Zhang, E. Sakai and Y. Wei, Ind. Eng. Chem. Res., 2014, 53, 3448-3454.

130 R. Liu, Y. Guo, G. Odusote, F. Qu and R. D. Priestley, ACS Appl. Mater. Interfaces, 2013, 5, 9167-9171.

131 R. Batul, T. Tamanna, A. Khaliq and A. Yu, Biomater. Sci., 2017, 5, 1204-1229.

132 J. Manna, S. Akbayrak and S. Özkar, Appl. Catal., B, 2017, 208, 104-115.

133 M. Zhao, C. Deng and X. Zhang, Chem. Commun., 2014, 50, 6228-6231.

134 R. Zhang, Z. Wang, Z. Zhou, D. Li, T. Wang, P. Su and Y. Yang, Ind. Eng. Chem. Res., 2019, 58, 3876-3884.

135 A. R. Chowdhuri, T. Singh, S. K. Ghosh and S. K. Sahu, ACS Appl. Mater. Interfaces, 2016, 8, 16573-16583.

136 Y. Xu, J. Jin, X. Li, Y. Han, H. Meng, J. Wu and X. Zhang, J. Sep. Sci., 2016, 39, 3647-3654.

137 Z. Jin, Y. Luan, M. Yang, J. Tang, J. Wang, H. Gao, Y. Lu and G. Wang, RSC Adv., 2015, 5, 78962-78970.

138 M. Zhao, X. Zhang and C. Deng, Chem. Commun., 2015, 51, 8116-8119.

139 Y. Xie and C. Deng, Sci. Rep., 2017, 7, 1-8.

140 J. Zhou, Y. Liang, X. He, L. Chen and Y. Zhang, ACS Sustainable Chem. Eng., 2017, 5, 11413-11421.

141 J. Zhou, P. Wang, C. Wang, Y. T. Goh, Z. Fang, P. B. Messersmith and H. Duan, ACS Nano, 2015, 9, 6951-6960.

142 Q. Yang, J. Wang, X. Chen, W. Yang, H. Pei, N. Hu, Z. Li, Y. Suo, T. Li and J. Wang, J. Mater. Chem. A, 2018, 6, 2184-2192.

143 B. Luo, Q. Chen, J. He, Z. Li, L. Yu, F. Lan and Y. Wu, ACS Sustainable Chem. Eng., 2019, 7, 6043-6052.

144 X. Yue, W. Guo, X. Li, H. Zhou and R. Wang, Environ. Sci. Pollut. Res., 2016, 23, 15218-15226.

145 Q. Yang, Y. Zhu, B. Luo, F. Lan, Y. Wu and Z. Gu, Nanoscale, 2017, 9, 527-532.

146 Z. Miao, X. Shu and D. Ramella, RSC Adv., 2017, 7, 2773-2779.

147 T. Zhang, X. Zhang, X. Yan, L. Kong, G. Zhang, H. Liu, J. Qiu and K. L. Yeung, Chem. Eng. J., 2013, 228, 398-404.

148 J. Li, H. Gao, L. Tan, Y. Luan and M. Yang, Eur. J. Inorg. Chem., 2016, 4906-4912.

149 C. Zhang, L. Ai and J. Jiang, J. Mater. Chem. A, 2015, 3, 3074-3081.

150 H. Li, Q. Li, X. He, N. Zhang, Z. Xu, Y. Wang and Y. Wang, Cryst. Growth Des., 2018, 18, 6248-6256.

151 H. Liu, X. Ren and L. Chen, J. Ind. Eng. Chem., 2016, 34, 278-285.

152 A. Samui, A. R. Chowdhuri, T. K. Mahto and S. K. Sahu, RSC Adv., 2016, 6, 66385-66393.
153 X. Cao, G. Liu, Y. She, Z. Jiang, F. Jin, M. Jin, P. Du, F. Zhao, Y. Zhang and J. Wang, RSC Adv., 2016, 6, 113144-113151.

154 S. Yadav, S. Sharma, S. Dutta, A. Sharma, A. Adholeya and R. K. Sharma, Inorg. Chem., 2020, 59, 8334-8344.

155 M. G. Quesne, F. Silveri, N. H. De Leeuw and C. R. A. Catlow, Front. Chem., 2019, 7, 182.

156 L. Rogers and K. F. Jensen, Green Chem., 2019, 21, 3481-3498.

157 A. Dhakshinamoorthy, A. M. Asiri and H. Garcia, ACS Catal., 2018, 9, 1081-1102.

158 D. Farrusseng, S. Aguado and C. Pinel, Angew. Chem., Int. Ed., 2009, 48, 7502-7513.

159 A. Dhakshinamoorthy, M. Alvaro and H. Garcia, Catal. Sci. Technol., 2011, 1, 856-867.

160 Y.-B. Huang, J. Liang, X.-S. Wang and R. Cao, Chem. Soc. Rev., 2017, 46, 126-157.

161 O. A. Kholdeeva and O. V. Zalomaeva, Coord. Chem. Rev., 2016, 306, 302-330.

162 Z. Guo, B. Liu, Q. Zhang, W. Deng, Y. Wang and Y. Yang, Chem. Soc. Rev., 2014, 43, 3480-3524.

163 P. Zhang, H. Lu, Y. Zhou, L. Zhang, Z. Wu, S. Yang, H. Shi, Q. Zhu, Y. Chen and S. Dai, Nat. Commun., 2015, 6, 1-10.

164 A. Dhakshinamoorthy, M. Alvaro and H. Garcia, J. Catal., 2012, 289, 259-265.

165 L. Kesavan, R. Tiruvalam, M. H. Ab Rahim, M. I. bin Saiman, D. I. Enache, R. L. Jenkins, N. Dimitratos, J. A. Lopez-Sanchez, S. H. Taylor and D. W. Knight, Science, 2011, 331, 195-199.

166 F. Wang, J. Xu, X. Li, J. Gao, L. Zhou and R. Ohnishi, Adv. Synth. Catal., 2005, 347, 1987-1992.

167 S. Fan, W. Dong, X. Huang, H. Gao, J. Wang, Z. Jin, J. Tang and G. Wang, ACS Catal., 2017, 7, 243-249.

168 J. Schneidewind, R. Adam, W. Baumann, R. Jackstell and M. Beller, Angew. Chem., Int. Ed., 2017, 56, 1890-1893.

169 W. H. Bernskoetter and N. Hazari, Acc. Chem. Res., 2017, 50, 1049-1058.

170 J. A. Osborn, F. Jardine, J. F. Young and G. Wilkinson, J. Chem. Soc. A, 1966, 1711-1732.

171 R. Crabtree, Acc. Chem. Res., 1979, 12, 331-337.

172 D. Wang and D. Astruc, Chem. Rev., 2015, 115, 6621-6686.

173 S. Werkmeister, J. Neumann, K. Junge and M. Beller, Chem. - Eur. J., 2015, 21, 12226-12250.

174 V. Y. Doluda, A. Filatova, E. Sul'man, V. Matveeva, S. Mikhailov, A. Sidorov and Y. Y. Kosivtsov, Catal. Ind., 2018, 10, 328-334.

175 C. S. Couto, L. M. Madeira, C. P. Nunes and P. Araújo, Chem. Eng. Technol., 2015, 38, 1625-1636.

176 R. Xu, S. Chakraborty, S. M. Bellows, H. Yuan, T. R. Cundari and W. D. Jones, ACS Catal., 2016, 6, 2127-2135.

177 H.-j. Zhang, X.-y. Niu, J. Hu, C.-l. Ren, H.-l. Chen and X.-g. Chen, Catal. Sci. Technol., 2014, 4, 3013-3024.

178 F. Ke, L. Wang and J. Zhu, Nanoscale, 2015, 7, 1201-1208. 179 S. Yang, Z. H. Zhang, Q. Chen, M. Y. He and L. Wang, Appl. Organomet. Chem., 2018, 32, e4132.

180 X. Chen, Y. Zhang, Y. Zhao, S. Wang, L. Liu, W. Xu, Z. Guo, S. Wang, Y. Liu and J. Zhang, Inorg. Chem., 2019, 58, 12433-12440. 
181 S. Chang, C. Liu, Y. Sun, Z. Yan, X. Zhang, X. Hu and H. Zhang, ACS Appl. Nano Mater., 2020, 3, 2302-2309.

182 L. Yang, Y. Jin, X. Fang, Z. Cheng and Z. Zhou, Ind. Eng. Chem. Res., 2017, 56, 14182-14191.

183 Y. Zhong, Y. Mao, S. Shi, M. Wan, C. Ma, S. Wang, C. Chen, D. Zhao and N. Zhang, ACS Appl. Mater. Interfaces, 2019, 11, 32251-32260.

184 A. Biffis, P. Centomo, A. Del Zotto and M. Zecca, Chem. Rev., 2018, 118, 2249-2295.

185 C. M. Volla, I. Atodiresei and M. Rueping, Chem. Rev., 2014, 114, 2390-2431.

186 P. Ruiz-Castillo and S. L. Buchwald, Chem. Rev., 2016, 116, 12564-12649.

187 L. Xue and Z. Lin, Chem. Soc. Rev., 2010, 39, 1692-1705.

188 Q. Li, S. Jiang, S. Ji, D. Shi and H. Li, J. Porous Mater., 2015, 22, 1205-1214.

189 S. Jiang, J. Yan, F. Habimana and S. Ji, Catal. Today, 2016, 264, 83-90.

190 Y. Hu, S. Zheng and F. Zhang, Front. Chem. Sci. Eng., 2016, 10, 534-541.

191 T. D. Diep, P. D. Q. Dao and C. S. Cho, Eur. J. Org. Chem., 2019, 4071-4079.

192 A. Nuri, N. Vucetic, J.-H. Smått, Y. Mansoori, J.-P. Mikkola and D. Y. Murzin, Catal. Lett., 2020, 150, 2617-2629.

193 A. Mohammadinezhad and B. Akhlaghinia, New J. Chem., 2019, 43, 15525-15538.

194 A. Domling, W. Wang and K. Wang, Chem. Rev., 2012, 112, 3083-3135.

195 S. Zhi, X. Ma and W. Zhang, Org. Biomol. Chem., 2019, 17, 7632-7650.

196 M. S. Singh and S. Chowdhury, RSC Adv., 2012, 2, 4547-4592.

197 H.-Y. Zhang, X.-P. Hao, L.-P. Mo, S.-S. Liu, W.-B. Zhang and Z.-H. Zhang, New J. Chem., 2017, 41, 7108-7115.

198 L. Wang, S. Yang, L. Chen, S. Yuan, Q. Chen, M.-Y. He and Z.-H. Zhang, Catal. Sci. Technol., 2017, 7, 2356-2361.

199 A. Gupta, F. K. Sarkar, R. Sarkar, R. Jamatia, C. Y. Lee, G. Gupta and A. K. Pal, Appl. Organomet. Chem., 2020, 34, e5782.

200 Q. Li, S. Jiang, S. Ji, M. Ammar, Q. Zhang and J. Yan, J. Solid State Chem., 2015, 223, 65-72.

201 F. Pang, M. He and J. Ge, Chem. - Eur. J., 2015, 21, 6879-6887.

202 A. Schejn, T. Mazet, V. Falk, L. Balan, L. Aranda, G. Medjahdi and R. Schneider, Dalton Trans., 2015, 44, 10136-10140.

203 W. Li, G. Li and D. Liu, RSC Adv., 2016, 6, 94113-94118.

204 Y. Zhang, T. Dai, F. Zhang, J. Zhang, G. Chu and C. Quan, Chin. J. Catal., 2016, 37, 2106-2113.

205 Y. Zhang, F. Zhang, X. Zhang, Y. Xu, X. Qi and C. Quan, Chem. Res. Chin. Univ., 2018, 34, 655-660.
206 T. Toyao, M. J. Styles, T. Yago, M. M. Sadiq, R. Riccò, K. Suzuki, Y. Horiuchi, M. Takahashi, M. Matsuoka and P. Falcaro, CrystEngComm, 2017, 19, 4201-4210.

207 E. Rafiee and F. Rahimi, Monatsh. Chem., 2013, 144, 361-367.

208 M. R. Sazegar, S. Mahmoudian, A. Mahmoudi, S. Triwahyono, A. A. Jalil, R. R. Mukti, N. H. N. Kamarudin and M. K. Ghoreishi, RSC Adv., 2016, 6, 11023-11031.

209 N. H. Jadhav, S. S. Sakate, N. K. Rasal, D. R. Shinde and R. A. Pawar, ACS Omega, 2019, 4, 8522-8527.

210 N. G. Khaligh, Catal. Sci. Technol., 2012, 2, 1633-1636.

211 Q. Li, S. Jiang, S. Ji, D. Shi, J. Yan, Y. Huo and Q. Zhang, Ind. Eng. Chem. Res., 2014, 53, 14948-14955.

212 H. Yan, J. S. Oh, J.-W. Lee and C. E. Song, Nat. Commun., 2012, 3, 1-7.

213 M. M. Mostafavi and F. Movahedi, Appl. Organomet. Chem., 2018, 32, e4217.

214 Z. Wu, C. Chen, H. Wan, L. Wang, Z. Li, B. Li, Q. Guo and G. Guan, Energy Fuels, 2016, 30, 10739-10746.

215 D. Zhou, X. Chen, B. Liang, X. Fan, X. Wei, J. Liang and L. Wang, Microporous Mesoporous Mater., 2019, 289, 109615.

216 E. M. Dias and C. Petit, J. Mater. Chem. A, 2015, 3, 22484-22506.

217 L. Yu, H. Wang, Y. Zhang, B. Zhang and J. Liu, Environ. Sci.: Nano, 2016, 3, 28-44.

218 H. Niu, Y. Zheng, S. Wang, L. Zhao, S. Yang and Y. Cai, J. Hazard. Mater., 2018, 346, 174-183.

219 A. Fujishima and K. Honda, Nature, 1972, 238, 37-38.

220 S. Abedi and A. Morsali, ACS Catal., 2014, 4, 1398-1403.

221 J. Cai, J.-Y. Lu, Q.-Y. Chen, L.-L. Qu, Y.-Q. Lu and G.-F. Gao, New J. Chem., 2017, 41, 3882-3886.

222 C. Yang, X. You, J. Cheng, H. Zheng and Y. Chen, Appl. Catal., B, 2017, 200, 673-680.

223 C.-F. Zhang, L.-G. Qiu, F. Ke, Y.-J. Zhu, Y.-P. Yuan, G.-S. Xu and X. Jiang, J. Mater. Chem. A, 2013, 1, 14329-14334.

224 S. Li, J. Cui, X. Wu, X. Zhang, Q. Hu and X. Hou, J. Hazard. Mater., 2019, 373, 408-416.

225 H. Tian, J. Peng, Q. Du, X. Hui and H. He, Dalton Trans., 2018, 47, 3417-3424.

226 X. Ma, S. Wen, X. Xue, Y. Guo, J. Jin, W. Song and B. Zhao, ACS Appl. Mater. Interfaces, 2018, 10, 25726-25736.

227 S. Neupane, K. Patnode, H. Li, K. Baryeh, G. Liu, J. Hu, B. Chen, Y. Pan and Z. Yang, ACS Appl. Mater. Interfaces, 2019, 11, 12133-12141.

228 J. Huo, J. Aguilera-Sigalat, S. El-Hankari and D. Bradshaw, Chem. Sci., 2015, 6, 1938-1943.

229 C. Lin, K. Xu, R. Zheng and Y. Zheng, Chem. Commun., 2019, 55, 5697-5700. 